$$
\begin{gathered}
\text { Universidade de Brasília } \\
\text { Faculdade de Medicina } \\
\text { Programa de Pós-Graduação em Medicina Tropical }
\end{gathered}
$$

\author{
Mábia Milhomem Bastos
}

Carga de doença por tuberculose pulmonar para cenários de desigualdades sociais no Brasil, no ano de 2014.

BRASÍLIA 


\section{Carga de doença por tuberculose pulmonar para cenários de desigualdades sociais no Brasil, no ano de 2014.}

\section{Mábia Milhomem Bastos}

Dissertação de mestrado apresentada ao Programa de Pós-Graduação em Medicina Tropical da Universidade de Brasília, como requisito parcial para a obtenção do título de Mestre em Medicina Tropical. Área de concentração: Epidemiologia e Controle de Doenças Infecciosas e Parasitárias.

Orientador: Professor Doutor Wildo Navegantes de Araújo Co-orientador: Professor Doutor Walter Massa Ramalho

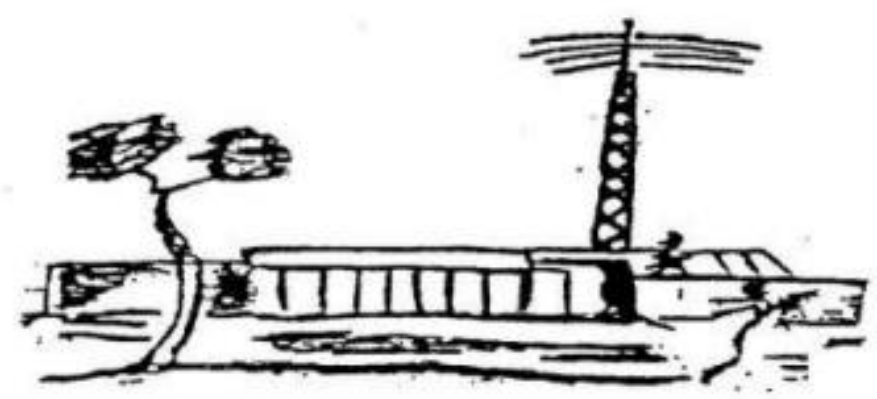

BRASÍLIA 
FICHA CATALOGRÁFICA

Ficha catalográfica elaborada automaticamente, com os dados fornecidos pelo(a) autor(a)

\section{Milhomem Bastos, Mábia}

Carga de doença por tuberculose pulmonar para cenários de desigualdades sociais no Brasil, no ano de 2014. / Mábia Milhomem Bastos; orientador Wildo Navegantes de Araújo; co-orientador Walter Massa Ramalho. -- Brasilia, 2017.

$144 \mathrm{p}$.

Dissertação (Mestrado - Mestrado em Medicina Tropical) -- Universidade de Brasilia, 2017.

1. Tuberculose Pulmonar. 2. Carga de Doença. 3. Disability Adjusted Life Years. 4. Desigualdades Sociais. 5. Desigualdades em Saúde. I. Navegantes de Araújo, Wildo, orient. II. Massa Ramalho, Walter, co orient. III. Título. 


\title{
Carga de doença por tuberculose pulmonar para cenários de desigualdades sociais no Brasil, no ano de 2014.
}

\section{Mábia Milhomem Bastos}

\section{Data da defesa}

10 de Março de 2017

\section{Composição da Banca Examinadora}
Orientador: Professor Doutor Wildo Navegantes de Araújo (Presidente) Universidade de Brasília

\author{
Doutora Aglaêr Alves da Nóbrega (Membro) \\ Ministério da Saúde \\ Professor Doutor Mauro Niskier Sanchez (Membro) \\ Universidade de Brasília \\ Professora Doutora Elisabeth Carmem Duarte (Suplente) \\ Universidade de Brasília
}

\section{BRASÍLIA}




\section{DEDICATÓRIA}

Aos gestores e formuladores de políticas de saúde e pesquisadores das doenças infecciosas negligenciadas.

Aos mestres e funcionários do Núcleo de Medicina

Tropical da Universidade de Brasília.

Aos meus familiares, namorado e amigos. 


\section{AGRADECIMENTOS}

A Deus por me amparar, me conceder forças e por iluminar o meu caminho.

Ao meu querido mestre Wildo Navegantes por todos os valorosos ensinamentos, pela paciência, motivação, suporte e confiança. Pelo excepcional educador e exemplo de honestidade, dedicação, comprometimento, sabedoria, humanidade e humildade.

Ao meu querido mestre Walter Ramalho pela disponibilidade e prazer em ensinar. Serei eternamente grata por todo o aprendizado desde os anos da graduação. Pela atenção, dedicação, paciência, incentivo, companheirismo, preocupação e bom humor.

Aos profissionais do Programa Nacional de Controle da Tuberculose por todo o suporte necessário para a realização desse trabalho, em especial à Daniele Pelissari, Marli Rocha, Fernanda Dockhorn, Andréia Lobo, Patrícia Bartholomay e Denise Arakaki-Sanchez.

Aos meus pais, Do Carmo e Ivan, pelo amor, pela compreensão, apoio, carinho e motivação.

Às minhas irmãs, Karen e Rogéria, por estarem sempre ao meu lado e aos meus sobrinhos pelos sorrisos e alegria.

Ao meu amor, Tahigo Alves, pela compreensão, paciência pelo companheirismo, por ser meu suporte em momentos de crise, pela ajuda e contribuições, pelo incentivo, motivação e por me fazer acreditar que tudo ia dar certo. 
Aos meus amigos Lucas Garcia e Nathália Bariani, por estarem sempre comigo e serem um dos meus pontos de apoio.

Aos companheiros da jornada acadêmica Jeane Kelly, Diogo Santos, Olga Maíra, Tatiana Eustáquia e Luciana Gallo, por todo o aprendizado e compartilhamento de sentimentos.

Aos amigos de uma vida inteira, Carol, Karen, Walter e Bárbara.

Aos demais amigos, Carol Camargo, Lílian Macedo, Guilherme Barbarioli, Bárbara Tobias, Laura Beatriz, Natália Zacariotti e a todos que torceram e acreditarem em mim.

Aos meus familiares.

Aos funcionários e colegas do Núcleo de Medicina Tropical. 


\section{LISTA DE QUADROS}

Quadro 1 - Pilares e componentes da Estratégia pelo Fim da TB.....

40

Quadro 2 - Descrição e pesos da incapacidade para dois níveis de severidade do adoecimento por tuberculose.

Quadro 3 - Indicadores socioeconômicos, epidemiológicos e operacionais utilizados. 


\section{LISTA DE TABELAS}

Tabela 1 - Objetivos e metas da Estratégia pelo Fim da TB em relação aos três indicadores - número de óbitos, coeficiente de incidência e famílias afetadas por custos catastróficos - propostos pela OMS. 39

Tabela 2 - Tábua de Vida de Referência para o cálculo da expectativa de vida.

\section{LISTA DE TABELAS DO ARTIGO}

Tabela 1. Análise descritiva e indicadores socioeconômicos associados com a taxa de DALY padronizada por tuberculose $(n=3178)$.

Tabela 2. Análise descritiva segundo cenários socioeconômicos $(n=5565)$.

Tabela 3. Indicadores epidemiológicos e operacionais associados com a taxa de DALY padronizada por tuberculose segundo cenários socioeconômicos.

Tabela 4. Análise descritiva dos indicadores socioeconômicos, epidemiológicos e operacionais segundo subcenários (cenário 1) de Tuberculose, Brasil 2010 e 2014.

Tabela 5. Análise descritiva dos indicadores socioeconômicos, epidemiológicos e operacionais segundo subcenários (cenário 2) de Tuberculose, Brasil 2010 e 2014. 


\section{LISTA DE FIGURAS}

Figura 1 - Listas dos países com maior carga de tuberculose que serão utilizadas pela OMS no período de 2016 a 2020 e suas áreas de sobreposição.

Figura 2 - Estimativa dos coeficientes de incidência (por 100.000 habitantes)

por tuberculose no mundo, 2015.

Figura 3 - Tendência mundial dos números estimados de casos novos e número de óbitos (em milhões) por tuberculose entre 2000 e 2015.

Figura 4 - Estimativa dos coeficientes de mortalidade (por 100.000 habitantes) por tuberculose no mundo, 2015.

Figura 5 - Série histórica dos coeficientes de incidência por tuberculose no

Brasil, segundo Grandes Regiões, 1990 - 2015

Figura 6 - Tendência do coeficiente de mortalidade por tuberculose no Brasil, $2004-2014$. 48

Figura 7 - Série histórica dos coeficientes de mortalidade por tuberculose no Brasil, segundo Grandes Regiões, 1990 - 2015

Figura 8 - Determinantes Sociais de Saúde. 53

\section{LISTA DE FIGURAS DO ARTIGO}

Fig. 1. Fluxograma dos procedimentos para estimativa da carga da doença. 114

Fig. 2. Distribuição da taxa de DALY padronizada por tuberculose no Brasil, 2014.

Fig. 3. Taxa de DALY padronizada por tuberculose segundo porte municipal. 116

Fig. 4. Municípios de acordo com os subcenários dos cenários 1(a), 2(b) e 3(c), Brasil, 2014 


\section{LISTA DE SIGLAS E ABREVIATURAS}

$\begin{array}{ll}\text { Aids } & \text { Síndrome de Imunodeficiência Adquirida } \\ \text { APVP } & \text { Anos Potenciais de Vida Perdidos } \\ \text { BAAR } & \text { Bacilos álcool ácido resistentes } \\ \text { BK } & \text { Bacilo de Koch } \\ \text { CDSS } & \text { Comissão dos Determinantes Sociais em Saúde } \\ \text { CEP } & \text { Comitê de Ética em Pesquisa } \\ \text { CI } & \text { Coeficiente de incidência } \\ \text { CID 10 } & \text { Classificação Internacional de Doenças 10a revisão } \\ \text { CM } & \text { Coeficiente de mortalidade } \\ \text { CONEP } & \text { Comissão Nacional de Ética em Pesquisas } \\ \text { DALY } & \text { Disability Adjusted Life Years } \\ \text { DCN } & \text { Doenças crônicas não transmissíveis } \\ \text { DIP } & \text { Doenças infecciosas e parasitárias } \\ \text { DNA } & \text { Ácido Desoxirribonucleico } \\ \text { DOTS } & \text { Direct Observed Treatment Strategy Short Course } \\ \text { DSS } & \text { Determinantes sociais em saúde } \\ \text { DW } & \text { Disability Weight - Peso da incapacidade } \\ \text { E } & \text { Etambutol } \\ \text { et al. } & \text { Et alter - e outro } \\ \text { GBD } & \text { Global Burden of Disease } \\ \text { H } & \text { Isoniazida } \\ \text { HALE } & \text { Healthy life expectancy } \\ \text { HIV } & \text { Vírus da Imunodeficiência Humana } \\ \text { I } & \text { Número de casos incidentes } \\ \text { IBGE } & \text { Instituto Brasileiro de Geografia e Estatística } \\ \text { IHME } & \text { Institute for Health Metrics and Evaluation } \\ & \end{array}$


L

Lacen

$\mathrm{mmHg}$

MNT

MRD-TB

N

nqx

ODM

ODS

OMS

PCR

$\mathrm{Ph}$

PNCT

PPD

PTO

$\mathrm{R}$

SIM

SINAN-TB

TB

TCLE

TCU

TDO

TRM-TB

TSA

YLD

YLL

Z
Expectativa de vida na idade do óbito em anos

Laboratório Central de Saúde Pública

Milímetro de mercúrio

Micobactérias não tuberculosas

Tuberculose Multidroga resistente

Número de óbitos na população

Probabilidade de morte em cada faixa etária

Objetivos de Desenvolvimento do Milênio

Objetivos de Desenvolvimento Sustentável

Organização Mundial da Saúde

Reação da Cadeia da Polimerase

Potential of hydrogen

Programa Nacional de Controle da Tuberculose

Derivado proteico purificado

Person trade-off

Rifampicina

Sistema de Informação sobre Mortalidade

Sistema Nacional Agravos de Notificação -

Tuberculose

Tuberculose

Termo de Consentimento Livre Esclarecido

Tribunal de Contas da União

Tratamento Diretamente Observado

Teste rápido molecular para TB

Teste de sensibilidade antimicrobiano

Years Lived with Disability

Years of Life Lost

Pirazinamida 


\section{FINANCIAMENTO}

Instituição financiadora: Coordenação de Aperfeiçoamento de Pessoal de Nível Superior (CAPES).

Apoio Financeiro: Bolsa de mestrado no período de 24 meses. 


\section{ÍNDICE}

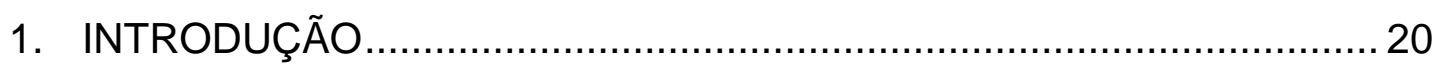

1.1. Características Clínicas da Tuberculose …................................... 20

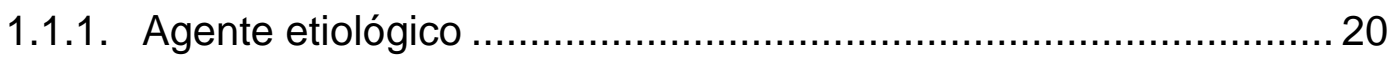

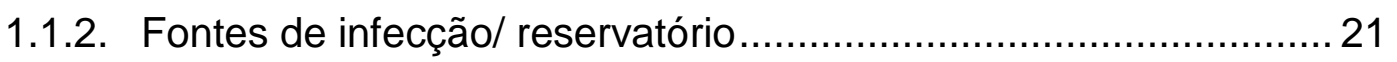

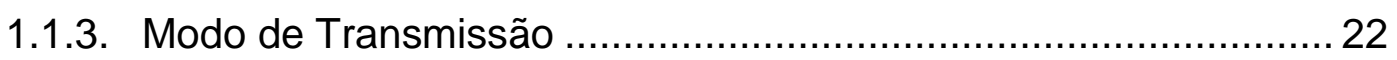

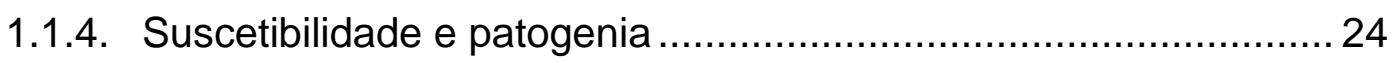

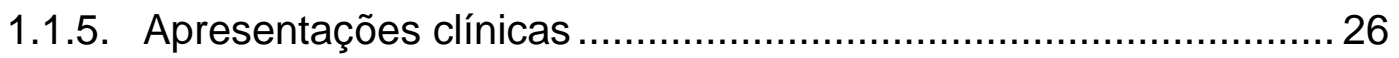

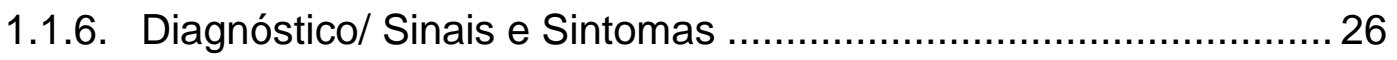

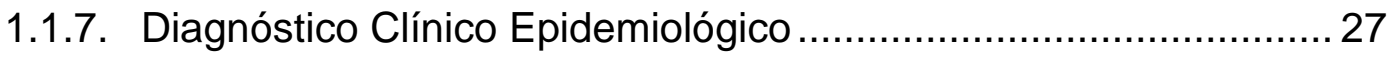

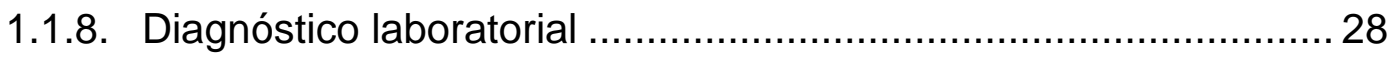

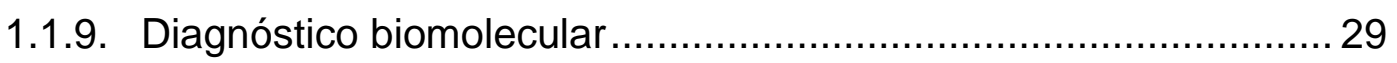

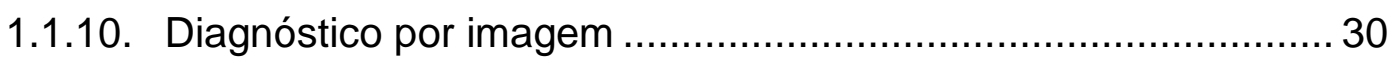

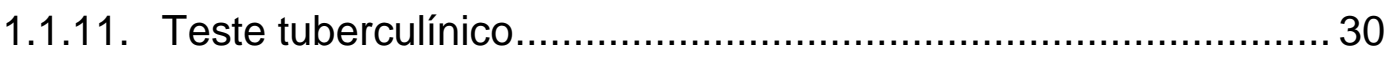

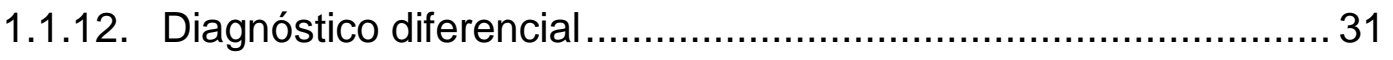

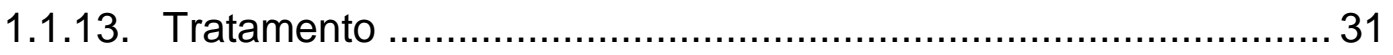

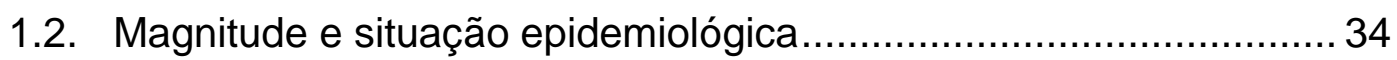

1.3. Situação epidemiológica da tuberculose no cenário mundial .......... 42

1.4. Situação epidemiológica da Tuberculose no Brasil ........................ 46

1.5. Desigualdades Sociais e Determinantes Sociais de Saúde ............ 49

1.6. Carga de doença e Anos de Vida Perdidos Ajustados por Incapacidade - Disability Adjusted Life Years (DALY) .............................. 55

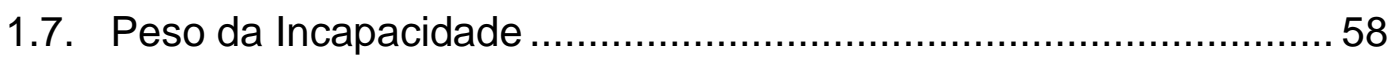

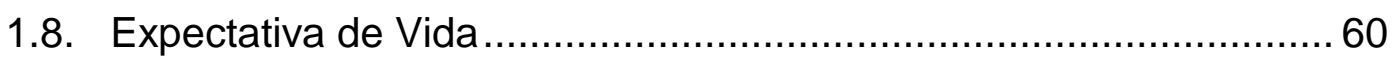

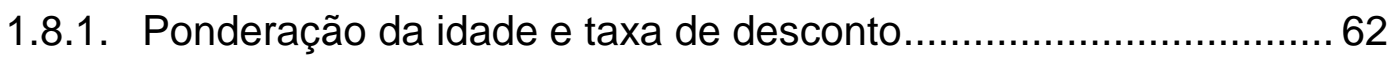

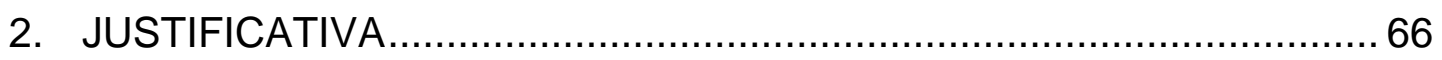

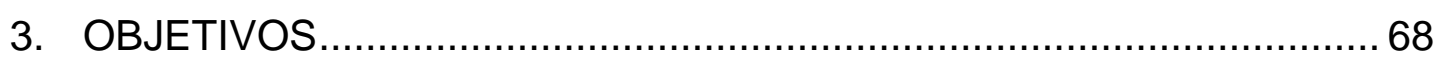

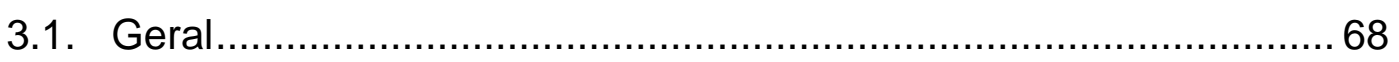

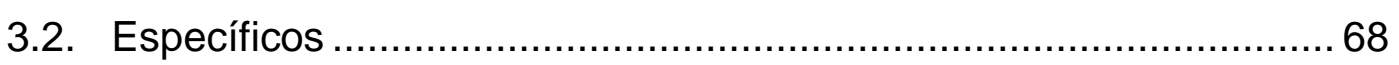

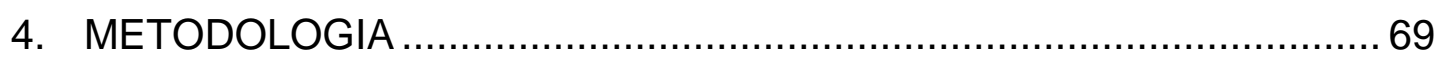

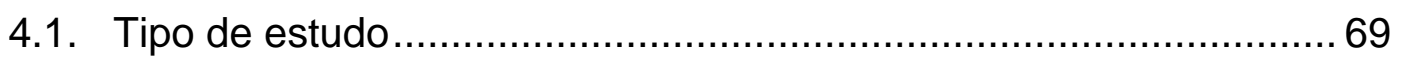

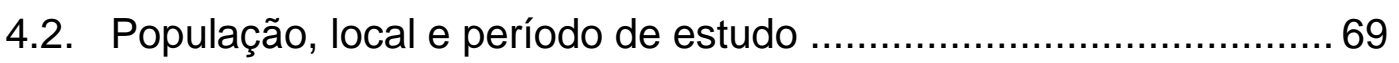


4.3. Procedimentos para seleção dos casos elegíveis ........................... 69

4.4. Relacionamento probabilístico (Linkage)...................................... 70

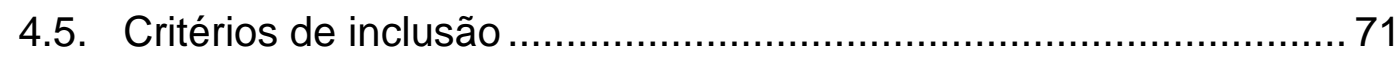

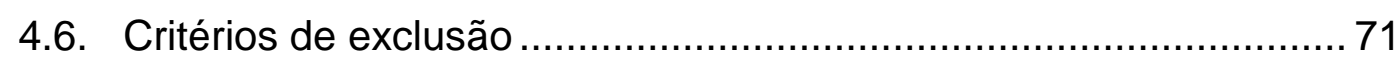

4.7. Denominadores Populacionais e Padronização ………………........ 71

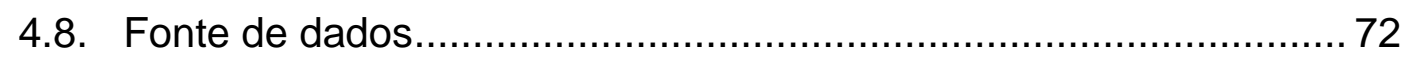

4.9. Procedimentos Analíticos ........................................................... 72

4.9.1. Coeficientes de incidência e mortalidade..................................... 72

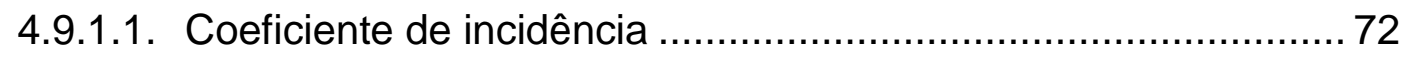

4.9.1.2. Coeficiente de mortalidade.................................................. 73

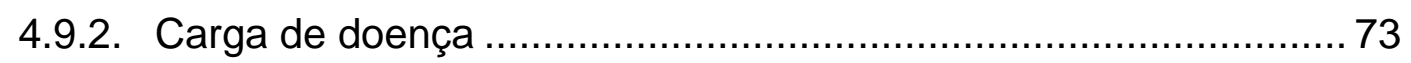

4.9.3. Anos de Vida Perdidos (Years of Life Lost - YLL) ........................ 73

4.9.3.1. População, local e período do estudo ....................................... 73

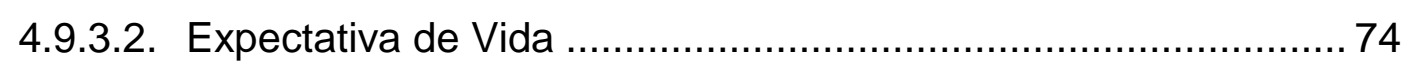

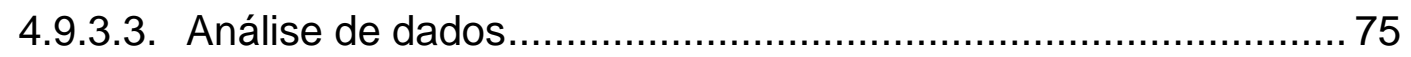

4.9.4. Anos Vividos com Incapacidade (Years Lived with Disability - YLD) 77

4.9.4.1. População, local e período de estudo ……….......................... 77

4.9.4.2. Peso da Incapacidade (Disability Weight) ................................ 77

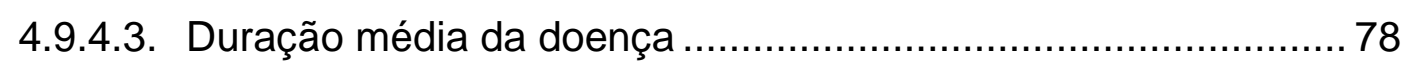

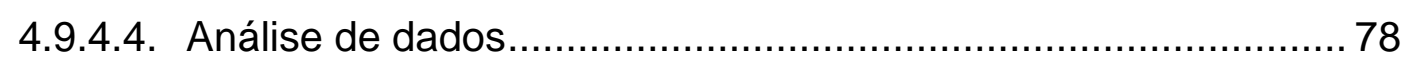

4.10. Indicadores socioeconômicos, epidemiológicos e operacionais

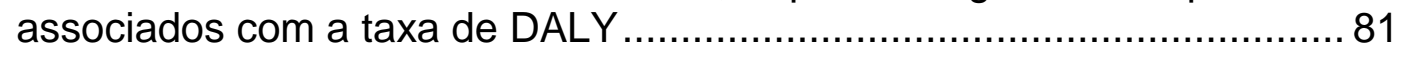

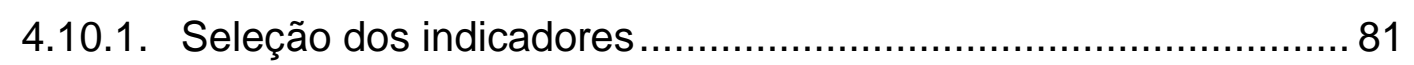

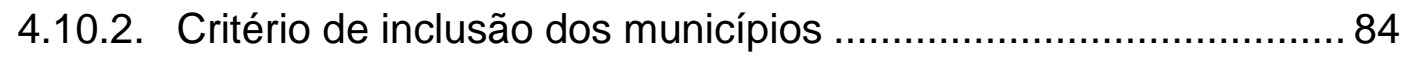

4.10.3. Variáveis dependentes e independentes .................................. 84

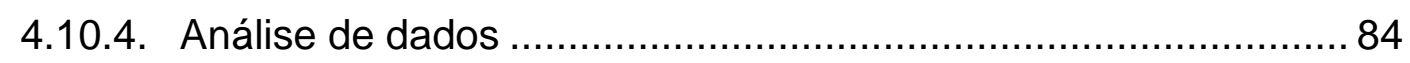

4.11. Agrupamento dos municípios quanto suas similaridades e cenários

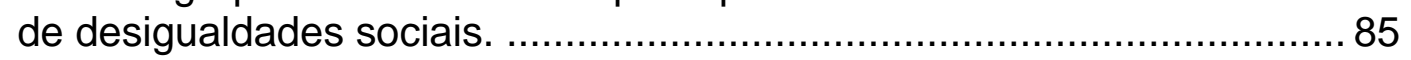

4.12. Gerenciamento e Processamento de Dados ................................. 86

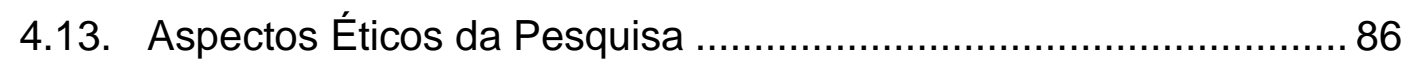

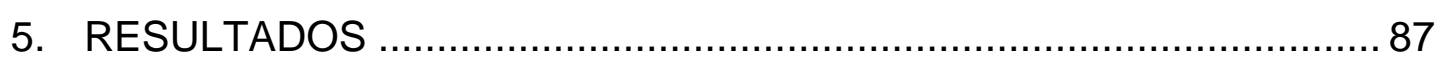

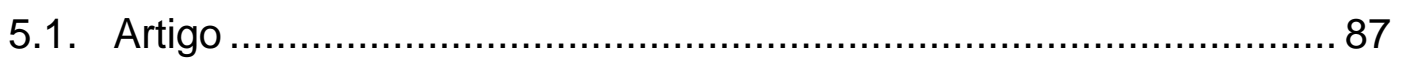

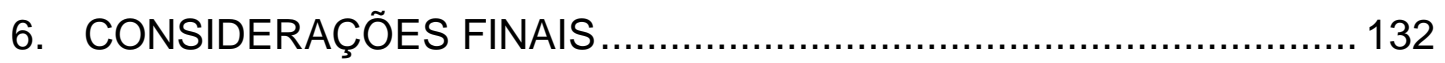

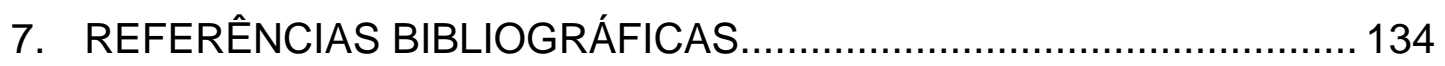

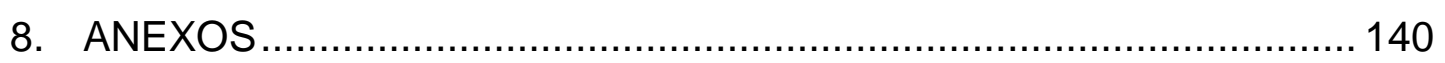




\section{RESUMO}

Introdução: A tuberculose é uma doença infecciosa causada pelo Mycobacterium tuberculosis e afeta mais comumente os pulmões, sendo denominada tuberculose pulmonar. Foram estimados no mundo 10,4 milhões de casos novos da doença em 2015 e 1,4 milhões de mortes. No Brasil foram identificados 67.790 casos novos em 2015 e 4.374 óbitos em 2014. O país está entre os 30 países com maior carga da doença. A Organização Mundial de Saúde lançou a estratégia End TB, que propõe a eliminação global da tuberculose até $2035 \mathrm{com}$ medidas que incluem 0 enfrentamento das vulnerabilidades e da pobreza e o desenvolvimento de novas ferramentas e tecnologias. Estimar a carga da doença e avaliar como ela se distribui nos municípios brasileiros é fundamental para o planejamento de ações que vão de encontro com as metas propostas pelo End TB. Objetivo: Analisar a carga de doença por tuberculose pulmonar nos cenários de desigualdades sociais segundo indicadores socioeconômicos, epidemiológicos e operacionais no Brasil, no ano de 2014. Método: Foi conduzido um estudo ecológico transversal nos municípios brasileiros no ano de 2014. O estudo utilizou os dados dos sistemas de informação de notificação, SINAN, e de mortalidade, SIM e se dividiu em três momentos em que se estimou os Disability Adjusted Life Years (DALY), anos de vida perdidos ajustados por incapacidade, para os municípios brasileiros, identificou-se os indicadores socioeconômicos, epidemiológicos e operacionais associados à taxa de DALY padronizada $\left(D A L Y_{t x p}\right)$ e agrupouse os municípios quanto suas similaridades e os classificou em cenários de desigualdades sociais. O DALY foi obtido pela somatória dos Years of Life Lost (YLL), anos de vida perdidos, e dos Years Lived with Disabilities (YLD), anos de vida vividos com incapacidade. A identificação dos indicadores socioeconômicos, epidemiológicos e operacionais associados à $D A L Y_{t \times p}$ foram obtidos através de um modelo multivariado ajustado, utilizando regressão binomial negativa. A partir das variáveis associadas à $D A L Y_{t x p}$, 
agrupou-se os municípios quanto suas similaridades utilizando o método não hierárquico de K-means. Resultados: O DALY se distribuiu de forma heterogênea nos municípios brasileiros. Dentre as variáveis socioeconômicas testadas, a única que permaneceu associada à $D A L Y_{\text {txp }}$ no modelo final foi a taxa de desocupação. A partir disso, foram identificados três cenários socioeconômicos. O cenário um apresentou 2.436 municípios, enquanto os cenários dois e três apresentaram 661 e 2.468 municípios, respectivamente. No cenário dois se encontram as maiores medianas em indicadores como taxa de mortalidade infantil e taxa de analfabetismo e menores medianas no que se refere aos indicadores de renda. $O$ cenário três apresenta uma mediana mais baixa da taxa de desemprego e maior mediana de Índice de Desenvolvimento Humano Municipal (IDHM). Com a inclusão das variáveis epidemiológicas e operacionais nos cenários, foram identificadas associações mais plausíveis de variáveis operacionais com a DALY txp. A partir dos cenários um e três, cinco subcenários foram identificados, enquanto que no cenário dois foram identificados quatro subcenários. Conclusão: A carga da tuberculose pulmonar não se distribui de forma homogênea na população e as ações no âmbito da vigilância e na oferta de serviços precisam considerar as particularidades de cada localidade, atuando sobre os determinantes sociais da saúde e fazendo o uso de novas metodologias e tecnologias. 


\section{ABSTRACT}

Introduction: Tuberculosis (TB) is an infectious disease caused by Mycobacterium tuberculosis and it most commonly affects the lungs, being called pulmonary tuberculosis. Worldwide, 10.4 million of new TB cases were estimated in 2015 and 1.4 million deaths occurred. In Brazil were identified 67,790 in 2015 and 4,374 deaths were registered in 2014. This country is among the 30 countries with the high burden of the disease. The World Health Organization launched the End TB strategy, which proposes the global elimination of tuberculosis by 2035 with goals that address vulnerability and poverty and encourage the development of new tools and technologies. Estimating the burden of disease and assessing the distribution of this burden in Brazilian municipalities is crucial for planning actions that meet the goals proposed by End TB. Objective: To analyze the burden of disease due to pulmonary tuberculosis in social inequality scenarios according to socioeconomic, epidemiological and operational indicators in Brazil, in 2014. Method: An ecological cross-sectional study was conducted in Brazilian municipalities in 2014. The research used data from SINAN, which is a Brazilian notification information system and SIM, an information system about mortality. The study was divided into three moments: 1) Estimation of burden of disease due to pulmonary tuberculosis in Brazilian municipalities, using the Disability Adjusted Life Years (DALY); 2) Identification of socioeconomic, epidemiological and operational indicators of the disease associated to the standard DALY rate (DALYsr) and 3) Identification of municipalities clusters according to similarities of the associated variables into scenarios of social inequalities. The DALY was obtained by the sum of the Years of Lost Life (YLL) and the Years Lived with Disabilities (YLD). The socioeconomic, epidemiological and operational indicators associated with the DALYsr were obtained through a multivariate model, using a negative binomial regression. Using the variables associated 
with the DALYsr, the municipalities were grouped according to its similarities through the non-hierarchical K-means method. Results: The DALY had a heterogeneous distribution in Brazilian municipalities. Among the socioeconomic variables tested, the only one that remained associated with the DALYsr, in the final model was the lack of occupational rate, which is similar to the unemployment rate. Using this variable, three socioeconomic scenarios were identified. Scenario one presented 2,436 municipalities, while scenarios two and three presented 661 and 2,468 municipalities, respectively. In scenario 2 , we found the highest medians in indicators such as infant mortality rate and illiteracy rate, and lowest median to income indicators. Scenario 3 presents a lower median of unemployment rate and higher median of the municipal human development index. With the inclusion of epidemiological and operational variables in the scenarios, more plausible associations of operational variables with DALYsr, were identified. From scenarios one and three, five sub-scenarios were identified and from scenario two, we identified four sub-scenarios. Conclusion: The burden of pulmonary tuberculosis is not homogeneously distributed in the Brazilian population. Actions regarding the surveillance and provision of care need to consider the particularities of each locality, acting on the social determinants of health and supported by new methodologies and Technologies. 


\section{INTRODUÇÃO}

\subsection{Características Clínicas da Tuberculose}

\subsubsection{Agente etiológico}

A tuberculose pode ser causada por microorganismos que taxonomicamente pertencem à ordem Actinomycetales, à família Mycobacteriaceae e seu único gênero, Mycobacterium. Os bacilos

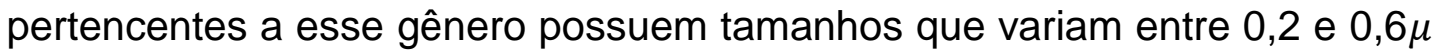
por 1 e $10 \mu$, são imóveis, não formam esporos ou cápsulas e possuem um tempo de geração longo. As espécies que possuem um crescimento mais rápido levam cerca de 3 horas para se reproduzirem enquanto as de crescimento mais lento, levam em média 18 horas. Esses bacilos também são resistentes à descoloração por solução contendo álcool e ácido, em razão da elevada quantidade de lipídeos em sua parede ?. As sete espécies que integram o complexo Mycobacterium tuberculosis e podem participar da cadeia causal da tuberculose são: $M$.tuberculosis, $M$. bovis, $M$. africanum, $M$. canétti, M. microti, M. pinnipedi e M. caprae (Melo et al., 2009; Farga e Caminero, 2011; Frazier e Drzymkowski, 2013).

O microorganismo mais importante para a transmissão da tuberculose em humanos é o M.tuberculosis, contudo outras espécies podem causar a doença, embora com menos frequência. $\mathrm{O} M$. bovis tem importância em países com poucos recursos em que não há o controle dos animais, o $\mathrm{M}$. africanum é responsável por um reduzido número de casos na África e possuem uma virulência baixa. Já a espécie $M$. microti, apesar de ser agente etiológico para a transmissão de TB em roedores, pode provocar a doença em humanos imunodeprimidos. O M. pinnipedi também pode afetar 
os humanos, embora esteja associado à doença em focas (Farga e Caminero, 2011).

O M. tuberculosis é também conhecido como bacilo de Koch (BK), por ter sido isolado, descrito e cultivado por Robert Koch em 1882. É um bacilo delgado, ligeiramente curvo e possui forma irregular, com um tamanho que varia entre 1 a 4 micras de comprimento. Sua parede celular é bastante complexa, com uma membrana grossa e forte que contém um alto teor de lipídeos, que ajudam a proteger $\mathrm{o}$ bacilo contra a destruição dos macrófagos. Sua estrutura química é composta de proteínas, carboidratos, vitaminas do complexo $\mathrm{B}$ e minerais como o fósforo, o magnésio e o cálcio. Essa membrana complexa também protege o bacilo contra agentes químicos. Contudo, ele pode ser destruído por agentes físicos como raios ultravioletas, radiações ionizantes e luz solar (Melo et al., 2009).

O M. tuberculosis não se encontra livre, portanto, depende do parasitismo. Ele se multiplica lentamente, em média de 18 a 48 horas, e por ser anaeróbico, depende da quantidade de oxigênio disponível, em que a pressão ideal se encontra entre 100 e $140 \mathrm{mmHg}$. Para sua multiplicação, o bacilo também depende do $\mathrm{pH}$ do meio (que vai idealmente de 7,30 a 7,40) e dos nutrientes presentes. Apesar de possuir um componente antigênico complexo com altos graus de virulência e de patogenicidade, o bacilo de Koch não possui toxinas conhecidas, e portanto não consegue romper a barreira epitelial íntegra, infectando o hospedeiro quando o mesmo está com seu sistema imunológico comprometido (Melo et al., 2009; Farga e Caminero, 2011).

\subsubsection{Fontes de infecção/ reservatório}

O principal reservatório para o M. tuberculosis é o homem doente (bacilífero). O homem torna-se fonte de infecção quando está sadio, infectase e permanece assintomático, apresenta bacilos em fase latente e que, devido a um comprometimento do sistema imunológico, desenvolve tuberculose em algum ponto do tempo. $O$ paciente com tuberculose 
pulmonar (quando a doença afeta o pulmão) é um reservatório ainda mais importante, pois excreta uma quantidade maior de bacilos. Portadores que apresentam formas crônicas assintomáticas também são fontes de infecção, ainda que constituem-se de eliminadores eventuais (Hijjar et al., 2005, Frazier e Drzymkowski, 2013).

Além do ser humano, é possível identificar animais que servem como reservatório para as espécies do complexo Mycobacterium tuberculosis como aves e mamíferos. O gado bovino, por exemplo, é o principal reservatório animal para o $M$. bovis. A contaminação pode ocorrer quando há o consumo de leite e derivados não pasteurizados, ou fervidos de animais infectados e aonde não há o controle sanitário dos gados. Quase todos os animais podem atuar como reservatórios, contudo, o potencial de contaminação é baixo, considerando que a população bacilar é reduzida (Farga e Caminero, 2011; Brasil, 2014).

\subsubsection{Modo de Transmissão}

Estudos experimentais que abordavam a transmissão por tuberculose começaram a ficar evidentes na literatura entre 1949 e 1954. Foram conduzidos estudos com modelos humanos em que observava-se a transmissão da doença de humanos bacilíferos para animais. Os indivíduos doentes eram colocados em enfermarias fechadas e com pouca ventilação em que as únicas saídas de ar consistiam nos ductos no teto. As cobaias eram posicionadas nesses ductos e infectadas pelos bacilos eliminados pelos pacientes doentes que permaneciam suspensos e eram contagiantes para os animais (Melo et al., 2009).

A via mais importante para a transmissão da tuberculose é a via aérea. Os doentes bacilíferos expelem através da fala, tosse e espirro através de gotículas que são carregadas de microbactérias. As partículas maiores, apesar de possuírem mais bacilos, são mais pesadas e ficam no chão ou se depositam na via aérea superior; no entanto, não são infecciosas. Já as partículas menores, com um tamanho entre 5 e $10 \mu \mathrm{m}$, 
chamadas de partículas de Plugger, se depositam nas vias aéreas mais proximais, em que os bacilos encontram condições adequadas para a reprodução (Melo et al., 2009; Farga e Caminero, 2011; Frazier e Drzymkowski, 2013).

Contudo, dessas partículas, só são contagiantes as que se ressecam (evaporam água). Elas são conhecidas como Núcleo de Wells e ao serem eliminadas por pacientes bacilíferos e inaladas, podem chegar aos alvéolos pulmonares e causar infecção. Os núcleos de Wells possuem características aerodinâmicas e possuem baixa carga bacilar, em torno de 1 a 5 bacilos por gotícula. As partículas não ressecadas e que carregam muitos bacilos ficam no trajeto da árvore brônquica, são digeridas e eliminadas pelos sistemas muco ciliar e digestivo (Farga e Caminero, 2011).

Existem outra formas de contágio que não são muito comuns, como por exemplo, a transmissão oral-digestiva, através do leite de vaca contaminado com alta carga bacilar, em que a penetração ocorre através do tecido linfático, orofaringe ou mucosa intestinal. Outra forma de contágio é a transmissão urogenital que ocorre em quando há contato do indivíduo saudável com a urina contaminada. Pode ocorrer transmissão também por via sexual e transplacentária, dando origem à TB congênita (Hijjar et al., 2005).

A transmissibilidade do foco, ou seja, o potencial de infectividade de um doente aumenta ou diminui dependendo do grau da doença. Dessa forma, o indivíduo com tuberculose pulmonar e com a presença de cavidades, que são corriqueiras nas formas de reativação, possui maior capacidade de infectar outro indivíduo. O potencial de infectividade também aumenta quando a tosse é muito severa e quando o escarro apresenta alta carga bacilar. Outro fator importante que influencia na transmissibilidade é a introdução de um tratamento eficaz. O doente em tratamento para TB é menos infectante, pois além de curar o doente, o tratamento reduz o tempo de transmissão, rompendo assim com a cadeia epidemiológica da doença (Brasil, 2011; Hijjar et al., 2005). 
O risco de transmissão de TB depende também das características da exposição, como a concentração de bacilos na atmosfera, condições de habitação, o grau de exposição e o tempo de contato com o doente. Quanto maior a convivência entre contato e foco, maior a possibilidade de transmissão, principalmente se a relação for íntima e dentro do mesmo domicílio. A proximidade física e de parentesco possui uma relação direta com a infecção. O tempo de exposição necessário estimado para a infecção é de 100 a 200 horas. Indivíduos que residem em aglomerados urbanos, com condições precárias de moradia em ambientes fechados, sem luz e ventilação, estão mais expostos ao risco de transmissão da doença. O risco também é aumentado para pacientes que são portadores do Vírus da Imunodeficiência Humana (HIV) (Melo et al., 2009; Brasil, 2014).

Em síntese, pode-se dizer que a transmissão da tuberculose depende do foco da infecção, do contato suscetível, do ambiente de exposição e do tipo de relacionamento e proximidade entre o foco e o contato.

\subsubsection{Suscetibilidade e patogenia}

Praticamente todos os indivíduos são suscetíveis à infecção e ao adoecimento por tuberculose. Contudo, nem todas as pessoas que são expostas ao bacilo se infectam e nem todas que se infectam adoecem. A probabilidade de a infecção evoluir para a doença depende de uma série de fatores e características do agente etiológico e do hospedeiro, como o número de bacilos inalados, a virulência e a resistência natural e adquirida do organismo infectado. Quando há uma pequena quantidade de bacilos inalados, por exemplo, eles são destruídos antes de produzirem lesão ou de induzirem resposta imunológica. Apesar de o bacilo possuir mecanismos elaborados para tentar ultrapassar as defesas do hospedeiro, a maior parte dos indivíduos infectados resiste ao adoecimento e logo desenvolvem imunidade parcial à doença (Hijjar et al., 2005; Melo et al., 2009).

De acordo com Hijjar et al. (2005), quando os bacilos conseguem infectar o indivíduo, quatro cenários são possíveis: 
1) Eliminação dos bacilos e impedimento da evolução da infecção para doença: acontece quando as respostas do hospedeiro são totalmente eficazes;

2) Tuberculose primária ou primo-infecção: os bacilos se multiplicam e crescem logo após a infecção;

3) Infecção latente: os bacilos permanecem em estado quiescente e nunca evoluem para a doença; e

4) Tuberculose secundária ou de reativação: quando os bacilos que estavam em estado latente voltam a se multiplicar após encontrar condições oportunas.

Parte dos bacilos que são inalados durante à exposição aos mesmos permanecem retidos. Os cílios nasais, a tosse e a eliminação muco-ciliar são exemplos de mecanismos físicos do sistema respiratório que favorecem essa retenção. Outros bacilos ultrapassam essas barreiras inespecíficas e se instalam no pulmão. A partir disso, os bacilos podem se difundir através da circulação linfática até os linfonodos regionais do pulmão, dessa forma se estabelece o complexo primário. Com início da lesão gerada no pulmão, pode haver a disseminação da infecção pela corrente sanguínea, através do rompimento dos vasos sanguíneos. Dessa maneira a infecção pode se instalar em outras partes do corpo, constituindo possivelmente a doença em sua forma extrapulmonar, que ocorre em cerca de 10\% dos casos (Melo et al., 2009; Farga e Caminero, 2011)

Estima-se que $5 \%$ das pessoas não conseguem impedir a multiplicação inicial do bacilo e logo adoecem e que $5 \%$ dos indivíduos bloqueiam a infecção inicial mas adoecem posteriormente, por reativação endógena, na qual ocorre a reativação dos bacilos que estavam em estado latente ou através da reinfecção exógena, quando o indivíduo é exposto a uma nova fonte de infecção. Do total de infectados, cerca de 10\% evoluem para a tuberculosa ativa (não latente) e isso depende da virulência e patogenia do bacilo, da proximidade e do tempo de exposição e contato com a fonte de infecção e com a competência imunológica do hospedeiro (Melo et al., 2009; Farga e Caminero, 2011). 
Dentre os principais fatores que afetam o sistema de defesa do hospedeiro estão: a idade avançada do indivíduo, desnutrição e a presença de comorbidades como HIV, diabetes e neoplasias. A tuberculose latente e o adoecimento não impedem recidivas e novas infecções (Melo et al., 2009; Farga e Caminero, 2011).

\subsubsection{Apresentações clínicas}

Como descrito anteriormente, a tuberculose pode se manifestar na forma pulmonar - quando atinge os pulmões - ou na forma extrapulmonar quando, atinge outros locais ou órgãos do corpo.

O pulmão é o primeiro órgão a ser afetado pela infecção porque possui condições ideais para o bacilo se multiplicar como, por exemplo, a quantidade de oxigênio ofertada. Cerca de $90 \%$ das vezes a doença se localiza no pulmão e a doença pulmonar se constitui como a forma de maior importância para a saúde pública, pois ela é a responsável por perpetuar a cadeia de transmissão da doença. Pode-se, no entanto, encontrar a forma extrapulmonar associada à forma pulmonar, sendo chamada de tuberculose mista. A doença tem uma variedade de formas clínicas pulmonares que dependem da carga bacilar e das respostas do organismo. Nos pacientes que vivem com HIV, por exemplo, a apresentação clínica da tuberculose depende do grau de imunossupressão do indivíduo (Brólio e Lima Filho, 1976; Brasil, 2011; 2014).

Em relação à tuberculose extrapulmonar, a forma mais frequente é a pleural, no entanto, outras formar comuns são à ganglionar periférica, meningoencefálica, miliar, laríngea, pericárdica, óssea, renal, ocular e peritoneal (Hijjar et al., 2005; Melo et al., 2009).

\subsubsection{Diagnóstico/ Sinais e Sintomas}

O diagnóstico da tuberculose, segundo Robert Koch, consiste no encontro do agente etiológico da doença nos tecidos e nas secreções 
estudadas. A técnica para a identificação de bacilos, no entanto, foi desenvolvida pelos pesquisadores Franz Ziehl e Friendrich K. Nielsen, cujos nomes foram dados ao método. Outro fato primordial que marcou 0 diagnóstico da tuberculose e de outras doenças foi a descoberta do raio-X por Wilhelm Conrad Rontgen em 1895. Com o desenvolvimento das técnicas radiológicas no século $X X$, métodos convencionais e outros como fluoroscopia e tomografia, permitiu-se um melhor monitoramento da TB. Após esse período, novos métodos foram integrados para apoiar 0 diagnóstico da doença. Algumas técnicas mais modernas são de extrema relevância para o diagnóstico de TB, todavia constituem-se de métodos ainda restritos para algumas localidades. A leitura radiométrica de culturas em meio líquido e a técnica da reação em cadeia da polimerase (PCR), são exemplos dessas técnicas (Brólio e Lima Filho, 1976; Melo et al., 2009).

A doença pode ser diagnosticada de diferentes maneiras e a busca ativa do sintomático respiratório, ou seja, do indivíduo que está tossindo por mais de três semanas, faz-se essencial para a detecção precoce dos casos, principalmente de indivíduos que possuam tuberculose pulmonar, considerando que é a forma clínica que apresenta maior importância para a transmissão da doença (Brasil, 2011; 2014). Os principais métodos e técnicas diagnósticas serão descritos a seguir:

\subsubsection{Diagnóstico Clínico Epidemiológico}

Sempre que um paciente está com suspeita de tuberculose deve-se realizar um exame físico com o objetivo de identificar os sinais/sintomas característicos da doença. A anamnese do paciente, além de ser de extrema importância para o diagnóstico de tuberculose, também possibilita a identificação de outras doenças que não são incomuns no quadro de TB. O diagnóstico clínico epidemiológico é bastante utilizado quando não é possível realizar exames laboratoriais, como os bacteriológicos e os biomoleculares, e utilizado em associação a outros exames complementares como os exames de imagem e os histológicos (Brasil, 2011; 2014). 
Os sinais e sintomas da doença variam de acordo com os órgãos e sistemas que foram infectados. Os principais sintomas dos indivíduos que tiveram acometimento pulmonar são: tosse persistente, hemoptise e dor torácica. Já os sintomas sistêmicos incluem: diminuição do apetite, fadiga, febre vespertina, sudorese noturna e palidez. Nas crianças os principais sinais e sintomas são compostos por irritabilidade, febre baixa, sudorese noturna e inapetência. Os pacientes acometidos com tuberculose secundária apresentam em geral: tosse seca ou produtiva, expectoração purulenta com ou sem sangue; febre vespertina, sem calafrios, sudorese noturna e anorexia (Brólio e Lima Filho, 1976; Frazier e Drzymkowski, 2013).

\subsubsection{Diagnóstico laboratorial}

- Baciloscopia direta de escarro: é o exame mais difundido e tem por objetivo a identificação de bacilos que são álcool ácido resistentes (BAAR) no escarro, através da técnica de Ziehl-Nielsen. O exame é de fácil execução, de baixo custo e seguro, possibilitando sua realização em laboratórios com poucos recursos. A baciloscopia permite a identificação da maioria dos casos de TB pulmonar com cerca de 60 a $80 \%$ de detecção dos casos. A mesma também está indicada para a detecção de sintomáticos respiratórios e para pacientes com suspeita clínica ou radiológica de TB pulmonar ou extrapulmonar, independente do tempo de tosse. No entanto o exame exige uma concentração de bacilos mínima de $10^{4}$ germes por milímetro de material para um resultado positivo. A baciloscopia deve ser feita em pelo menos duas amostras, sendo uma na primeira visita ou consulta do paciente e a segunda na manhã do dia seguinte, logo após despertar, independente do resultado da primeira. A amostra deve ser coletada a partir do escarro da árvore brônquica, logo após o paciente tossir. Com o intuito de acompanhar a evolução do paciente e a eficácia do tratamento, o exame deve ser realizado mensamente até que a baciloscopia produza um resultado negativo (Melo et al., 2009; Brasil, 2011; 2014). 
- Cultura para micobactéria: é um exame que possui elevada sensibilidade e especificidade, principalmente se comparada à baciloscopia. A técnica é menos utilizada em razão dos cuidados e recursos técnicos exigidos, dificultando a realização em lugares com recursos limitados. O exame pode detectar entre 10 e 100 germes na amostra e em casos pulmonares em que o resultado da baciloscopia foi negativo, pode-se aumentar o diagnóstico de TB em até $30 \%$. A cultura para micobactéria é realizada para casos suspeitos em que a baciloscopia foi negativa, formas paucibaliares da doença, formas extrapulmonares, pacientes que são HIV positivos, casos de retratamento, recidivas, suspeita de resistência as drogas (seguida de teste de sensibilidade) e bactérias não tuberculosas. Os meios mais comuns para a realização de cultura são os meios sólidos e o método mais utilizado é o de Lowenstein-Jensen, em que o exame é realizado em meio é à base de ovo. O tempo médio de crescimento das bactérias é de quatro semanas (Hijjar et al., 2005; Farga e Caminero, 2011).

- Teste de sensibilidade antimicrobiano (TSA): é utilizado para testar a resistência do bacilo de Koch à antimicrobianos que são utilizados no tratamento da tuberculose. São primeiramente testados os fármacos de primeira linha que são a rifampicina, a isoniazida, o etambutol e a estreptomicina. Caso haja resistência, o caso deve ser investigado pelo Laboratório Central de Saúde Pública (Lacen) para que se realize a testagem dos fármacos de segunda linha, que são a canamicina, amicacina, capriomicina e ofloxacina (Melo et al., 2009; Brasil, 2011; 2014).

\subsubsection{Diagnóstico biomolecular}

- Teste rápido molecular para TB (TRM-TB): esse teste é realizado por meio da amplificação de ácidos nucleicos, ou seja, do material genético do agente etiológico, em que é possível identificar o Ácido Desoxirribonucleico (DNA). Com o TRM-TB também é possível detectar 
as cepas resistentes à rifampicina, através da técnica de Reação da Cadeia da Polimerase (PCR) em tempo real, que é rápida e possui baixo risco de contaminação. Considerando que a técnica de PCR identifica ácidos nucleicos de microrganismos vivos e mortos, não é indicado 0 teste para acompanhamento do paciente com TB. No entanto, pode ser utilizado para o diagnóstico de TB pulmonar em crianças e adultos. $O$ teste também pode ser utilizado para a identificação de pessoas com TB extrapulmonar, todavia, caso o teste produza um resultado negativo, não se exclui a possibilidade da doença e a investigação deve prosseguir. A técnica biomolecular é mais sensível em amostras com baciloscopia positiva e possui um proveito diagnóstico baixo em amostras com baciloscopia negativa (Brasil, 2014).

\subsubsection{Diagnóstico por imagem}

- Radiografia de tórax: esse exame tem como objetivo principal descartar a possiblidade de outras doenças que não sejam tuberculose quando a baciloscopia de escarro apresentar resultado positivo. Dessa maneira, o exame é uma ferramenta importante no processo de busca pela TB. Deve-se solicitar o exame sempre que houver suspeita clínica da doença, no entanto os resultados do exame de imagem não indicarão certeza da doença, apenas achados que indicam suspeita do acometimento no passado e no presente. Portanto, devem ser utilizados outros exames para confirmar o diagnóstico (Brasil, 2011; 2014).

- Outros exames: o diagnóstico e/ou investigação de TB pode ser feito por meio de outros exames de imagem como: a broncoscopia, a ultrassonografia e a tomografia (Brasil; 2014).

\subsubsection{Teste tuberculínico}

A prova tuberculínica é realizada através da injeção intradérmica de um antígeno do agente etiológico. $\mathrm{O}$ antígeno que se utiliza no teste é o 
derivado proteico purificado (PPD). O exame é indireto e funciona através da mensuração da hipersensibilidade ou alergia produzida pelo desenvolvimento da imunidade específica da TB. O teste mede então, a resposta imunológica celular ao antígeno inoculado. Quando o mesmo é injetado no corpo humano (na face ventral no braço esquerdo) ocorre uma reação que provoca vasodilatação, edema e acúmulo celular no local, permitindo, dessa maneira, identificar se a pessoa foi infectada ou não. $\mathrm{Na}$ investigação dos contatos assintomáticos de pessoas com TB, a prova tuberculínica se faz importante, assim como, para assistir o diagnóstico de TB ativa em crianças (Brasil, 2011; 2014).

\subsubsection{Diagnóstico diferencial}

Esse tipo de diagnóstico é realizado com o intuito de diferenciar as infecções por TB de outras infecções que produzem quadros clínicos semelhantes. As microbactérias não tuberculosas (MNT) são um exemplo disso; logo, faz-se necessário a tipificação das espécies, permitindo assim estimar a prevalência de MNT. O diagnóstico diferencial pode ser realizado por diferentes métodos, incluindo, técnicas bioquímicas associadas com meios sólidos de cultura (Melo et al., 2009; Brasil, 2011).

\subsubsection{Tratamento}

O tratamento da tuberculose consiste essencialmente na terapia medicamentosa que é de fundamental importância para o controle da doença. Se seguida da maneira adequada, a quimioterapia pode reduzir a mortalidade pela doença e seu tempo de transmissibilidade. A TB possui um bom prognóstico e os casos incidentes da doença são curáveis em quase sua totalidade se esses forem sensíveis aos fármacos utilizados para 0 tratamento e se forem seguidas as regras primordiais da quimioterapia, que consistem na utilização de drogas combinadas corretamente, nas doses e 
duração adequadas, além da condução correta do tratamento (Frazier MS, Drzymkowski; Brasil, 2014).

Os indivíduos que forem diagnosticados com TB possuem o direito de serem adequadamente tratados, oportunamente. É de responsabilidade dos serviços de saúde fornecer todos os recursos e suporte necessário para que os pacientes sigam corretamente o tratamento. Faz-se extremamente necessário que a equipe esteja preparada para acolher, escutar e atender as necessidades dos indivíduos acometidos que buscam o serviço de saúde. Dessa maneira, espera-se que o paciente receba todo o cuidado necessário de forma compromissada, solidária e responsável (Brasil; Farga e Caminero, 2011).

A equipe de saúde também deve fornecer ao paciente todas as informações necessárias sobre a TB, suas características, as condições e duração do tratamento. Além disso, o indivíduo diagnosticado deve compreender a importância da terapia medicamentosa para seu quadro clínico, as consequências severas de se abandonar ou interromper a quimioterapia, além dos possíveis eventos adversos. Esse diálogo e acompanhamento do paciente devem acontecer durante a primeira consulta e perdurar durante todo o tratamento. É fundamental para que haja uma mobilização conjunta do serviço de saúde, da família e do próprio indivíduo para que o mesmo possa aderir ao tratamento. Além de favorecer a adesão à quimioterapia, essas ações fortalecem o vínculo entre a equipe de saúde $e$ a pessoa acometida por TB e sua família. Os pacientes que fazem parte das populações vulneráveis (pessoas em situação de rua, HIV positivos, indígenas, pacientes institucionalizados, usuários de drogas e álcool e casos de retratamento) devem receber atenção redobrada (Brasil, 2011; 2014).

O tratamento da tuberculose dura no mínimo seis meses e a principal estratégia para adesão à terapia medicamentosa consiste no Tratamento Diretamente Observado (TDO). Esse representa uma mudança na maneira como os fármacos para tratamento da TB são administrados. No TDO a ingestão dos medicamentos é observada diariamente por um profissional de saúde capacitado. São realizadas, no mínimo, três observações durante a 
semana em todo o período de tratamento. $O$ paciente pode receber 0 medicamento em casa, através da visita do profissional capacitado ou poderá ir ao serviço de saúde. Os horários e o local em que o tratamento será administrado nunca deverão ser estabelecidos para melhor se adequar à situação do serviço de saúde, e sim à situação do paciente. $\mathrm{O}$ indivíduo em tratamento pode tomar os medicamentos em qualquer horário; no entanto, devem ser administrados somente uma vez durante o dia (Brasil; Farga e Caminero, 2011).

Para escolher o melhor esquema terapêutico para o paciente, devese considerar o local em que o bacilo está instalado e como ele se comporta metabolicamente. Para ser efetivo, o tratamento deve incluir a atividade bactericida precoce, que se traduz na capacidade de eliminar a maior quantidade de bacilos em um menor tempo possível. Dessa maneira é possível diminuir a capacidade de infectar do paciente bacilífero. A condução do tratamento com drogas que possuem atividade bactericida precoce ajudam a diminuir em duas ou três semanas os indivíduos bacilíferos. Para garantir o sucesso do tratamento, também se deve prevenir a emergência de bacilos resistentes às drogas antiTB. Portanto, é necessário que se utilize um esquema de combinação de drogas, pois se garante assim que bacilos que sejam resistentes a um medicamento possam ser afetados por outros. Por fim, o esquema de tratamento deve ter como meta a atividade esterilizante, que consiste na eliminação de todos os bacilos de uma lesão, impossibilitando que ocorra uma recidiva após 0 tratamento (Brasil; Farga e Caminero, 2011; Brasil, 2014).

Nos esquemas de tratamento, que são padronizados, são utilizadas as drogas isoniazida $(H)$, rifampicina $(R)$, pirazinamida $(Z)$ e etambutol $(E)$. São indicadas para adultos e adolescentes a combinação desses fármacos, RHZE e RH em doses fixas. Já para as crianças não se recomenda o uso de etambutol e as doses variam de acordo com o peso (Brasil, 2011; 2014). 


\subsection{Magnitude e situação epidemiológica}

Diante das preocupações globais com a eclosão da tuberculose de forma pandêmica e acentuada no anos de 1990, o controle da doença vêm sendo discutido nas agendas internacionais e nacionais com o intuito de estabelecer objetivos e metas e unir esforços para o combate da doença. A Organização Mundial de Saúde colocou a TB como emergência global no ano de 1993 (WHO, 2002). Como reflexo das conferências e encontros das Nações Unidas, foi estabelecido em 2000, após o encontro de líderes mundiais na cidade de Nova York, a Declaração do Milênio das Nações Unidas. Foram adotados os Objetivos de Desenvolvimento do Milênio (ODMs), em que foram propostas metas para oito objetivos que incluem a redução da pobreza, o acesso a educação e o combate de doenças infecciosas, como por exemplo, o HIV. A tuberculose foi contemplada no objetivo 6c, que propunha que entre 2000 e 2015, a incidência da doença fosse "detida e revertida" (United Nations, 2000; WHO, 2016).

Ainda em resposta as necessidades que surgiam em relação à contenção da doença, foi criado em 2001 a iniciativa Stop TB Partnership,como resultado de um movimento global para acelerar ações políticas e socias para o controle da TB. Além da meta proposta pelo ODM 6c, a iniciativa também incluía a redução pela metade das taxas de prevalência e incidência de TB até 2015, comparados com as taxas de 1990 (WHO, 2000; WHO e The World Bank, 2001a).

Dessa forma, foi elaborado o The Global Plan to Stop TB, um Plano Global para Deter a TB, que foi dividido em três fases. A primeira estabelecia quatro objetivos para o período de 2001 a 2005, que envolviam a expansão da estratégia Direct Observed Treatment Strategy Short Course (DOTS); adaptação dessa estratégia para atender as necessidades dos pacientes com a coinfecção TB-HIV e pacientes com resistência às drogas utilizadas no tratamento; melhorar as técnicas para diagnóstico, medicamentos e vacinas; e, por fim, o fortalecimento da iniciativa The Global Partnership to Stop TB, com o intuito de garantir que as técnicas que são de 
fato efetivas para o controle da tuberculose, sejam aplicadas (WHO e The World Bank, 2001a; 2001b).

A segunda fase foi marcada pelo período de 2006 a 2015, em que monitorou-se os avanços propostos pelo plano anterior, identificou-se os desafios que ainda necessitavam ser enfrentados e estabeleceu-se objetivos para o período. Eles consistem basicamente no uso amplo e adequado das ferramentas para o controle da TB; desenvolver e adaptar estratégias para dar conta dos desafios existentes, principalmente considerando as populações que estão sob risco; acelerar a eliminação da TB através de pesquisa e desenvolvimento tecnológico e garantir o acesso e o uso dessas ferramentas de maneira apropriada e acessível. O plano proposto para esse período incorporou a Stop TB Strategy, iniciativa recomendada pela OMS para a redução da carga de tuberculose alinhada com os objetivos propostos até $\mathrm{o}$ ano de 2015. A estratégia envolve seis elementos chaves que além de fornecer suporte a iniciativa anterior, incorpora uma visão abrangente e inclusiva dos direitos humanos e o fortalecimento dos sistemas de saúde (WHO, 2006).

Um último plano foi desenvolvido para os últimos anos antes de 2015, a terceira fase foi marcada pelo período entre 2011 e 2015. Com o intuito de acompanhar o controle da doença, o The Global Plan to Stop TB 2011-2015, monitorou os objetivos e avanços colocados pelo plano anterior. As ações e proposições para essa última fase, foram ancoradas nas metas do ODMs e na Stop TB Strategy, recomendada pela OMS. O estabelecimento de objetivos para esse plano se propôs a considerar dentre outros fatores, $O$ progresso feito na segunda fase, os custos das drogas para TB multirresistente e as projeções epidemiológicas para o acompanhamento da tendência e das estimativas de carga da doença. Com o intuito de atingir as metas propostas para 2015, o plano para 2011-2015 foi estruturado em duas partes: Implementação e Pesquisa e Desenvolvimento. A primeira parte compreende componentes relacionados à estratégia DOTS, TB drogaresistente, TB-HIV e fortalecimento laboratorial em todos esses componentes. Já a segunda parte abrange indicadores ligados à pesquisa 
básica, novos diagnósticos, drogas e vacinas e pesquisa operacional (WHO, 2010).

Considerando todos os esforços desenvolvidos ao longo desses últimos 15 anos, as metas globais para a redução da incidência, prevalência e mortalidade por Tuberculose foram atingidas em outubro de 2015. Os ODMs para o controle da tuberculose foram atingidos de maneira geral nas seis Regiões adotadas pela OMS e em 16 países entre os 22 com mais alta carga de TB no mundo, segundo a classificação estabelecida pela mesma organização no período de 2002 a 2015. Ocorreu em todo o globo uma redução de 47\% na taxa de mortalidade no período de 1990 e 2015 e a taxa de prevalência global caiu $42 \%$ no mesmo período. As metas de redução de $50 \%$ foram atingidas em quatro e três Regiões da OMS, para as taxas de mortalidade e prevalência, respectivamente (United Nations, 2015a; WHO, 2015a; 2016).

Apesar dos resultados alcançados, as ações em prol do controle e eliminação da doença ainda precisam avançar consideravelmente. Nessa perspectiva, uma era pós 2015 surge para tentar dar conta das necessidades que a contenção da epidemia de TB demanda.

Os Objetivos de Desenvolvimento Sustentável (ODSs), adotados em setembro de 2015 pelos Estados Membros das Nações Unidas, passaram a substituir os ODMs em uma perspectiva mais abrangente e com metas mais incisivas para o período de 2016 a 2035. Os 17 ODSs se constituem a partir de uma abordagem centrada no indivíduo e de amplo alcance. Dentre os objetivos estão: acabar com a pobreza, com a fome e garantir educação de qualidade (United Nations, 2015b).

A tuberculose é comtemplada no objetivo número três, que trata de "Assegurar uma vida saudável e promover o bem-estar para todos, em todas as idades". Esse objetivo é composto por 13 metas, sendo a 3.3 a que se refere diretamente à eliminação da epidemia de TB e incorpora também a eliminação de outras doenças infecciosas importantes como a Aids. A meta 3.8 também compreende a TB, considerando que visa "atingir a cobertura universal de saúde, incluindo a proteção do risco financeiro, o acesso a 
serviços de saúde essenciais de qualidade e o acesso a medicamentos e vacinas essenciais seguros, eficazes, de qualidade e a preços acessíveis para todos". Dessa forma, a pesquisa, o desenvolvimento de tecnologias profiláticas e diagnósticas, medicamentos gratuitos e a garantia do acesso ao serviço de saúde se constituem de ações fundamentais em direção ao fim da epidemia da doença. Além disso, outros ODSs podem estar relacionados com a tuberculose como o objetivo número 8 , que propõe a redução das iniquidades nos países e entre eles, por meio da inclusão social, econômica e política, da garantia da proteção social e da redução de desigualdades (United Nations, 2015; WHO, 2016).

Estudando um possível cenário pós-2015, em 2012 a OMS começou a delinear novas perspectivas a serem adotadas após o fim da Stop TB Strategy. Em 2014 a nova estratégia foi discutida na $67^{\text {a }}$ Assembléia Mundial de Saúde e aprovada por seus Estados Membros. A mesma foi nomeada como End TB Strategy(Estratégia pelo Fim da TB), e propõe a eliminação da epidemia global de tuberculose até $2035 \mathrm{com}$ medidas audaciosas que exigem um esforço conjunto de todos os países, envolvendo uma mudança de paradigma e ações focadas e multisetoriais. Nesse contexto, entende-se por eliminação, a redução da incidência para aproximadamente 10 novos casos para cada 100.000 pessoas anualmente (WHO, 2014).

A Estratégia pelo Fim da TB, que tem por visão um mundo livre de TB e por objetivo principal o fim da epidemia global da doença, está estritamente ancorada nos ODS. O conjunto de ações e intervenções que necessitam ser desenvolvidas para 0 alcance dos objetivos propostos permeiam aspectos biomédicos e socioeconômicos atrelados à saúde pública em consonância com pesquisa e inovação. A OMS delineou a nova estratégia pautada por três indicadores principais e metas relacionadas que envolvem os ODSs, para 2030 e 2035, e objetivos intermediários para os anos de 2020 e 2025. Os três indicadores são: o número de mortes por TB por ano, a taxa de incidência por ano e o percentual de famílias afetadas pela TB que experimentam custos catastróficos em decorrência da doença (WHO, 2014; 2015b). 
Tomando como base o ano de 2015, os percentuais de redução para o ano de 2035 para esses três indicadores são de 95\%, 90\% e 0\%, respectivamente. Na perspectiva das metas relacionadas com os ODSs, a redução proposta é de $90 \%$ para os óbitos, $80 \%$ no coeficiente de incidência (Cl) e $0 \%$ para os custos catastróficos sofridos pelas famílias. Foram estabelecidos também objetivos intermediários para 2020 e 2025, apresentados na tabela 1 (WHO, 2014; 2015b).

A Estratégia pelo Fim da TB é fundamentada em quatro princípios: 1) Administração governamental e prestação de contas, com monitoramento e avaliação; 2) Forte aliança com as organizações da sociedade civil e comunidades; 3) Proteção e promoção dos direitos humanos, da ética e da equidade e; 4) Adaptação da estratégia e das metas ao nível de país, com colaboração global (WHO, 2014; 2015b).

O primeiro princípio se refere à administração responsável em todos os níveis de governo, federal, estadual e municipal, com divisões de responsabilidades. Além do setor de saúde, deve haver o envolvimento de setores sociais e a participação de diferentes ministérios. As comunidades afetadas pela TB, os pacientes e os profissionais de saúde devem receber 0 suporte necessário para o desenvolvimento de ações para o combate da doença. Além disso, deve haver o monitoramento e avaliação das ações, através da coleta sistemática de dados, validação de instrumentos e métricas e a incorporação progressiva de ferramentas digitais. $\mathrm{O}$ segundo princípio está relacionado com o fortalecimento das coalizões com a comunidade e sociedade civil, com o intuito de que as pessoas participem das ações e intervenções das quais elas mesmas irão se beneficiar. A participação ativa desses indivíduos permite o levantamento de questões importantes que concernem a eles próprios, colocação de suas necessidades e preocupações e o fortalecimento das ações a serem desenvolvidas (WHO, 2015b).

No terceiro princípio há a colocação da importância da garantia e promoção dos direitos humanos individuais e proteção social através de políticas, serviços e ações que permitam o acesso e cuidado adequado e de 
qualidade. Deve haver equidade, responsabilidade e não descriminação nas práticas e intervenções. Além disso, deve haver o enfrentamento das inequidades, da pobreza e populações marginalizadas, que detém uma alta carga da doença. $O$ último princípio é pautado pela adequação das ações às realidades dos países e aos programas nacionais. Cada país deve traçar suas próprias metas e ações partindo do objetivo global, no entanto, considerando suas próprias particularidades, com a cooperação entre países (WHO, 2015b).

Tabela 1 - Objetivos e metas da Estratégia pelo Fim da TB em relação aos três indicadores - número de óbitos, coeficiente de incidência e famílias afetadas por custos catastróficos - propostos pela OMS.

\begin{tabular}{|c|c|c|c|c|}
\hline \multirow{2}{*}{ Indicadores } & \multicolumn{2}{|c|}{$\begin{array}{c}\text { Objetivos } \\
\text { intermediários }\end{array}$} & \multirow{2}{*}{$\begin{array}{l}\text { ODS } \\
2030\end{array}$} & \multirow{2}{*}{$\begin{array}{c}\text { Estratégia } \\
\text { pelo Fim da } \\
\text { TB } \\
2035\end{array}$} \\
\hline & 2020 & 2025 & & \\
\hline $\begin{array}{l}\text { Percentual de redução no } \\
\text { número de óbitos }\end{array}$ & $35 \%$ & $75 \%$ & $90 \%$ & $95 \%$ \\
\hline $\begin{array}{l}\text { Percentual de redução no } \\
\text { coeficiente de incidência }\end{array}$ & $20 \%$ & $50 \%$ & $80 \%$ & $90 \%$ \\
\hline $\begin{array}{c}\text { Percentual de famílias afetadas } \\
\text { enfrentando custos } \\
\text { catastróficos }\end{array}$ & $0 \%$ & $0 \%$ & $0 \%$ & $0 \%$ \\
\hline
\end{tabular}

Fonte: WHO, 2016

Esses princípios guiam o desenvolvimento de ações baseados em três pilares principais e seus componentes. Os pilares são: a integração dos cuidados e prevenção centrados no paciente; políticas arrojadas e sistemas de apoio e; intensificação das pesquisas e inovação. Os componentes desses pilares estão sumarizados no Quadro 1 (WHO, 2014; 2015b). 
Quadro 1 - Pilares e componentes da Estratégia pelo Fim da TB.

\begin{tabular}{|c|c|c|}
\hline \multicolumn{3}{|c|}{$\begin{array}{l}\text { Pilares e componentes } \\
\text { Estratégia pelo Fim da TB }\end{array}$} \\
\hline $\begin{array}{l}\text { 1) Integração dos } \\
\text { cidados e } \\
\text { prevenção centrada } \\
\text { no paciente: } \\
\text { - Diagnóstico precoce } \\
\text { - Tratamento para } \\
\text { todas as pessoas } \\
\text { - Atividades } \\
\text { colaborativas para } \\
\text { TB/HIV } \\
\text { - Tratamento } \\
\text { preventivo para } \\
\text { pessoas de alto risco } \\
\text { e vacinação contra } \\
\text { TB }\end{array}$ & $\begin{array}{c}\text { 2) Políticas arrojadas e } \\
\text { sistemas de apoio: } \\
\text { - Comprometimento político } \\
\text { - Engajamento comunitário, } \\
\text { das organizações da } \\
\text { sociedade civil e dos } \\
\text { prestadores de cuidados } \\
\text { - Política de cobertura } \\
\text { universal de saúde, sistemas } \\
\text { de informação integrados, } \\
\text { uso racional de } \\
\text { medicamentos } \\
\text { - Proteção social aos } \\
\text { paciente, enfrentamento da } \\
\text { pobreza e ações sob a ótica } \\
\text { dos determinantes sociais da } \\
\text { TB }\end{array}$ & $\begin{array}{l}\text { 3) Intensificação das } \\
\text { pesquisas e } \\
\text { inovação: } \\
\text { - Desenvolvimento e } \\
\text { incorporação de } \\
\text { novas ferramentas, } \\
\text { tecnologias e } \\
\text { estratégias } \\
\text { - Pesquisa para } \\
\text { otimização da } \\
\text { implementação e do } \\
\text { impacto e, promover } \\
\text { inovações }\end{array}$ \\
\hline
\end{tabular}

Fonte: WHO, 2016

A era pós-2015 também foi marcada por mudanças nas listas de classificação dos países que possuíam alta carga de tuberculose, coinfecção TB-HIV e Tuberculose Multidroga resistente (MDR-TB), definidas pela OMS. 
As listas se mantiveram inalteradas até o ano de 2015 e foram alteradas em razão das novas perspectivas, objetivos e metas posteriores ao ano de 2015. As novas listas para países com alta carga de TB foram definidas para o período de 2016 a 2020 e foram divididas da seguinte forma: uma lista para TB, uma para MDR-TB e uma para TB/HIV. Cada uma das listas possui 30 países e as mesmas se sobrepõem, sendo que 48 países estão em pelo menos uma lista e 14 que pertencem as três listas ao mesmo tempo.

Os critérios para classificação foram os 20 países com maior número de casos novos, somados aos 10 países com maior taxa de incidência per capita que não estão nos 20 primeiros por números absolutos e que possuem um número mínimo de casos incidentes de 10.000 por ano para TB e 1.000 por ano para MDR-TB e TB/HIV. O Brasil, que anteriormente se encontrava na lista dos 22 países com maior carga de doença, agora está na lista de TB e TB/HIV. A nova classificação da OMS está ilustrada na figura 1 (WHO, 2016). 
Figura 1 - Listas dos países com maior carga de tuberculose que serão utilizadas pela OMS no período de 2016 a 2020 e suas áreas de sobreposição.

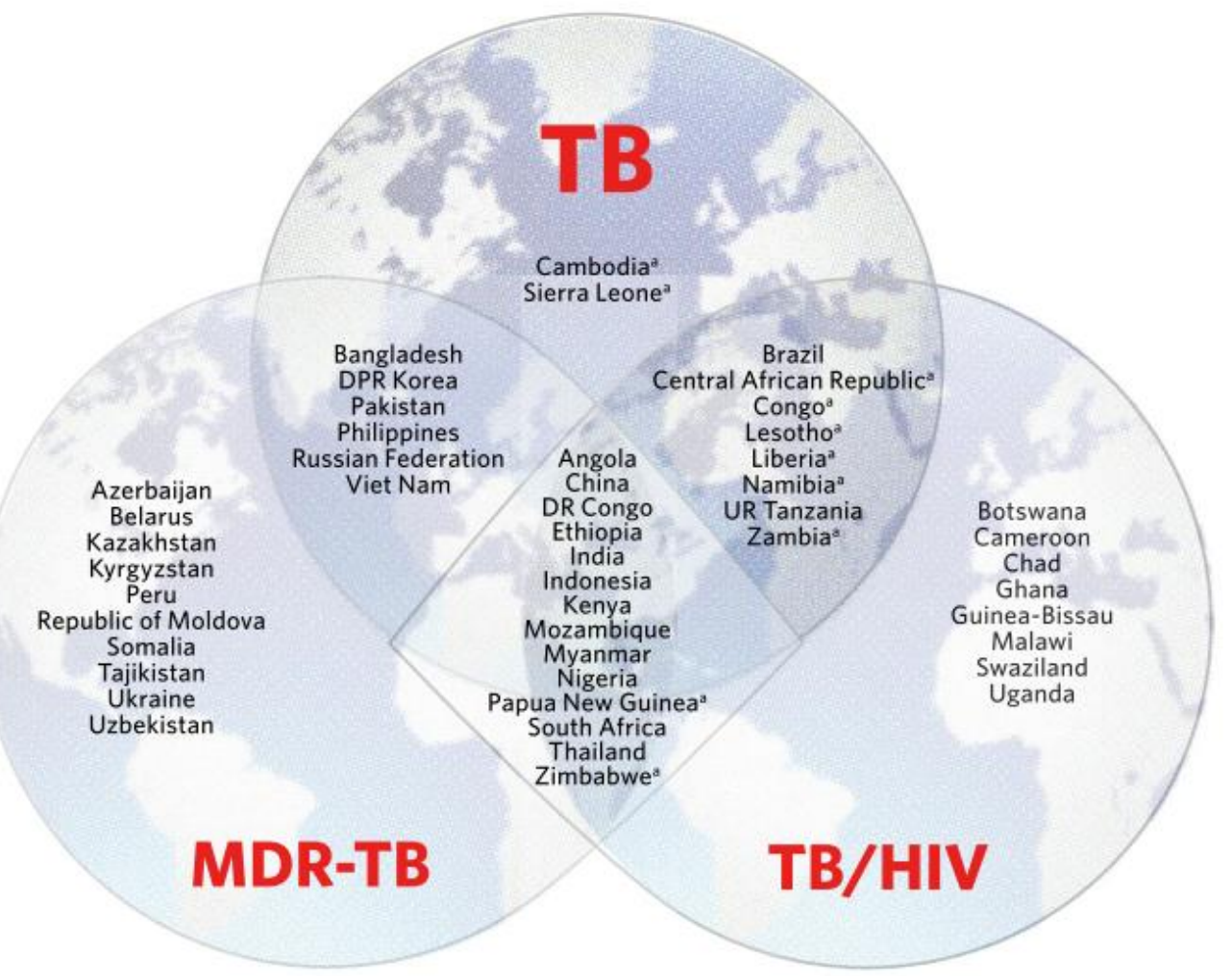

Fonte: WHO, 2016

\subsection{Situação epidemiológica da tuberculose no cenário mundial}

Com os avanços alcançados com os ODMs e com a Stop TB Partnership, o panorama da TB no mundo melhorou: 49 milhões de vidas foram salvas entre 2000 e 2015 como resultado do diagnóstico oportuno e do tratamento. Apesar dos progressos realizados, a epidemia da doença ainda se constitui como um problema de grande magnitude. Mesmo com o decréscimo de 22\% nas mortes entre 2000 e 2015, a doença ainda está entre as dez que mais matam no mundo, de acordo com a Organização Mundial de Saúde (2016). 
Foram estimados 10,4 milhões de casos novos de TB mundialmente em 2015, que representa 142 casos para cada 100.000 habitantes. A maioria dos casos incidentes ocorreu entre os homens, com 5,9 milhões de registros, representando $56 \%$ do total de casos novos da doença. Entre as mulheres, ocorreram 3,5 milhões de novos casos (34\%) e 10\% entre as crianças, com um milhão de casos novos (WHO, 2016). A estimativa mundial da incidência em 2015 apresentou-se consideravelmente maior do que a estimada anteriormente pela OMS em sua publicação do ano de 2015, mesmo considerando que as taxas de incidência estão em declínio. Isso pode ser explicado pelas estimativas da Índia, que, após intensa revisão, foram reveladas como sendo significativamente mais elevadas, gerando impacto nas estimativas anuais (WHO, 2015; 2016).

Em 2015 o maior número de casos, cerca de 61\%, ocorreram na Ásia e $26 \%$ dos casos foram observados na Região Africana, delimitada pela OMS. Na Região das Américas foi registrado um percentual de 3\% dos casos. Em relação aos 30 países que detém a maior carga de TB, $87 \%$ do total de casos incidentes ocorreram nesse grupo de países. Seis deles juntos (Índia, Indonésia, China, Nigéria, Paquistão e África do Sul) foram responsáveis por $60 \%$ da incidência global e apresentaram os maiores números de casos novos em 2015. Os coeficientes de incidência variam consideravelmente entre os 30 países com mais elevada carga de TB. No sul do continente Africano os coeficientes de incidência são muito elevados, chegando a mais de 300 casos para cada 100.000 habitantes (WHO, 2016). O número de casos novos pela população de cada país pode ser observado na Figura 2, e sua redução nos últimos anos está ilustrada na Figura 3. Apesar dos coeficientes de incidência estarem em redução nos últimos anos, para atingirem os objetivos intermediários propostos pela Estratégia pelo Fim da TB os $\mathrm{Cl}$ precisam diminuir de 4 a $5 \%$ anualmente em todo 0 mundo (WHO, 2016). 
Figura 2 - Estimativa dos coeficientes de incidência (por 100.000 habitantes) por tuberculose no mundo, 2015.

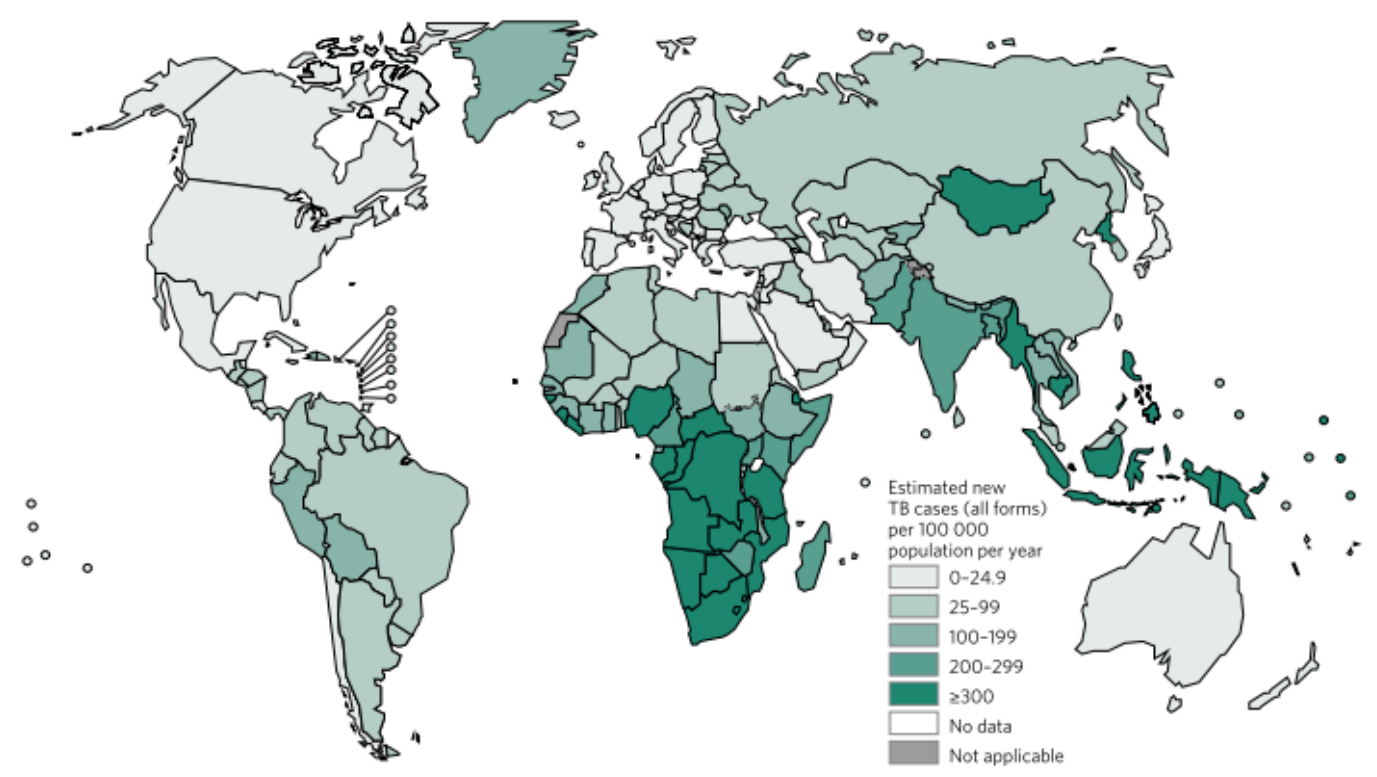

Fonte: WHO, 2016

Com relação à mortalidade, a tuberculose foi responsável por 1,4 milhão de mortes no mundo, sendo $28,57 \%$ ocorridas entre pessoas vivendo com HIV. Entre esses indivíduos, a TB lidera as causas de morte, sendo que $35 \%$ de todos os óbitos de pessoas HIV-positivas foram em decorrência da tuberculose. O número de óbitos vem decaindo nos últimos anos no mundo (Figura 3). No período de 2000 a 2015 houve uma queda de 34\% no número de mortes, reduzindo de 1,8 milhão em 2000 para 1,4 milhão em 2015. Uma queda de 2,7\% ocorreu entre 2014 e 2015, sendo o declínio mais lento na Região Africana da OMS. Para atingir os objetivos intermediários da OMS é necessário que ocorra uma redução de $10 \%$ ao ano no número de óbitos em todo o mundo (WHO, 2016).

Do total de mortes que aconteceram no mundo, cerca de $95 \%$ ocorreram em países com renda média e baixa, sendo as regiões da África e do Sudeste da Ásia da OMS os locais mais acometidos por TB em indivíduos HIV-negativos. A Índia e a Nigéria contribuem com $48 \%$ do total de mortes para indivíduos HIV-negativos e $43 \%$ considerando tanto indivíduos HIV negativos quanto indivíduos HIV positivos. O coeficiente de 
mortalidade (CM) global por TB entre pessoas sem HIV é de 19 mortes para cada 100.000 habitantes e quando pessoas vivendo com HIV são incluídas, o CM é de 24/100.000. Os coeficientes de mortalidade entre indivíduos HIV negativos no mundo no ano de 2015 estão ilustrados na Figura 4.

Figura 3 - Tendência mundial dos números estimados de casos novos e número de óbitos (em milhões) por tuberculose entre 2000 e 2015.
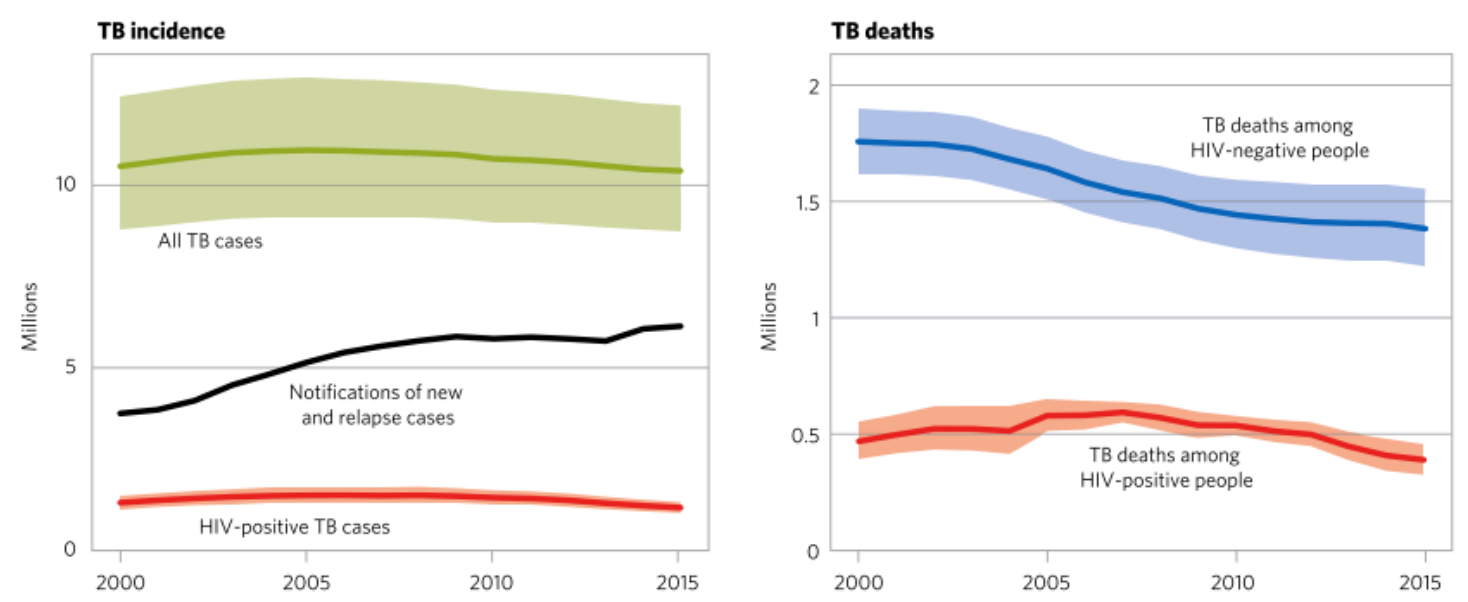

Fonte: WHO, 2016

${ }^{*}$ As áreas sombreadas representam os intervalos de confiança. A linha preta representa 0 número de casos novos e reincidentes. 
Figura 4 - Estimativa dos coeficientes de mortalidade (por 100.000 habitantes) por tuberculose no mundo, 2015.

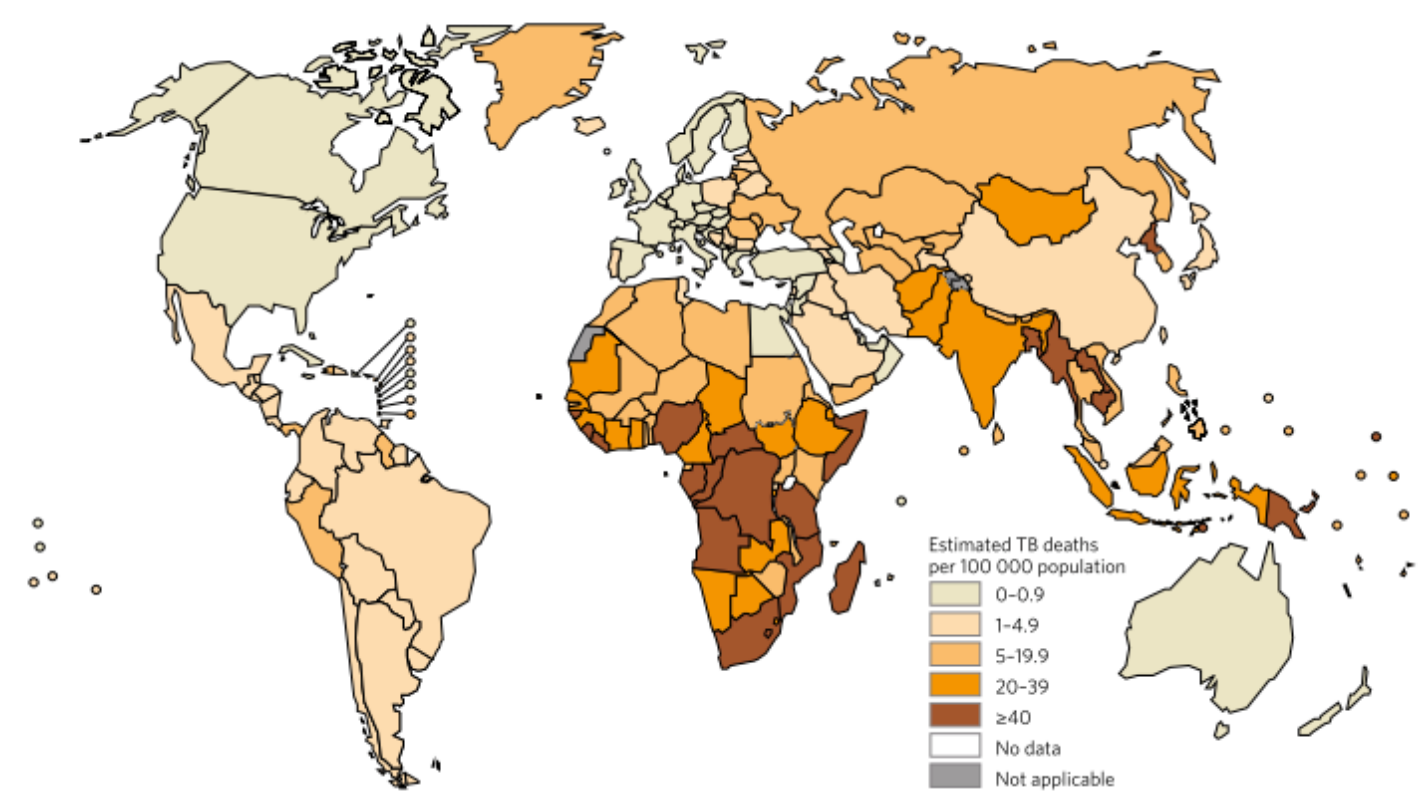

Fonte: WHO, 2016

\subsection{Situação epidemiológica da Tuberculose no Brasil}

De acordo com a OMS, o Brasil alcançou todas as metas propostas pelos ODMs de parar e reverter a incidência da TB, e as metas propostas pela estratégia Stop TB Partnership, de reduzir pela metade a prevalência e mortalidade da doença (WHO, 2015). Embora as metas propostas até 2015 tenham sido atingidas, o Brasil ainda se encontra entre os 30 países com maior carga de doença por TB e ainda enfrenta grandes desafios com relação a populações vulneráveis, como é o caso de pessoas portadoras do vírus HIV (Brasil, 2016a).

Segundo o Ministério da Saúde, ocorreram 67.790 novos casos de tuberculose em 2015, aproximadamente 1.480 casos a menos do que durante o ano de 2014. O coeficiente de incidência caiu de 47,8 casos novos para cada 100.000 habitantes em 2000 para 33,6 no ano de 2015. O maior coeficiente para esse ano pode ser observado na região Norte, com 41 casos por 100.000 habitantes. Dentro dessa Região, o estado do Amazonas 
é o que detém o maior $\mathrm{Cl}$ do país, com 71 casos por 100.000 habitantes. $\mathrm{O}$ menor $\mathrm{Cl}$ se encontra na região Centro-Oeste, com 21,6/100.000 habitantes. O Distrito Federal é o detentor do menor $\mathrm{Cl}$ do país, com 11,9 casos para cada 100.000 habitantes. A tendência dos $\mathrm{Cl}$ no Brasil por região, entre 1990 e 2015 pode ser observada na Figura 5 (Brasil, 2016b; 2016c).

Figura 5 - Série histórica dos coeficientes de incidência por tuberculose no Brasil, segundo Grandes Regiões, 1990 - 2015.

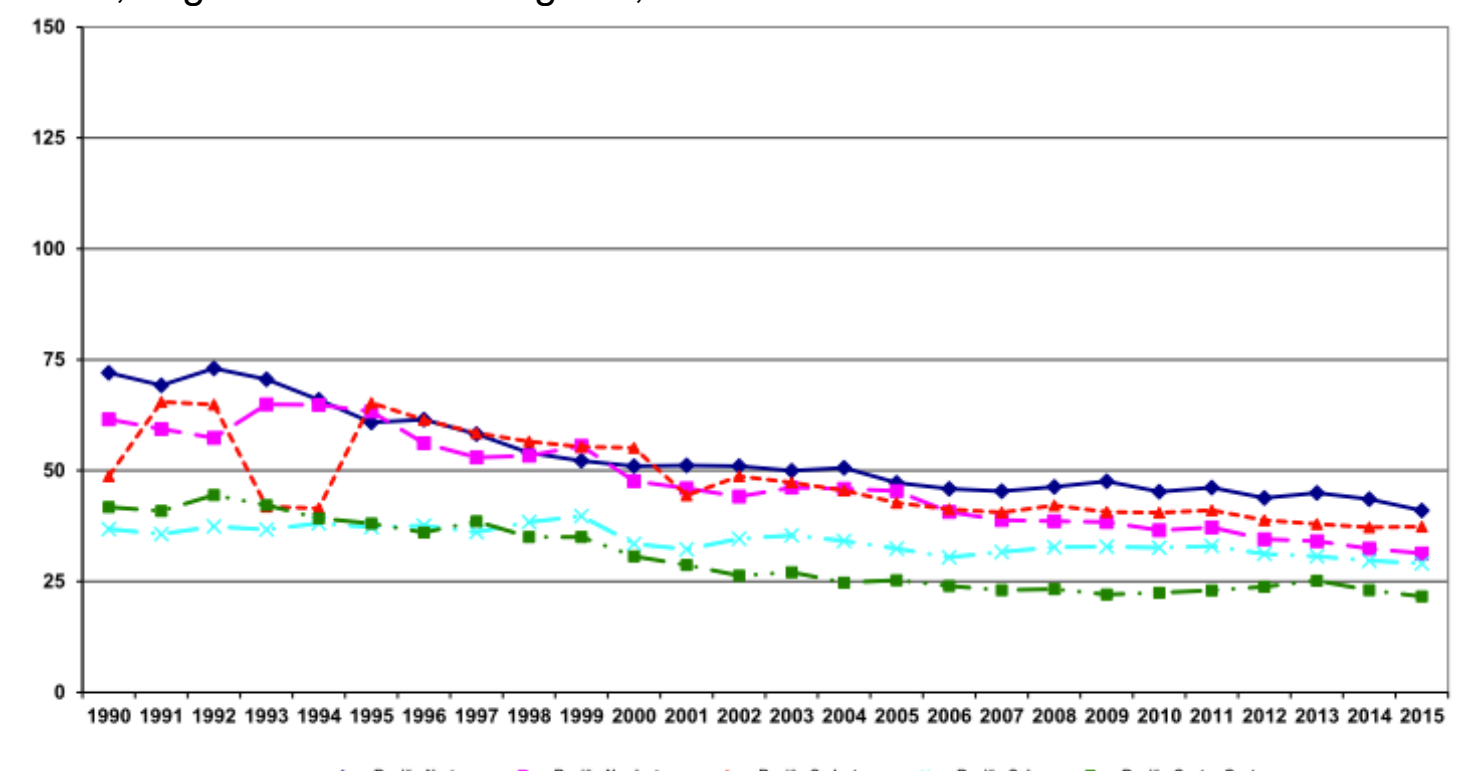

Fonte: Brasil, 2016c

Em relação à mortalidade, o Ministério da Saúde registrou em 20144.374 óbitos por tuberculose no Brasil, representando $0,4 \%$ do total de óbitos dos residentes no Brasil e $8,4 \%$ dos óbitos por doenças infecciosas e parasitárias, sendo os homens os mais acometidos. A redução do coeficiente de mortalidade em relação ao ano de 2004 foi de 15,4\% conforme a publicação "Panorama da tuberculose no Brasil: A mortalidade em números", passando de 2,8 óbitos por 100.000 habitantes para 2,2 óbitos por 100.000 habitantes. Após reprodução do cálculo da redução utilizando os valores acima foi encontrado um decréscimo de 21,4\% (Figura 6) (Brasil, 2016d). 
Figura 6 - Tendência do coeficiente de mortalidade por tuberculose no Brasil, $2004-2014$.

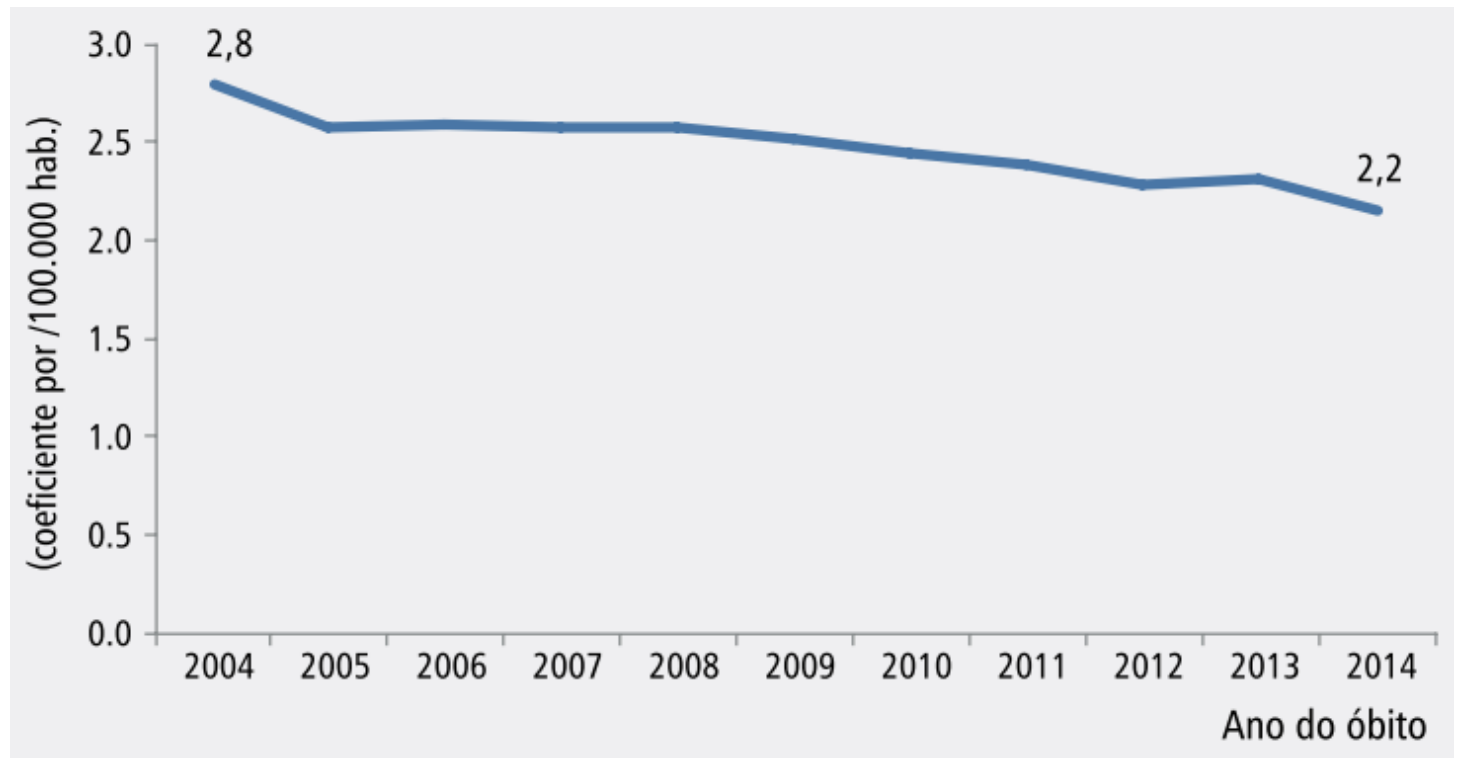

Fonte: Brasil, 2016d

Em 2015 o coeficiente de mortalidade da TB permaneceu inalterado em relação a 2014. Durante o período, a região Nordeste foi a mais acometida com um CM de 2,6 óbitos por 100.000 habitantes, no entanto o estado com maior CM foi o Rio de Janeiro com cinco óbitos por 100.000 habitantes. A região que obteve o menor $\mathrm{CM}$ em 2015 foi a região Centro Oeste com 1,4 óbito por 100.000 habitantes e os estados com menor CM foram o Tocantins e o Distrito Federal, com 0,5 morte para cada 100.000 habitantes (Brasil, 2016e). A tendência de declínio do CM no período de 1990 a 2015, nas regiões brasileiras e no Brasil, pode ser vista na Figura 7. 
Figura 7 - Série histórica dos coeficientes de mortalidade por tuberculose no Brasil, segundo Grandes Regiões, 1990 - 2015.

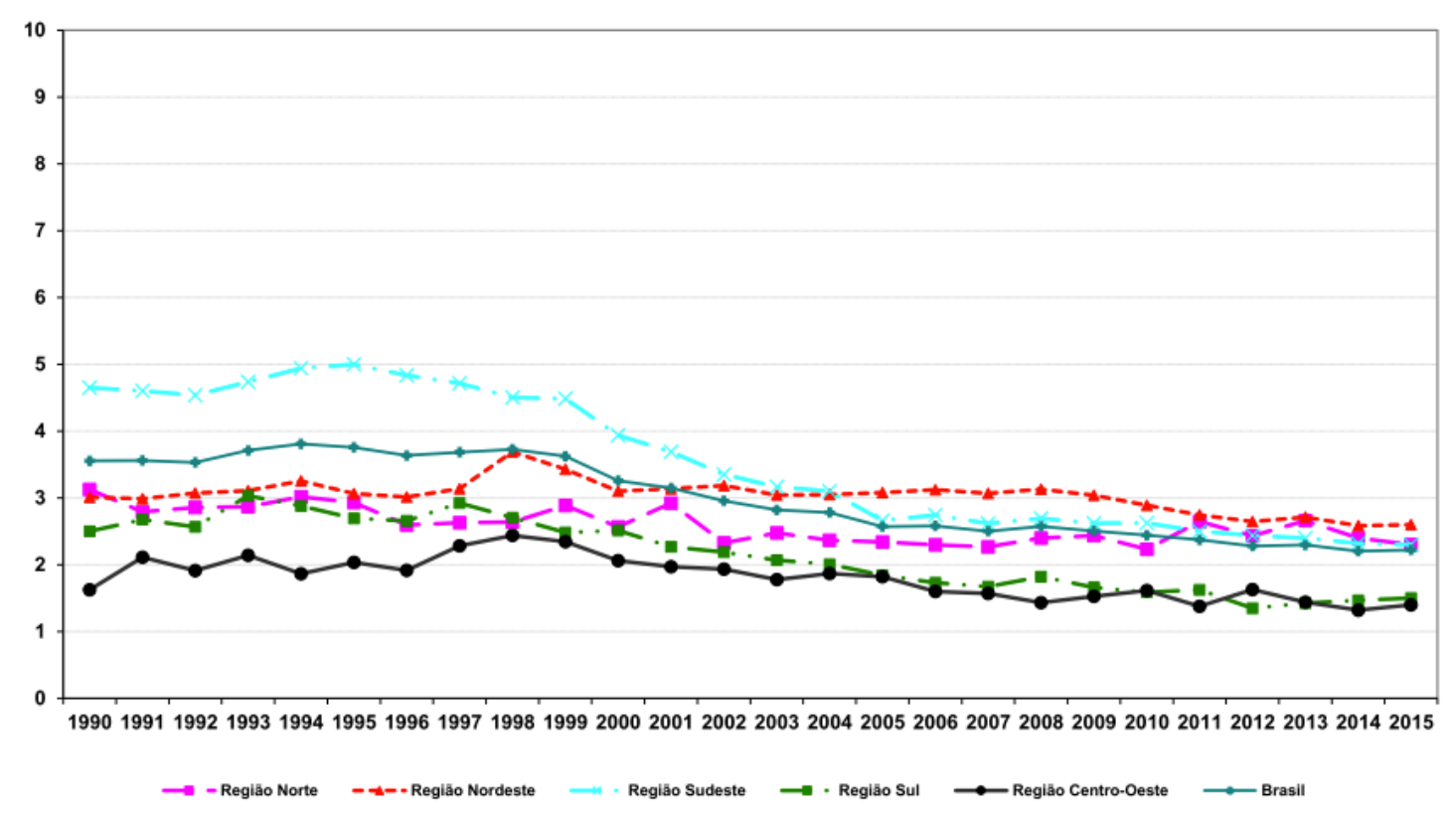

Fonte: Brasil, 2016e

\subsection{Desigualdades Sociais e Determinantes Sociais de Saúde}

Segundo Travassos e Castro (2008) o risco de adoecer e morrer está mais distribuído entre grupos que são desprivilegiados na sociedade em detrimento de grupos sociais mais favorecidos. Os autores colocam que as condições de saúde da coletividade associam-se substancialmente com os padrões de desigualdades sociais.

$\mathrm{Na}$ mesma perspectiva, Duarte et al. (2002) indicam que esses padrões variam temporalmente e espacialmente e explicitam que as condições de vida e de saúde da população são um reflexo das desigualdades sociais. Isso advém da possível distribuição desigual dos recursos, dos fatores de exposição e do risco de morrer ou adoecer em grupos distintos. Esses fatores são influenciados por questões como 0 acesso aos serviços e bens, de questões ambientais, demográficas e urbanas, do nível socioeconômico e do papel social que o indivíduo desempenha na sociedade (Ramalho e Duarte, 2015). 
As desigualdades sociais foram observadas em todas as sociedades existentes identificadas, contudo com padrões e causalidades diferentes (Silva e Barros, 2002). As mesmas são definidas por diversos autores, sendo consensual que as desigualdades sociais só se constituem de um problema quando estão ligadas à ideia de injustiça.

Silva e Barros (2002) entendem as desigualdades como sendo naturais, quando há a diferença entre os indivíduos, como sexo e idade, por exemplo, e sociais, que são desigualdades produzidas pela diferença na ocupação de posições referentes ao processo de produção. Os autores pontuam que as desigualdades naturais só produzem desigualdades sociais quando essas diferenças naturais são utilizadas para atribuir papéis na sociedade. Partindo dessas definições, os autores explicitam que as desigualdades sociais por si só não estão ligadas a ideia de injustiça, mas somente quando há um julgamento de valor. Surge a partir disso a noção de iniquidade que vai além de uma concepção mais descritiva e permeia-se por uma noção mais normativa.

De maneira similar, Kawachi, Subramanian e Almeida-Filho (2002) argumentam que a igualdade e as desigualdades são parâmetros quantitativos e dimensionais, enquanto que equidade e inequidade se tratam de conceitos políticos que remetem à noção de justiça. Já as desigualdades em saúde são descritas por esses autores como um conceito genérico que se refere às diferenças nas conquistas de saúde individuais e coletivas. As iniquidades em saúde, por sua vez, são definidas como desigualdades injustas ou oriundas de alguma injustiça.

Por outro lado, o conceito de iniquidades sociais em saúde, proposto por Dahlgren e Whitehead (2006), incorpora a noção de que as diferenças socioeconômicas entre os grupos são sistemáticas e que são socialmente produzidas, modificáveis e injustas. Essas diferenças são mensuradas através da renda, educação e ocupação.

A Comissão dos Determinantes Sociais em Saúde (CDSS), criada pela OMS em 2005, indica que as condições em que as pessoas crescem, vivem, trabalham e envelhecem influenciam na saúde desses indivíduos e 
que as desigualdades nessas condições levam as desigualdades em saúde. As desigualdades na saúde dentro dos países são evitáveis e, por tanto, injustas (CDSS, 2007).

Essas condições de vida dos indivíduos e de grupos sociais são compreendidas por Silva e Barros (2002) como "o conjunto das condições materiais necessárias à subsistência e que são fortemente condicionadas, ainda que com mediações, pelos modelos vigentes de organização da produção social" (p. 377).

Essas conceituações amplas das condições em que os indivíduos e grupos estão inseridos na sociedade e suas relações com a saúde, que podem provocar desigualdades injustas, ou seja, iniquidades esbarram na definição de determinantes sociais em saúde (DSS). Os mesmos também são conceituados por diversos autores, mas as definições com maior ou menor detalhe culminam em uma noção conceitual convergente.

Os determinantes sociais de saúde são conceituados por Raphael (2009) como sendo os fatores econômicos e condições sociais que moldam a saúde dos indivíduos, da comunidade e a jurisdição como um todo. Os determinantes sociais em saúde podem ser enxergados em uma definição estreita de saúde, podendo ser definidos como sendo os primeiros determinantes que influenciam no adoecimento ou não dos indivíduos. A conceituação de determinantes sociais em saúde também se encaixa em uma definição mais ampla de saúde, em que os DSS determinam o grau em que uma pessoa possui recursos físicos, sociais e pessoais para identificar e alcançar as aspirações sociais, satisfazer suas necessidades e lidar com meio ambiente. O autor entende que os determinantes sociais de saúde se baseiam na quantidade e na qualidade da diversidade de recursos que a sociedade coloca disponível para seus membros.

Dahlgren e Whitehead (2006) conceituam os determinantes da saúde como sendo os fatores que interferem na saúde de maneira positiva ou negativa. Os autores argumentam que esses fatores podem ser ou não influenciados por decisões políticas, comerciais e decisões individuais. Os determinantes de saúde sociais, econômicos e de estilo de vida podem 
sofrer essas influências. Por outro lado, determinantes de saúde como, por exemplo, sexo, idade e fatores genéticos não são influenciados por questões políticas. Os pesquisadores diferenciam a conceituação de determinantes da saúde da definição de determinantes sociais das iniquidades em saúde. Essa última é colocada como sendo os determinantes sociais, econômicos e de estilo de vida que aumentam ou diminuem as desigualdades em saúde. Nesse caso, esses fatores podem ser influenciados por questões políticas, econômicas e por escolhas individuais.

Os autores colocam que essas conceituações são comumente misturadas pelos formuladores de políticas e tomadores de decisões uma vez que são utilizadas como sinônimos. Dessa maneira, as políticas de saúde são desenvolvidas em uma abordagem geral e se tornam pouco efetivas na redução das iniquidades. Para a compreensão dos determinantes sociais das iniquidades em saúde, os autores explicitam como sendo fundamental a compreensão dos determinantes da saúde. Em 1993 foi proposto um modelo de determinação do processo saúde-doença em forma de arco-íris e com inúmeras camadas de influência (Dahlgren e Whitehead, 2006).

O modelo proposto (Figura 8 ) destaca que há interações entre os determinantes de saúde nas diversas camadas. Os indivíduos a partir do seu estilo de vida estão abarcados pelas normas e redes sociais, que por sua vez compreendem as condições de vida e trabalho que se relacionam com as condições socioeconômicas e ambientais (Dahlgren e Whitehead, 2006). 
Figura 8 - Determinantes Sociais de Saúde.

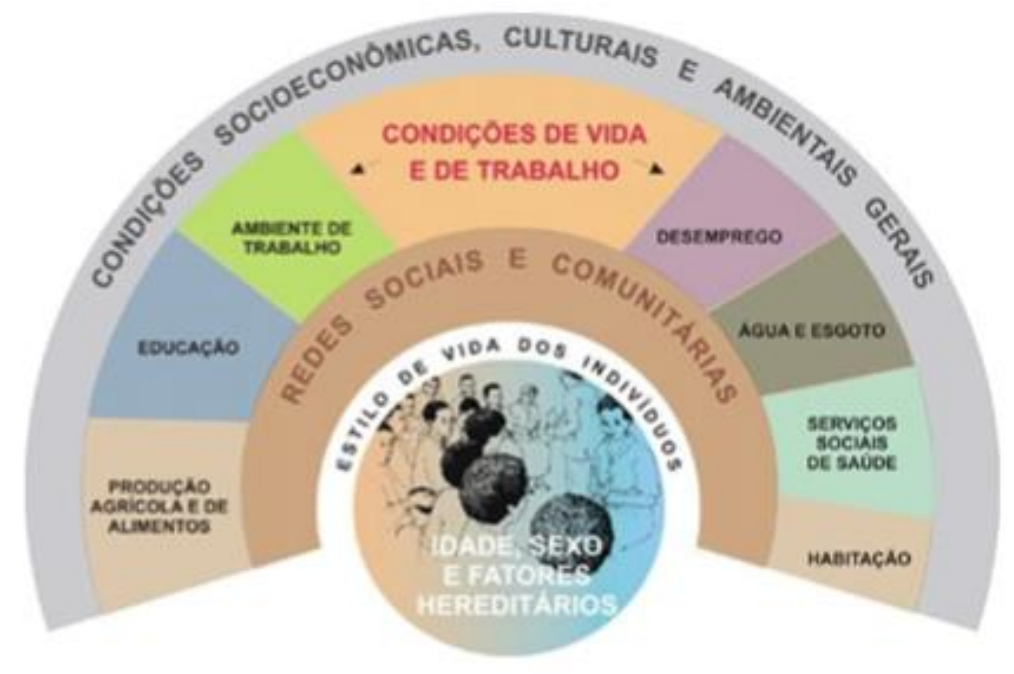

Fonte: Dahlgren e Whitehead, 1993

A partir desse modelo proposto, Carvalho e Buss (2008) afirmam que o processo para lidar com a causa das causas, ou seja, os determinantes no processo saúde e doença vai além das ações pontuais no sistema de atenção à saúde com mudança na estrutura assistencial e dos indivíduos envolvidos. Ações são necessárias no âmbito das condições socioeconômicas, ambientais e culturais permeadas por ações nos diversos setores da sociedade. Para esses autores, são necessárias políticas de desenvolvimento que estejam atreladas a uma distribuição mais equânime dos recursos que são produzidos na sociedade e que subordinem a economia ao bem-estar social.

Segundo Dean e Fenton (2010) as doenças infecciosas como a tuberculose, HIV/AIDS, hepatites virais e doenças sexualmente transmissíveis surgem em decorrência das circunstâncias em que os indivíduos crescem, vivem, trabalham, socializam e constroem relações. Além disso, o surgimento dessas condições está ligado aos sistemas desenvolvidos para lidar com a doença, sendo que esses sofrem influências políticas, sociais e econômicas.

Os fatores estruturais e sociais são apresentados como parte fundamental da compreensão dessas condições de saúde em diversos 
níveis. Os fatores estruturais incluem aqueles físicos, sociais e culturais, econômicos, legais, comunitários e econômicos do ambiente que influenciam positivamente ou negativamente na transmissão de doença. Já os fatores sociais se constituem de questões econômicas e condições sociais que exercem influência na saúde individual e coletiva. Esses fatores incluem condições para o desenvolvimento infantil, educação, segurança alimentar, acesso aos serviços de saúde, moradia, o estigma, entre outros (Dean e Fenton, 2010).

A CDSS argumenta que não é surpreendente o fato de que pessoas pobres em países em desenvolvimento adoecem mais, principalmente por doenças infecciosas. Esses indivíduos estão submetidos ao acesso limitado de alimentos, aos baixos níveis de saneamento, moradia precária, água potável sem tratamento e a ausência de um cuidado de saúde adequado.

A tuberculose tem sido considerada como um dos exemplos mais clássicos de "doença social" com grande influência dos DDS (Lönnroth et al., 2009). O estigma se constitui de um determinante social importante para essa doença. Esse está intrinsicamente relacionado com os comportamentos dos indivíduos acometidos em relação à procura dos serviços de saúde e para o manejo dessas condições (Dean e Fenton, 2010).

Em seu estudo de revisão, Lönnroth et al. (2009) reúnem os determinantes da tuberculose em níveis mais distais e proximais. Em nível mais distal a TB têm seguido um gradiente socioeconômico forte entre países e dentro dos países e das comunidades, embora os processos que levam a uma possível causalidade entre pobreza e baixo status socioeconômicos não estarem bem compreendidos.

Em um nível mais proximal os fatores que contribuem para 0 adoecimento da TB estão associados ao contato direto com as partículas infectadas com o Bacilo de Koch. O contato com pessoas infectadas e a carga de doença na comunidade influenciam no risco de adoecer. $O$ risco de adoecer também é influenciado for fatores físicos do ambiente como umidade, fluxo de ar e aglomeração. Outros fatores proximais que foram 
encontrados nos estudos reunidos pelos autores incluem os que influenciam no comprometimento do sistema imunológico, como por exemplo, coinfecção por HIV e outras co-morbidades, tabagismo, subnutrição, alcoolismo, poluição e contaminação do ar por queima de combustíveis, entre outros (Lönnroth et al., 2009).

O controle da tuberculose deve considerar uma combinação de fatores que envolvem ações preventivas e tratamento oportuno, considerando as questões biológicas, socioeconômicas, comportamentais e a resposta do serviço de saúde e essas questões (CDSS, 2007).

\subsection{Carga de doença e Anos de Vida Perdidos Ajustados por Incapacidade - Disability Adjusted Life Years (DALY)}

O mundo e o Brasil vêm passando por uma transição demográfica e epidemiológica em que a população mundial está envelhecendo, a expectativa de vida está aumentando ao passo que a carga das doenças crônicas não transmissíveis (DCN) está ganhando cada vez mais espaço em detrimento das doenças infecciosas e parasitárias (DIP), principalmente em países desenvolvidos. Entretanto, países como o Brasil ainda estão enfrentando uma dupla carga de doença em que, apesar do aumento das DCN, as DIP ainda se constituem um problema preocupante. Atrelado a este contexto, há um grande aumento das causas externas, como acidentes e violência que acabam por completar a tríade dos problemas e agravos em saúde.

Diante desse contexto e dos desafios de lidar com uma demanda larga por cuidados e serviços de saúde e a disponibilidade limitada de recursos, é imprescindível que haja uma compreensão da situação de saúde de determinada população, considerando os agravos e problemas existentes. Dessa forma, o planejamento de ações, intervenções e a alocação de recursos demandam informações precisas e confiáveis acerca 
das incidências das doenças, suas consequências e causas para guiar a tomada de decisão (Mathers et al., 2001).

Nessa perspectiva, no ano de 1993, a Escola de Saúde Pública de Harvard em parceria com o Banco Mundial se propuseram a mensurar a carga global de doença em um projeto intitulado Global Burden of Disease $(G B D)$. O GBD se constituía de um projeto amplo que propunha gerar estimativas completas, precisas e consistentes de mortalidade e morbidade, estratificadas por sexo, faixa etária e região. Além disso, o grupo desenvolveu uma métrica para quantificar a carga de doença, chamada de Disability Adjusted Life Years (DALY), traduzida como anos de vida perdidos ajustados por incapacidade, um indicador composto que engloba mortalidade e incapacidade em uma única medida. A mortalidade prematura é mensurada através do componente anos de vida perdidos, do inglês Years of Life Lost (YLL), enquanto que a incapacidade é medida através dos anos vividos com incapacidade, Years Lived with Disability (YLD). O DALY foi utilizado para mensurar a carga global de mais de 100 doenças em oito regiões, para homens e mulheres de cinco grupos etários (Murray, Lopez e Jamison, 1994; Mathers et al., 2001; Lopez et al., 2006).

O DALY é uma métrica que complementa o conceito de Anos Potenciais de Vida Perdidos (APVP), que trata-se de uma ferramenta que objetiva mensurar os anos de vida perdidos em razão de uma morte prematura, atribuindo um peso maior aos óbitos de indivíduos mais jovens. O APVP foi utilizado por Dempsey (1947) como uma métrica adicional aos indicadores tradicionais de mortalidade, aplicando-o em uma análise da tendência de declínio das taxas de mortalidade por tuberculose nos Estados Unidos no período de 1924 e 1944. Além da mortalidade prematura, o $D A L Y$ incorpora os anos de vida saudáveis que são perdidos em razão de um estado de saúde inadequado ou de incapacidade gerada por uma doença, isso é traduzido pelo componente YLD (Murray, 1994; Murray e Acharya, 1996).

Dessa forma, o DALY se constitui de um indicador de saúde que mensura uma discrepância entre dois estados de saúde, o atual e um estado 
ideal no qual todos vivem até uma determinada idade esperada, livre de doença ou incapacidade. Portanto, um DALY pode ser entendido como um ano de vida saudável perdido (Murray e Acharya, 1996; Lopez et al., 2006). A partir de uma perspectiva populacional, condições e doenças de maior impacto em saúde pública contribuem com mais $D A L Y S$ do que aquelas doenças de menor impacto (Devleesschauwer et al., 2014).

O indicador pode ser calculado, de forma simplificada, pela somatória dos anos de vida perdidos, Years of Life Lost (YLL), e dos anos vividos com incapacidade, Years Lived with Disability (YLD), dados pela seguinte expressão:

\section{$D A L Y=Y L L+Y L D$}

Em que o YLL é dado por:

\section{$\mathrm{YLL}=\mathbf{N} \times \mathbf{L}$}

onde:

$\mathbf{N}$ = número de óbitos na população;

$\mathbf{L}=$ expectativa de vida na idade do óbito em anos;

O YDL pode ser obtido por:

YLD $=I \times D W \times L$

Em que:

I = número de casos incidentes;

DW = peso da incapacidade;

$\mathbf{L}=$ duração média da doença . 
O peso da incapacidade é um valor que traduz a severidade da doença em uma escala que varia de 0 a 1 , sendo 0 o estado de saúde perfeito e 1 correspondendo à morte.

\subsection{Peso da Incapacidade}

Murray (1994) coloca como um imenso desafio a definição de peso para mensurar incapacidade, de forma que se englobem dimensões múltiplas da função humana em um único modelo.

Em um primeiro momento foram definidas seis classes de incapacidade que transitam entre a saúde perfeita e a morte. A classe 1 possuía peso de 0,096 que correspondia a limitação na habilidade de realizar ao menos uma atividade das áreas de recreação, educação, procriação ou ocupação. Foi atribuído um peso de 0,920 para a classe 6 , que se referia à necessidade de ajuda com atividades diárias como se alimentar, uso do banheiro e higiene pessoal. Dessa maneira, as incapacidades individuais eram atribuídas a cada uma dessas categorias (Murray, 1994).

No GBD 2000 foram atribuídos pesos para 22 condições que serviram de base para outros estados de saúde. Já para o GBD 2010 foram estabelecidos pesos para 220 estados de saúde em que foi possível classificar as condições como leves, moderadas e graves. Na mesma perspectiva, o GBD 2013 contava com a definição de 306 estados de saúde com quatro níveis de severidade (Murray, 1994; Salomon et al, 2012; GBD 2013 e HALE Collaborators; 2015).

Entretanto, ao longo dos anos diferentes metodologias foram empregadas para o cálculo do peso da incapacidade para inúmeras condições e níveis de severidade e, apesar dos avanços, muitas dúvidas surgiram em torno de como esses pesos foram obtidos, aplicados e interpretados (Chen et al, 2015). Segundo Murray (1994), uma série de técnicas podem ser utilizadas para a avaliação das preferências por estados de saúde dos indivíduos como a classificação de escalas, estimação da 
magnitude, standard gambles, time trade-offs e person trade-offs (Murray, 1994; Mathers et al, 2001). Para ajudar na definição de pesos, os primeiros estudos do GBD utilizaram o método person trade-off (PTO) em que pessoas são indagadas acerca de suas preferências entre dois grupos de indivíduos distintos. Foram utilizadas duas abordagens, a partir do PTO, em que os participantes de um painel de especialistas, em um modelo teórico, primeiramente decidiam entre estender a vida de indivíduos saudáveis ou salvar pessoas que viviam com alguma condição. Posteriormente, os especialistas teriam de decidir entre estender a vida de pessoas saudáveis ou melhorar a qualidade de vida de uma pessoa vivendo com alguma incapacidade (Murray e Acharya, 1997).

O PTO foi substituído por outra metodologia que, ao invés de utilizar painéis de especialistas, faz uso de inquéritos de base populacional. Esses inquéritos começaram a ser desenvolvidos nos anos 2000 em diversos países e combinam diferentes metodologias de avaliação das preferências por estados de saúde. Pessoas da população geral e pessoas com um nível elevado de educação que participavam dos inquéritos utilizaram técnicas diferentes para atribuir valor a um estado de saúde. Os pesos para as incapacidades gerados a partir desses inquéritos realizados foram incorporados a partir do GBD 2010. Nesse último estudo foram utilizadas perguntas de comparação pareadas em que os participantes teriam que escolher entre dois cenários em que havia indivíduos com diferentes estados de saúde. A escolha seria feita baseada em qual indivíduo ele consideraria mais saudável. Essas escolhas estariam ligadas a perda de saúde em detrimento do bem-estar que se traduz de forma mais abrangente, incorporando outros fatores que possam interferir na vida do indivíduo doente (Mathers et al, 2001; Salomon et al, 2012; Chen et al, 2015). 


\subsection{Expectativa de Vida}

Como explicitado anteriormente, o YLL se propõe a mensurar a duração do tempo de vida perdido em razão de uma morte prematura, ou seja, os anos perdidos devidos a uma morte precoce. Diversas metodologias distintas da inicialmente proposta por Dempsey (1947) surgiram para a mensuração desse indicador. Com o objetivo de esclarecer e dar suporte aos métodos de cálculo propostos para o $D A L Y$, Murray (1994) discute as quatro principais metodologias utilizadas para mensurar o tempo de vida perdido em razão de uma morte prematura.

O primeiro método apresentado é os Anos Potenciais de Vida Perdidos (APVP), já citado anteriormente. O APVP é considerado o método mais simples e seu cálculo consiste primeiramente na definição de um limite potencial de vida para todos os grupos etários e, posteriormente, na subtração dos óbitos em cada idade desse limite estabelecido. Apesar de diferentes limites propostos e de sua facilidade de cálculo, o APVP é colocado como sendo um método desvantajoso porque despreza os óbitos que ocorrem em uma idade superior ao limite proposto. Partindo-se do pressuposto que a sociedade se importa e investe recursos significantes nesses grupos etários não contabilizados pelo indicador, essa metodologia não é utilizada no $D A L Y$. (Murray, 1994). Além disso, as intervenções em saúde que reduziriam a mortalidade acima do limite não impactariam na redução do $D A L Y$ populacional (WHO, 2003; Chen et al, 2015)

O segundo método discutido é dos Anos de Vida Perdidos Esperados. Essa metodologia utiliza a expectativa de vida local em cada idade para mensurar os anos de vida perdidos em cada idade. Apesar de ser considerada uma forma mais realista de mensuração, em que a expectativa de vida não chega a zero em um determinado grupo etário, o método não é incorporado ao DALY. A justificativa é que cada população de diferentes localidades possui expectativas de vida distintas e isso compromete a comparabilidade, uma vez que conclusões errôneas poderiam ser tiradas na medida em que pessoas com a mesma idade em 
diferentes países contribuiriam de formas distintas para a carga global de doença. Assim, desfechos equivalentes em saúde teriam maior carga em comunidades ricas em detrimento das mais pobres (Murray, 1994; WHO, 2003).

A terceira metodologia apresentada para mensuração do tempo de vida perdido por conta de uma morte prematura é a dos Anos de Vida Perdidos da Coorte Esperada. O método estima uma duração média de vida que uma coorte de fato iria experimentar em cada idade. A expectativa de vida nessa metodologia é superior aos Anos de Vida Esperados Perdidos, uma vez que se baseia na concepção de que os indivíduos vivos hoje têm uma probabilidade de viverem mais do que a expectativa de vida estimada para cada idade. Isso foi observado de acordo com os declínios dos padrões de mortalidade no passado. Apesar de ser considerado um método atrativo, ele se apresenta desfavorável para estimar a carga global de doença, pois ainda desconsidera as diferenças nas expectativas de vida de cada país, levando a conclusões desiguais. Dessa forma, uma morte em um país pobre, por exemplo, contribuiria menos para a carga global do que uma morte em um país rico (Murray, 1994; WHO, 2003).

O último método discutido é o Anos de Vida Perdidos Esperados Padronizados, que é o atualmente utilizada pelo GBD para o cálculo dos anos de vida perdidos em razão de uma morte prematura. $O$ método combina as vantagens dos Anos de Vida Perdidos da Coorte Esperada, mas ao invés de utilizar expectativas de vida para cada idade calculadas para coortes específicas, utiliza expectativas de vida para cada idade baseadas em um padrão ideal. Escolheu-se como padrão a mais alta expectativa de vida nacional observada, que foi a expectativa de vida ao nascer japonesa feminina, que é de 82 anos. Utilizou-se então a tábua de vida modelo do Oeste Nível 26 (West Level 26) em que a expectativa ao nascer é de 82,5 anos para mulheres (Murray, 1994; WHO, 2003).

O grupo do GBD passou a discutir se a expectativa de vida feminina seria a mesma da masculina. Concordaram, assim como explicitado na literatura, que havia de fato uma diferença biológica existente entre homens 
e mulheres e, portanto, a mortalidade não seria a mesma em ambos os sexos. Contudo, a diferença média proposta pela literatura de 7,2 anos na expectativa de vida ao nascer entre os sexos não foi aceita pelo grupo. Acreditavam que essa diferença não se dava somente pelo quesito biológico, mas por outras questões como o maior número de óbitos entre 0 sexo masculino ser devido a causas externas e uma maior exposição a fatores de risco como o tabagismo, por exemplo. Foi considerada uma diferença real na expectativa ao nascer entre ambos os sexos de dois a três anos. Dessa maneira, assumiu-se para os estudos do GBD uma expectativa de vida ao nascer de 80 anos para os homens e de 82,5 anos para as mulheres, considerando a tábua de vida modelo do Oeste (Murray, 1994; WHO, 2003). O grupo manteve essa metodologia de cálculo por muitos anos apesar das críticas que eram a favor de uma diferença entre sexos mais ampla do que 2,5 anos (Murray e Acharya, 1997).

As métricas do GBD 2010 foram atualizadas e passou-se a utilizar um padrão global baseado na taxa de mortalidade mais baixa observada em cada grupo etário em países no mundo. Uma nova tábua de vida de referência foi utilizada em que a expectativa de vida ao nascer empregada é de 86 anos para homens e mulheres (Murray et al., 2012). Os GBDs de 2013 e 2015 seguiram as mesmas bases do GBD 2010 com atualizações pontuais (GBD 2013 e HALE Collaborators, 2015; GBD 2015, 2016a). A expectativa de vida ao nascer padrão utilizada atualmente é de 86,59 anos para ambos os sexos (GBD 2015 Mortality e Causes of Death Collaborators, 2016b).

\subsubsection{Ponderação da idade e taxa de desconto}

O cálculo do $D A L Y$, na sua forma original, também incorpora outros dois componentes, além do peso da incapacidade e da expectativa de vida. No $Y L L$, a ponderação por idade, e no $Y L D$, a taxa de desconto. Esses ajustes no cálculo do $D A L Y$, de forma geral, atribuem valores maiores ao 
YLL e YLD de condições de saúde atuais e que afetam indivíduos jovens e conferem valores menores às condições de saúde futuras e que afetem indivíduos em idades mais avançadas (Chen et al, 2015).

A ponderação da idade fundamenta-se na ideia do valor social do tempo vivido em diferentes idades. Essa concepção baseia-se no pressuposto de que os papeis que os indivíduos desempenham na sociedade variam de acordo com a idade e que alguns grupos dependem financeiramente, emocionalmente e fisicamente de outros (Murray, 1994). Dessa forma, a valoração do tempo vivido em cada idade é baseada em uma ampla preferência social que considera, por exemplo, que um jovem adulto no auge de sua produtividade é mais "valioso" para a sociedade e contribui mais para a carga de doença do que um adulto com mais idade (Chen et al, 2015).

O ajuste diferenciado para cada idade é a valoração mais controversa dentro do cálculo do DALY (Mathers et al, 2001). Alguns críticos acham inaceitável que algumas idades sejam mais valorizadas do que outras, pois todo ano de vida é igual, independentemente da idade. Outros acreditam que a ponderação da idade não reflete de fato valor social e que deveria incorporar outras questões como fatores socioeconômicos e ocupação, e que é difícil defender esse ajuste somente por idade do ponto de visto ético (Anand S, Hanson K, 1997; Mathers et al, 2001). Murray (1994) discute que um peso maior atribuído à determinada idade não significa que esse tempo vivido seja mais importante individualmente, mas que devido aos papéis sociais a valoração social nessa idade seja mais elevada. É colocado também por Murray e Acharya (1997) que a ponderação por idade não é por si só desigual, considerando que os indivíduos vivem potencialmente todos os anos de suas vidas. Os autores argumentam que de fato há uma diferença de prioridades entre grupos etários do ponto de vista da sociedade e que haveria uma preocupação maior em melhorar o estado de saúde desses grupos.

A função de ponderação da idade pode ser expressa por: 


$$
C x e^{-\beta x}
$$

em que $0 x$ se refere a idade e $C e \beta$, sendo constantes em que são atribuídos normalmente os valores 0,1658 e 0,04, respectivamente.

A taxa de desconto, por sua vez, parte de um conceito econômico de time preference em que indivíduos optam por receber benefícios em curto prazo ao invés de benefícios futuros. Dessa forma, aplica-se uma taxa de desconto com o intuito de evitar que sejam poupados recursos para intervenções futuras em detrimento de investir em ações em curto prazo. É um incentivo para que as políticas e intervenções sejam implantadas de forma imediata. No $D A L Y$ a taxa de desconto atribui maior valor às reduções dos anos no presente do que no futuro (Murray, 1994).

Para o cálculo do DALY é recomendada uma taxa de desconto de $3 \%$ para representar os descontos dos anos de vida saudáveis vividos no futuro. No entanto, a escolha é arbitrária e sugere--se que os estudos sejam repetidos com taxas que variam entre 0 e 6\% (Mathers et al., 2001). Discussões surgiram em torno da aplicação ou não da taxa de desconto no cálculo do DALY. Anand e Hanson (1997) acreditam ser inaceitável a inclusão de uma taxa de desconto no $D A L Y$ porque a vida não pode ser reduzida a termos puramente monetários. Murray, Lopez e Jamison (1994), após a realização de uma análise de sensibilidade, concluíram que a taxa de desconto teve um impacto significativo na distribuição do $D A L Y$ por idade de início, mas que teve um impacto pequeno na carga de doença por causas específicas. Os autores sugerem a consistência de suas análises para justificar algumas suposições para a incorporação da taxa de desconto no cálculo do $D A L Y$.

A função de desconto temporal pode ser dada por:

$$
e^{-r(x-a)}
$$

em que $r$ corresponde a taxa de desconto, $x$ se refere a idade e $a$ é a idade em que a carga será atribuída. 
Incorporando no cálculo do $D A L Y$ a função da ponderação da idade no $Y L L$ e da taxa desconto no $Y L D$ podem-se obter as seguintes expressões:

$$
\begin{gathered}
Y L L=M \times \int_{A}^{A+L}\left\{K C x e^{-\beta x} e^{-r(x-a)}+(1-K) e^{-r(x-a)}\right\} d x \\
Y L D=N \times D W \times \int_{A}^{A+L}\left\{K C x e^{-\beta x} e^{-r(x-a)}+(1-K) e^{-r(x-a)}\right\} d x
\end{gathered}
$$

Os primeiros estudos do GBD incorporaram a função da ponderação da idade e a taxa de desconto (Murray, 1994; Murray, Lopez e Jamison, 1994; Mathers et al., 2001). No entanto, diante da falta de consenso e discussões acerca do uso da ponderação da idade e da taxa de desconto, os estudos do GBD dos últimos anos optaram por não incluir esses ajustes no cálculo do indicador (Murray et al., 2012; GBD 2013 e HALE Collaborators, 2015; GBD 2015, 2016a).

O DALY sofreu transformações desde sua criação que tornaram o indicador mais simples para o uso. Para Chen et al. (2015) a medida evoluiu de um indicador robusto para uma medida resumo sofisticada e que, apesar do indicador ainda ser complexo para o uso em populações locais devido aos inúmeros ajustes, da falta de clareza e descrição transparente do método e de suas atualizações pelos autores, o DALY é extremamente útil para destacar as emergências e tendências de saúde pública que exigem esforços e políticas públicas específicas. 


\section{JUSTIFICATIVA}

A tuberculose (TB) ainda representa um grande problema de saúde pública para o Brasil. O país alcançou os Objetivos de Desenvolvimento do Milênio (ODMs) propostos e as metas da estratégia STOP TB para a redução dos coeficientes de incidência e as metas de redução em $50 \%$ da prevalência e mortalidade de 1990 até 2015. Apesar disso, o Brasil ainda possui uma carga elevada da doença, com uma média anual de 70 mil casos novos registrados entre 2004 e 2015 (Brasil, 2016a).

Em uma era pós-2015, a Organização Mundial de Saúde propôs a estratégia End TB, pelo Fim da Tuberculose, em consonância com os Objetivos de Desenvolvimento Sustentável (ODSs), propostos pela Organização das Nações Unidas. Essas estratégias estabelecem metas ousadas e desafiadoras para a eliminação da TB como uma epidemia global até $\mathrm{o}$ ano de 2035, que se pautam pela redução do coeficiente de incidência para menos de 10 casos por 100 mil habitantes e dos óbitos por TB em $95 \%$ (WHO, 2015a; United Nations, 2015b).

Nos Planos Global e Regional para o Fim da TB, o paciente é colocado no centro do cuidado em saúde $e$ as vulnerabilidades socioeconômicas e os determinantes da tuberculose são ressaltados e elencados como prioridade para desenvolvimento de ações e estratégias para alcançar as metas propostas. No cenário nacional, o Brasil se prepara para a elaboração do Plano Nacional pelo Fim da Tuberculose como problema de saúde pública alinhado com as agendas internacionais (WHO, 2015a; OPAS, 2015; Brasil, 2016a).

Conjectura-se que a tuberculose pulmonar não se distribui de forma homogênea na população, considerando que a doença está ligada às condições de vida e trabalho dos indivíduos e ao contexto em que os mesmos estão inseridos. Isso reflete as desigualdades socioeconômicas, geográficas e de acesso aos serviços de saúde no Brasil. Nessa 
perspectiva, faz-se necessário o desenvolvimento de estudos que busquem observar como a carga da doença se distribui no país, considerando a morbimortalidade e a incapacidade gerada pela doença sob influência dos determinantes da TB.

A compreensão da influência desses determinantes, refletidos nos indicadores socioeconômicos e operacionais, na carga de tuberculose pulmonar em âmbito municipal é de extrema relevância para nortear as ações e estratégias de controle da doença na perspectiva nacional. Por conseguinte, pode-se se contribuir para o alcance das metas instituídas nas estratégias pelo fim da TB. Esse estudo pode constituir-se de uma importante ferramenta para elencar prioridades, orientar o planejamento de ações, a tomada de decisão e a alocação de recursos de forma equânime. 


\section{OBJETIVOS}

\subsection{Geral}

Analisar a carga de doença por tuberculose pulmonar nos cenários de desigualdades sociais, segundo indicadores socioeconômicos, epidemiológicos e operacionais no Brasil, no ano de 2014.

\subsection{Específicos}

1. Descrever o coeficiente de incidência e mortalidade por tuberculose pulmonar;

2. Estimar os Anos de Vida Perdidos Ajustados por Incapacidade (DALY) para os municípios brasileiros;

3. Identificar indicadores socioeconômicos, epidemiológicos e operacionais associados com o taxa de DALY;

4. Agrupar os municípios quanto às suas similaridades e classificá-los em cenários de desigualdades sociais. 


\section{METODOLOGIA}

\subsection{Tipo de estudo}

Foi conduzido um estudo ecológico transversal, de base populacional, para analisar a carga de doença por tuberculose pulmonar (Classificação Internacional de Doenças - CID 10 - A150 a A153 e A160 a A162) para cenários de desigualdade social no Brasil no ano de 2014.

\subsection{População, local e período de estudo}

A população de estudo foi constituída de casos confirmados de tuberculose pulmonar dos municípios brasileiros, registrados no Sistema de Informação de Agravos de Notificação - Tuberculose (Sinan-TB), diagnosticados no ano de 2014. Também fizeram parte da população de estudo os óbitos que tiveram tuberculose pulmonar (Classificação Internacional de Doenças - CID 10 - A150 a A153 e A160 a A162) como causa básica ou como causa associada à "Doença pelo vírus da imunodeficiência humana" (CID 10 - B20 a B24), registrados no Sistema de Informação sobre Mortalidade (SIM), no ano de 2014 ou 2015.

\subsection{Procedimentos para seleção dos casos elegíveis}

Foram utilizadas bases de dados nacionais do Sinan-TB e do SIM cedidas pelo Ministério da Saúde. Foi realizada pela instituição a técnica de relacionamento probabilístico de bases de dados entre Sinan-TB e SIM, com o auxílio do software Reclink III (Camargo Jr. e Coeli, 2000). A partir do relacionamento foi possível obter uma terceira base em que se encontravam os registros de óbitos presentes em ambas as bases de dados. No Sinan-TB 
utilizou-se a variável data de diagnóstico para selecionar as pessoas que foram diagnosticadas com TB em 2014 e evoluíram para óbito em 2014 ou 2015. As duplicidades do banco de dados foram removidas como parte da rotina do Programa Nacional de Controle da Tuberculose (PNCT).

\subsection{Relacionamento probabilístico (Linkage)}

Considerando a ausência de uma variável identificadora única entre as bases de dados necessárias para a identificação dos óbitos por tuberculose, realizou-se a técnica de relacionamento probabilístico entre os bancos do Sinan-TB e do SIM. Consideram-se os períodos de 2014 e 2015 para o relacionamento das bases e o processo foi realizado através de três principais etapas: Padronização, Relacionamento e Combinação (Camargo Jr. e Coeli, 2000; Santos, 2014). A primeira etapa consistiu-se na padronização dos campos das duas bases de dados com o intuito de manter campos idênticos em ambos os arquivos, minimizando-se, assim, os erros ortográficos e fonéticos. Todos os campos foram transformados em campo caracteres e dois arquivos foram obtidos a partir dos bancos originais.

$O$ relacionamento compreendeu duas outras etapas: a blocagem e 0 pareamento dos registros. A blocagem foi realizada através da criação de blocos lógicos dos registros, objetivando a otimização do processo de comparação, considerando que as comparações se restringiram aos blocos construídos. O pareamento, por sua vez, se deu pelo desenvolvimento de escores que foram obtidos a partir da blocagem. Os escores foram calculados considerando o grau de concordância entre os registros do mesmo par. Para o relacionamento utilizou-se inicialmente chaves de blocagem específicas passando para chaves mais sensíveis nos passos subsequentes. Definiram-se limiares para classificar os pares em verdadeiros, não pares e incertos em cada etapa da blocagem.

A terceira etapa, combinação, consistiu na revisão manual dos pares incertos em pares ou não pares e a combinação em um único arquivo dos 
pares verdadeiros encontrados nas múltiplas etapas. Outras estratégias de pareamento utilizando chaves menos específicas foram utilizadas para a classificação dos pares duvidosos em pares e não pares.

\subsection{Critérios de inclusão}

Foram considerados como casos elegíveis para o estudo os registros incidentes de tuberculose pulmonar do Sinan que foram diagnosticados em 2014; os óbitos por TB pulmonar como causa básica ou como causa associada à "Doença pelo vírus da imunodeficiência humana", encontrados no SIM. Foram incluídos também os óbitos por TB pulmonar identificados tanto no Sinan-TB quanto no SIM obtidos através do relacionamento probabilístico de bases de dados.

\subsection{Critérios de exclusão}

Foram eliminados os casos do Sinan que apresentavam na variável situação de encerramento de caso "Mudança de Diagnóstico".

\subsection{Denominadores Populacionais e Padronização}

Em razão da indisponibilidade da população municipal por sexo e faixa etária para o ano estudado, utilizou-se a população censitária do ano de 2010 e as estimativas realizadas para o ano de 2014. Dessa maneira, os denominadores populacionais para os municípios brasileiros no ano de 2014 foram obtidos através da multiplicação do tamanho da população residente nesse ano, a partir das estimativas do Instituto Brasileiro de Geografia e Estatística (IBGE) (feitas para o Tribunal de Contas da União - TCU), pela proporção de indivíduos em cada sexo e faixa etária, calculada com base na população advinda do Censo Demográfico realizado no ano de 2010. 
Para fins de comparação entre municípios, realizou-se uma padronização das taxas de DALY utilizadas, segundo sexo e faixa etária por meio da padronização direta (Costa et al., 2009). O intuito foi o de controlar o efeito dessas variáveis que podem influenciar na comparação entre os municípios. Utilizou-se a população brasileira, do ano de 2010, por sexo e faixa etária como população padrão.

\subsection{Fonte de dados}

Foram utilizados os dados advindos do Sistema de Informação de Agravos de Notificação - Tuberculose (Sinan-TB) e do Sistema de Informação sobre Mortalidade (SIM) sob responsabilidade da Secretaria de Vigilância em Saúde do Ministério da Saúde. Os dados populacionais e os indicadores socioeconômicos foram obtidos a partir do Instituto Brasileiro de Geografia e Estatística (IBGE) e das estimativas feitas por essa instituição para o TCU para o ano de 2014. Os dados de população foram extraídos através do Departamento de Informática do SUS (DATASUS) e os indicadores socioeconômicos a partir do Atlas de Desenvolvimento Humano no Brasil.

\subsection{Procedimentos Analíticos}

\subsubsection{Coeficientes de incidência e mortalidade}

\subsubsection{Coeficiente de incidência}

O coeficiente de incidência foi calculado utilizando como numerador o número de casos novos para cada 100 mil habitantes, e como denominador, a população residente em cada município, no ano de 2014. O número de casos incidentes foi obtido a partir do somatório das categorias "Caso Novo", "Não Sabe" e "Pós-óbito" da variável "Tipo de Entrada" do Sinan-TB. Foram 
utilizados apenas os casos de tuberculose pulmonar selecionados pela variável "forma".

\subsubsection{Coeficiente de mortalidade}

O coeficiente de mortalidade foi obtido a partir do número de óbitos por tuberculose pulmonar (CID 10 - A150 a A153 e A160 a A162), para cada 100 mil habitantes, registrados no SIM em 2014. Como denominador utilizou-se a população residente em cada município no mesmo ano.

\subsubsection{Carga de doença}

A carga de doença foi estimada através do indicador de Anos de Vida Perdidos Ajustados por Incapacidade (Disability Adjusted Life Years $D A L Y$ ), proposto por Murray e Lopez no início da década de 1990 (Murray; Murray e Lopez; 1994). Esse indicador é obtido pela soma dos Anos de Vida Perdidos (Years of Life Lost - YLL) em razão de uma morte prematura e dos Anos de Vividos com Incapacidade (Years Lived with Disability - YLD).

Para o cálculo do DALY esse estudo seguiu a metodologia mais atualizada do Estudo de Carga Global de Doenças, GBD 2015, em que não se utiliza ponderação da idade no componente $Y L L$ e nem taxa de desconto no YLD (IHME, 2017).

\subsubsection{Anos de Vida Perdidos (Years of Life Lost - YLL)}

\subsubsection{População, local e período do estudo}

Para a construção da população de estudo utilizou-se os óbitos identificados a partir do relacionamento probabilístico entre SINAN-TB e SIM no período de 2014 e 2015, conforme descrito acima. Foram incluídas as mortes que tiveram tuberculose pulmonar como causa básica (CID 10 - 
A150 a A153 e A160 a A162) e como causa associada à "Doença pelo vírus da imunodeficiência humana" (CID 10 - B20 a B24). A variável "causabas" da base de pares foi utilizada para a seleção da causa básica do óbito.

\subsubsection{Expectativa de Vida}

Para o cálculo da expectativa de vida utilizou-se a Tábua de Vida de Referência desenvolvida e utilizada pelo GBD 2015. A tábua foi construída com base na estimativa mais baixa das taxas de mortalidade específicas de todas as localidades, com populações acima de cinco milhões, em relação às estimativas do GBD 2013. Ela é constituída pela probabilidade de morte em cada faixa etária (nqx), a proporção dos sobreviventes da coorte hipotética na idade $x$ (Ix), e expectativa de vida na idade $x$ (Ex) para idades de 0 a 110+ com intervalos de cinco anos (GBD 2015, 2016a). A Tábua de Vida de Referência pode ser visualizada na tabela 2. 
Tabela 2 - Tábua de Vida de Referência para o cálculo da expectativa de vida.

\begin{tabular}{cccc}
\hline Idade & nqx & $\mathrm{Ix}$ & $\mathrm{Ex}$ \\
\hline 0 & 0.0019985 & 1 & 86.59408 \\
1 & 0.0004474 & 0.9980015 & 85.76748 \\
5 & 0.000328 & 0.997555 & 81.80519 \\
10 & 0.0003438 & 0.9972278 & 76.83121 \\
15 & 0.0007387 & 0.996885 & 71.85669 \\
20 & 0.0009189 & 0.9961486 & 66.90784 \\
25 & 0.000949 & 0.9952332 & 61.96704 \\
30 & 0.0013554 & 0.9942887 & 57.02344 \\
35 & 0.0020639 & 0.9929411 & 52.09721 \\
40 & 0.003427 & 0.9908918 & 47.19935 \\
45 & 0.0057396 & 0.987496 & 42.35229 \\
50 & 0.0088861 & 0.9818282 & 37.58122 \\
55 & 0.0128286 & 0.9731035 & 32.89429 \\
60 & 0.0191137 & 0.96062 & 28.28719 \\
65 & 0.0287862 & 0.942259 & 23.78644 \\
70 & 0.0485194 & 0.9151349 & 19.41143 \\
75 & 0.0866472 & 0.8707331 & 15.26225 \\
80 & 0.1632085 & 0.7952865 & 11.45059 \\
85 & 0.3016126 & 0.665489 & 8.152726 \\
90 & 0.5014129 & 0.4647691 & 5.526635 \\
95 & 0.7119718 & 0.2317279 & 3.7134 \\
100 & 0.8672966 & 0.0667442 & 2.500702 \\
105 & 0.9623104 & 0.0088572 & 1.621429 \\
110 & 1 & 0.0003338 & 1.372479 \\
\hline
\end{tabular}

Fonte: GBD 2015, 2016a

\subsubsection{Análise de dados}

Para estimar o YLL multiplicou-se o número de óbitos estimados por TB como causa básica ou doença pelo vírus do HIV como causa associada pela expectativa de vida na idade do óbito da tábua de vida de referência. $O$ $Y L L$ foi estimado segundo município, sexo e faixa etária. A figura 9 ilustra os procedimentos utilizados para o cálculo do YLL, os números entre parênteses representam as variáveis utilizadas. Os códigos podem ser visualizados no dicionário de variáveis que se encontra no Anexo I. 
Fiqura 9 - Procedimentos para o cálculo dos Anos de Vida Perdidos.

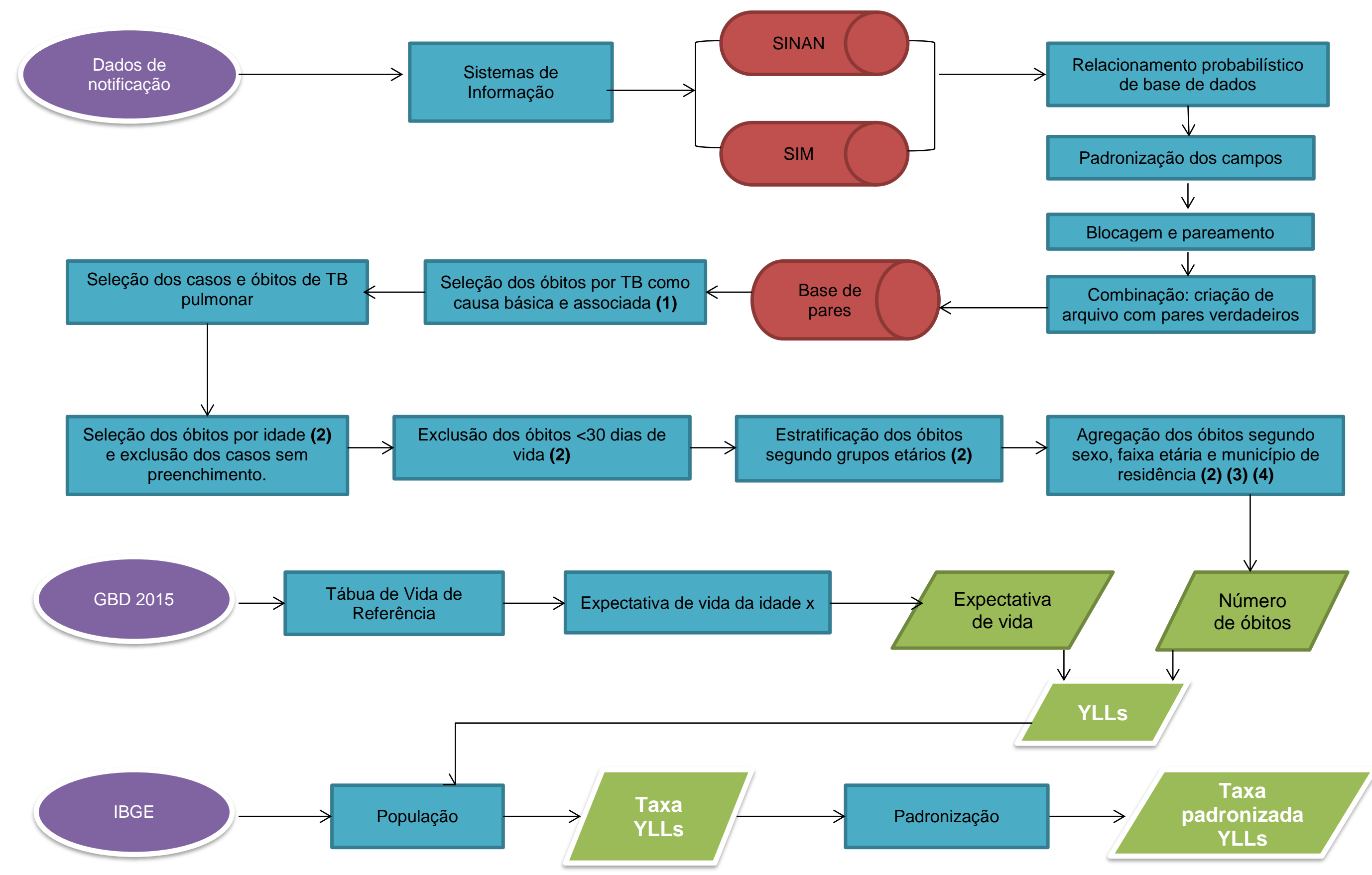




\subsubsection{Anos Vividos com Incapacidade (Years Lived with Disability - YLD)}

\subsubsection{População, local e período de estudo}

A população de estudo para estimar o YLD constituiu-se dos casos incidentes de tuberculose pulmonar (CID 10 - A150 a A153 e A160 a A162) diagnosticados em 2014 nos municípios brasileiros e registrados no SINANTB. Os casos incidentes foram obtidos a partir da variável "Tipo de Entrada" e da somatória de suas categorias 1 = "Caso Novo", 4 = "Não Sabe" e 6 = "Pós-óbito" (Brasil, 2016a).

Foram utilizados apenas casos pulmonares e casos pulmonares mais extrapulmonares selecionados através da variável "Forma", cujas categorias correspondiam a 1 = "Pulmonar" e 3 = "Pulmonar + Extrapulmonar". Não foi possível o acesso aos dados da variável no banco que descrevia os tipos de TB extrapulmonar, portanto esses casos não foram incluídos. Os casos classificados como "Mudança de Diagnóstico" e "Óbito por outras causas" na variável "Situação de encerramento" foram eliminados do banco. Também foram excluídos os casos de TB com tempo de vida menor do que o período de incubação da doença. Foram incluídos neste trabalho os casos com tempo de vida maior ou igual a 30 dias de vida (WHO, 2012).

\subsubsection{Peso da Incapacidade (Disability Weight)}

Esse estudo utilizou os valores dos pesos da incapacidade adotados pelo GBD 2015. (GBD 2015, 2016b). Foi considerada a tuberculose em dois níveis de severidade: tuberculose em que não há coinfecção por HIV e tuberculose com infecção por HIV. Os pesos utilizados para cada estado de saúde e a descrição da incapacidade são exibidos abaixo: 
Quadro 2 - Descrição e pesos da incapacidade para dois níveis de severidade do adoecimento por tuberculose.

\begin{tabular}{|c|c|c|}
\hline Estado de Saúde & Descrição & Peso (95\%IC) \\
\hline $\begin{array}{l}\text { Tuberculose sem } \\
\text { infecção por HIV }\end{array}$ & $\begin{array}{c}\text { Paciente com tosse } \\
\text { persistente e febre, se } \\
\text { sente fraco, com falta } \\
\text { de ar e tem perda de } \\
\text { peso. }\end{array}$ & $0,333(0,224-0,454)$ \\
\hline $\begin{array}{l}\text { Tuberculose com } \\
\text { infecção por HIV }\end{array}$ & $\begin{array}{l}\text { Paciente com tosse } \\
\text { persistente e febre, tem } \\
\text { falta de ar, sudorese } \\
\text { noturna, fraqueza e } \\
\text { fadiga e tem intensa } \\
\text { perda de peso }\end{array}$ & $0,408(0,274-0,549)$ \\
\hline
\end{tabular}

Fonte: Adaptado de GBD 2015, 2016b

\subsubsection{Duração média da doença}

O tempo de tratamento da tuberculose foi utilizado como uma aproximação da duração média da doença. A definição do tempo de tratamento da doença foi baseada na literatura e na consulta aos especialistas do Programa Nacional de Controle da Tuberculose (PNCT) do Ministério da Saúde (Gledovic, et al., 2006; Pasipanodya et al., 2010). Dessa maneira, foi definido a duração de 0,5 ano (seis meses) para todos os casos de TB, incluindo HIV, que não são droga-resistente (TB-DR). Para os casos de TB-DR, selecionados através da variável "Situação de encerramento", foi adotada a duração de 1,5 ano (18 meses), assumindo o tempo médio sob tratamento para os pacientes com tuberculose com e sem multirresistência.

\subsubsection{Análise de dados}


O YLD para tuberculose no ano de 2014 foi estimado por município, por sexo e por faixa etária por meio das expressões:

YLD $=I \times 0,333 \times 0,5$ para TB

YLD $=I \times 0,333 \times 1,5$ para TB-DR

YLD $=I \times 0,408 \times 0,5$ (ou 1,5 se TB-DR) para HIV

Em que I é o número de casos incidentes. O processo utilizado para o cálculo do YLD está ilustrado no fluxograma da figura 10. Os números entre parênteses representam as variáveis utilizadas. Os códigos podem ser visualizados no dicionário de variáveis que se encontra no Anexo I. 
Figura 10 - Procedimentos para o cálculo dos Anos de Vida Vividos com Incapacidade.

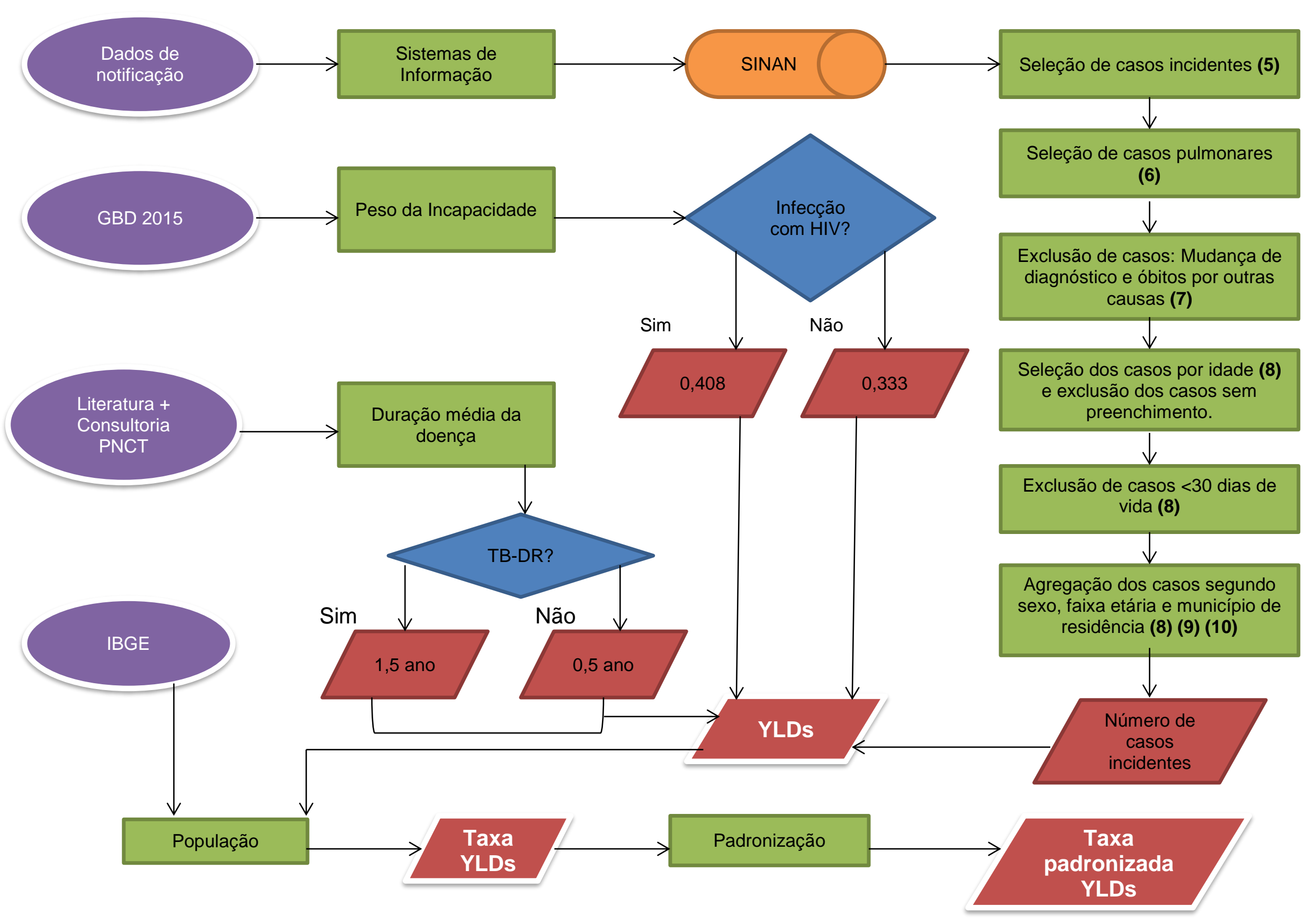




\subsection{Indicadores socioeconômicos, epidemiológicos e operacionais associados com a taxa de DALY}

\subsubsection{Seleção dos indicadores}

Para identificar os indicadores que se associavam com a taxa de $D A L Y$ padronizada, foram avaliados nesse estudo os indicadores socioeconômicos, epidemiológicos e operacionais da tuberculose. Os mesmos foram selecionados através dos critérios de disponibilidade, relevância e plausibilidade com doença e com o modelo de análise utilizado. No quadro 3 pode-se observar os indicadores selecionados, a descrição dos mesmos e a fonte dos dados.

Quadro 3 - Indicadores socioeconômicos, epidemiológicos e operacionais utilizados.

\begin{tabular}{|c|c|c|}
\hline Indicador & Definição & $\begin{array}{c}\text { Fonte de } \\
\text { dados }\end{array}$ \\
\hline $\begin{array}{l}\text { Índice de Desenvolvimento } \\
\text { Humano Municipal (IDHM) }\end{array}$ & $\begin{array}{l}\text { Índice de Desenvolvimento Humano } \\
\text { Municipal. Média geométrica dos índices das } \\
\text { dimensões Renda, Educação e } \\
\text { Longevidade, com pesos iguais. }\end{array}$ & IBGE \\
\hline $\begin{array}{l}\text { Índice de Desenvolvimento } \\
\text { Humano Municipal - Dimensão } \\
\text { Educação (IDHM-E) }\end{array}$ & $\begin{array}{l}\text { Índice sintético da dimensão Educação. É } \\
\text { obtido através da média geométrica do } \\
\text { subíndice de frequência de crianças e jovens } \\
\text { à escola, com peso de } 2 / 3 \text {, e do subíndice de } \\
\text { escolaridade da população adulta, com peso } \\
\text { de } 1 / 3 \text {. }\end{array}$ & IBGE \\
\hline $\begin{array}{l}\text { Índice de Desenvolvimento } \\
\text { Humano Municipal - Dimensão } \\
\text { Renda (IDHM-R) }\end{array}$ & $\begin{array}{l}\text { Índice da dimensão Renda. É obtido a partir } \\
\text { do indicador Renda per capita, através da } \\
\text { fórmula: [In (valor observado do indicador) - } \\
\text { In (valor mínimo)] / [ln (valor máximo) - In } \\
\text { (valor mínimo)], onde os valores mínimo e } \\
\text { máximo são } R \$ 8,00 \text { e } R \$ 4.033,00 \text { (a preços } \\
\text { de agosto de 2010). }\end{array}$ & IBGE \\
\hline Taxa de analfabetismo & $\begin{array}{l}\text { Razão entre a população de } 15 \text { anos ou } \\
\text { mais de idade que não sabe ler nem } \\
\text { escrever um bilhete simples e o total de } \\
\text { pessoas nesta faixa etária multiplicado por } \\
100 \text {. }\end{array}$ & IBGE \\
\hline $\begin{array}{l}\text { Produto Interno Bruto (PIB) per } \\
\text { capita }\end{array}$ & $\begin{array}{l}\text { Valor do PIB municipal per capita, calculado } \\
\text { como sendo o PIB Municipal do ano dividido } \\
\text { pela população do mesmo ano. Os valores } \\
\text { são apresentados em reais correntes, não } \\
\end{array}$ & IBGE \\
\hline
\end{tabular}




\begin{tabular}{|c|c|c|}
\hline & $\begin{array}{l}\text { sendo aplicado nenhum deflator ou fator de } \\
\text { correção. }\end{array}$ & \\
\hline $\begin{array}{l}\text { Renda média domiciliar per } \\
\text { capita (RPDC) }\end{array}$ & $\begin{array}{l}\text { Razão entre o somatório da renda de todos } \\
\text { os indivíduos residentes em domicílios } \\
\text { particulares permanentes e o número total } \\
\text { desses indivíduos. Valores em reais de } \\
01 / \text { agosto de } 2010 \text {. }\end{array}$ & IBGE \\
\hline $\begin{array}{l}\text { Proporção de extremamente } \\
\text { pobres (PIND) }\end{array}$ & $\begin{array}{l}\text { Proporção dos indivíduos com renda } \\
\text { domiciliar per capita igual ou inferior a } \mathrm{R} \$ \\
70,00 \text { mensais, em reais de agosto de } 2010 \text {. }\end{array}$ & IBGE \\
\hline $\begin{array}{l}\text { Proporção de vulneráveis à } \\
\text { pobreza (PPOB) }\end{array}$ & $\begin{array}{l}\text { Proporção dos indivíduos com renda } \\
\text { domiciliar per capita igual ou inferior a } R \$ \\
255,00 \text { mensais, em reais de agosto de } \\
2010 \text {, equivalente a } 1 / 2 \text { salário mínimo nessa } \\
\text { data. }\end{array}$ & IBGE \\
\hline $\begin{array}{l}\text { Percentual de vulneráveis à } \\
\text { pobreza que gastam mais de } \\
\text { uma hora até o trabalho }\end{array}$ & $\begin{array}{l}\text { Razão entre as pessoas que vivem em } \\
\text { domicílios vulneráveis à pobreza (com renda } \\
\text { per capita inferior a } 1 / 2 \text { salário mínimo de } \\
\text { agosto de 2010) e que gastam mais de uma } \\
\text { hora em deslocamento até o local de } \\
\text { trabalho e o total de pessoas ocupadas } \\
\text { multiplicado por } 100 \text {. }\end{array}$ & IBGE \\
\hline Índice de GINI & $\begin{array}{l}\text { Mede o grau de desigualdade existente na } \\
\text { distribuição de indivíduos segundo a renda } \\
\text { domiciliar per capita. Seu valor varia de } 0 \text {, } \\
\text { quando não há desigualdade (a renda } \\
\text { domiciliar per capita de todos os indivíduos } \\
\text { tem o mesmo valor), a } 1 \text {, quando a } \\
\text { desigualdade é máxima (apenas um } \\
\text { indivíduo detém toda a renda). }\end{array}$ & IBGE \\
\hline Mortalidade infantil & $\begin{array}{l}\text { Número de crianças que não deverão } \\
\text { sobreviver ao primeiro ano de vida em cada } \\
1000 \text { crianças nascidas vivas. }\end{array}$ & IBGE \\
\hline Taxa de desemprego & $\begin{array}{l}\text { Proporção da população residente } \\
\text { economicamente ativa de } 16 \text { anos e mais } \\
\text { que se encontra sem trabalho na semana de } \\
\text { referência, em determinado espaço } \\
\text { geográfico, no ano considerado. }\end{array}$ & IBGE \\
\hline $\begin{array}{l}\text { Taxa de desocupação - } 18 \text { anos } \\
\text { ou mais }\end{array}$ & $\begin{array}{l}\text { Percentual da população economicamente } \\
\text { ativa (PEA) com } 18 \text { anos ou mais que estava } \\
\text { desocupada, ou seja, que não estava } \\
\text { ocupada na semana anterior à data do } \\
\text { Censo, mas havia procurado trabalho ao } \\
\text { longo do mês anterior à data dessa } \\
\text { pesquisa. }\end{array}$ & IBGE \\
\hline $\begin{array}{l}\text { Percentual da população que } \\
\text { vive em domicílios com } \\
\text { densidade superior a duas } \\
\text { pessoas por dormitório }\end{array}$ & $\begin{array}{l}\text { Razão entre a população que vive em } \\
\text { domicílios particulares permanentes com } \\
\text { densidade superior a dois e a população } \\
\text { total residente em domicílios particulares } \\
\text { permanentes multiplicado por 100. A } \\
\text { densidade do domicílio é dada pela razão } \\
\text { entre o total de moradores do domicílio e o } \\
\text { número total de cômodos usados como } \\
\text { dormitório. }\end{array}$ & IBGE \\
\hline $\begin{array}{l}\text { Proporção de casos novos em } \\
\text { população privada de liberdade }\end{array}$ & $\begin{array}{l}\text { Percentual de casos novos de tuberculose } \\
\text { em PPL. }\end{array}$ & Sinan/MS \\
\hline
\end{tabular}




\begin{tabular}{|c|c|c|}
\hline \multicolumn{3}{|l|}{ (PPL) } \\
\hline $\begin{array}{l}\text { Proporção de casos novos entre } \\
\text { profissionais de saúde }\end{array}$ & $\begin{array}{l}\text { Percentual de casos novos de tuberculose } \\
\text { entre os profissionais de saúde. }\end{array}$ & Sinan/MS \\
\hline $\begin{array}{l}\text { Proporção de casos novos na } \\
\text { população em situação de rua } \\
\text { (PSR) }\end{array}$ & $\begin{array}{l}\text { Percentual de casos novos de tuberculose } \\
\text { na população em situação de rua. }\end{array}$ & Sinan/MS \\
\hline $\begin{array}{l}\text { Proporção de casos novos entre } \\
\text { indígenas }\end{array}$ & $\begin{array}{l}\text { Percentual de casos novos de tuberculose } \\
\text { entre indígenas }\end{array}$ & Sinan/MS \\
\hline $\begin{array}{l}\text { Proporção de casos novos entre } \\
\text { HIV positivos }\end{array}$ & $\begin{array}{l}\text { Percentual de casos novos de tuberculose } \\
\text { entre casos de HIV positivos }\end{array}$ & Sinan/MS \\
\hline $\begin{array}{l}\text { Proporção de casos novos com } \\
\text { pelo menos uma dessas } \\
\text { vulnerabilidades }\end{array}$ & $\begin{array}{l}\text { Percentual de casos novos que possuem } \\
\text { pelo menos umas das vulnerabilidades } \\
\text { anteriores. }\end{array}$ & Sinan/MS \\
\hline $\begin{array}{l}\text { Proporção de contatos } \\
\text { examinados entre casos novos }\end{array}$ & $\begin{array}{l}\text { Percentual de contatos de casos novos de } \\
\text { tuberculose que foram examinados. }\end{array}$ & Sinan/MS \\
\hline $\begin{array}{l}\text { Proporção de casos novos com } \\
\text { confirmação laboratorial }\end{array}$ & $\begin{array}{l}\text { Percentual de casos novos de tuberculose } \\
\text { confirmados por exame laboratorial - Teste } \\
\text { rápido molecular para TB (TRM-TB) e/ou } \\
\text { cultura de escarro e/ou baciloscopia. }\end{array}$ & Sinan/MS \\
\hline $\begin{array}{l}\text { Proporção de cura entre os casos } \\
\text { novos }\end{array}$ & $\begin{array}{l}\text { Percentual de casos novos de tuberculose } \\
\text { confirmados por exame laboratorial - teste } \\
\text { rápido molecular para TB (TRM-TB) e/ou } \\
\text { cultura de escarro e/ou baciloscopia - com } \\
\text { encerramento cura. }\end{array}$ & Sinan/MS \\
\hline $\begin{array}{l}\text { Proporção de abandono de } \\
\text { tratamento entre os casos novos }\end{array}$ & $\begin{array}{l}\text { Percentual de casos novos de tuberculose } \\
\text { confirmados por exame laboratorial - teste } \\
\text { rápido molecular para TB (TRM-TB) e/ou } \\
\text { cultura de escarro e/ou baciloscopia - com } \\
\text { encerramento abandono. }\end{array}$ & Sinan/MS \\
\hline $\begin{array}{l}\text { Proporção de casos novos com } \\
\text { encerramento ignorado ou } \\
\text { transferência }\end{array}$ & $\begin{array}{l}\text { Percentual de casos novos de tuberculose } \\
\text { cujo encerramento é ignorado ou } \\
\text { transferência }\end{array}$ & Sinan/MS \\
\hline $\begin{array}{l}\text { Proporção de casos novos } \\
\text { testados para o HIV }\end{array}$ & $\begin{array}{l}\text { Percentual de casos novos com realização } \\
\text { de testagem para HIV (categorias negativo e } \\
\text { positivo), no total de casos novos. }\end{array}$ & Sinan/MS \\
\hline Proporção de coinfecção TB-HIV & $\begin{array}{l}\text { Percentual de casos de tuberculose } \\
\text { coinfectados pelo vírus do HIV. }\end{array}$ & Sinan/MS \\
\hline $\begin{array}{l}\text { Taxa de detecção de casos de } \\
\text { Aids }\end{array}$ & $\begin{array}{l}\text { Proporção de casos de Aids detectados } \\
\text { entre os casos de tuberculose. }\end{array}$ & Sinan/MS \\
\hline $\begin{array}{l}\text { Proporção de casos de } \\
\text { retratamento }\end{array}$ & $\begin{array}{l}\text { Proporção de casos de retratamento entre os } \\
\text { casos de tuberculose - Os casos de } \\
\text { retratamento são a somatória dos casos de } \\
\text { recidiva e reingresso após abandono. }\end{array}$ & Sinan/MS \\
\hline $\begin{array}{l}\text { Proporção de exames de cultura } \\
\text { realizados em casos de } \\
\text { retratamento }\end{array}$ & $\begin{array}{l}\text { Proporção de exames de cultura realizados - } \\
\text { positivos e negativos - em casos de } \\
\text { retratamento. }\end{array}$ & Sinan/MS \\
\hline
\end{tabular}

Fonte: IBGE, 2010 e Sinan/MS, 2014 


\subsubsection{Critério de inclusão dos municípios}

Com o intuito de utilizar no modelo apenas municípios com consistência na notificação de casos e suavizar a variabilidade dos valores em municípios com pequena população, utilizou-se os seguintes procedimentos: 1) calculou-se a média móvel trienal dos coeficientes de incidência dos anos de 2001 a 2015; 2) calculou-se a variação anual da média móvel utilizando dois anos consecutivos e; 3) obteve-se a média da variação de todos os anos, somando-se todas as médias e dividindo pela quantidade de anos.

Foram incluídos apenas os municípios que obtiveram uma variação entre -8 e $8 \%$. Os coeficientes de incidência foram utilizados em detrimento das taxas de $D A L Y$ em razão da indisponibilidade dos relacionamentos probabilísticos das bases do SINAN e SIM para a série histórica utilizada, impossibilitando o cálculo do YLL de maneira precisa.

\subsubsection{Variáveis dependentes e independentes}

Foi utilizada como variável dependente a taxa de $D A L Y$ padronizada e como variáveis independentes foram utilizados os indicadores socioeconômicos, epidemiológicos e operacionais da TB.

\subsubsection{Análise de dados}

Para a identificação das variáveis associadas, utilizou-se a regressão binomial negativa, justificando-se o uso pela grande dispersão dos dados (Paula, 2013). Avaliou-se também a distribuição dos resíduos nos gráficos normais de probabilidades para os resíduos deviance, do modelo binomial negativo, com o intuito de verificar a qualidade de ajuste do modelo proposto. As variáveis independentes foram avaliadas em grupos distintos, a partir da construção de dois modelos de análise, o primeiro utilizando as 
variáveis socioeconômicas (modelo A) e o segundo compreendendo as variáveis epidemiológicas e operacionais da TB (modelo B).

Em um primeiro momento realizou-se uma análise bivariada em cada um dos modelos ( $\mathrm{A}$ e $\mathrm{B}$ ). Aquelas variáveis que se apresentaram associadas com significância de $p$ valor $<0,20$ foram testadas em uma matriz de correlação para avaliar colinearidade. Utilizou-se como ponto de corte uma correlação $<0,80$ e foram inclusas na análise multivariada aquelas variáveis que apresentaram maior associação com a variável dependente.

Todas as variáveis que se mostraram significantes na análise anterior, segundo os critérios estabelecidos, foram incluídas na análise multivariada que foi realizada também nos dois modelos ( $A$ e $B$ ) propostos. Para a seleção das variáveis para o modelo final partiu-se do modelo cheio para o vazio, utilizando a estratégia Backward. Foram mantidas aquelas variáveis que se apresentaram estatisticamente significantes com $p$ valor $<0,05$. Realizou-se uma análise ajustada pelo tamanho populacional dos municípios que foram divididos em pequenos, médios e grandes, com populações de $<20.000,20.000$ a 99.999 e $\geq 100.000$, respectivamente.

\subsection{Agrupamento dos municípios quanto suas similaridades e cenários de desigualdades sociais.}

Em um segundo momento, para o agrupamento dos municípios segundo suas similaridades, foi utilizado o método não-hierárquico de $\mathrm{K}$ means em que foi possível identificar clusters de municípios a partir de suas semelhanças (Lobo et al., 2016; Brasil, 2016a). Essa metodologia utiliza a medida da distância euclidiana entre os indicadores associados à taxa de DALY padronizada que foram identificados no Modelo A e B. O algoritmo utilizado no método minimiza a distorção dentro de cada cluster para todos os clusters, ou seja, minimiza a soma das distâncias de cada padrão ao centroide de cada agrupamento. A metodologia, no entanto, necessita que haja uma definição do número de clusters a priori. Dessa maneira, o número de clusters foi definido a partir do método de Elbow que consiste no 
relacionamento da variação percentual dentro dos grupos e o número de clusters (Davidson, 2002).

Os municípios foram agrupados segundo os cenários socioeconômicos a partir do modelo A. Em seguida, uma vez definidos os cenários socioeconômicos, as variáveis do modelo $B$ foram inseridas e a partir disso foram construídos os subcenários epidemiológicos e operacionais para a TB (Lobo et al., 2016; Brasil, 2016a) .

\subsection{Gerenciamento e Processamento de Dados}

Foram utilizados os softwares $\mathrm{R}$ para as análises descritivas, cálculo do DALY e modelagens estatísticas e o software Microsoft Excel versão 2010 para manipulação e gerenciamento dos dados.

\subsection{Aspectos Éticos da Pesquisa}

Os aspectos éticos e legais da pesquisa obedeceram a Resolução $n^{\circ}$ 466 de dezembro de 2012 da Comissão de Ética em Pesquisas (CONEP). Foi assegurado aos sujeitos de pesquisa o sigilo absoluto dos dados e foram excluídos os registros de identificação dos indivíduos logo após a realização do relacionamento probabilístico de base de dados (realizado pelo Ministério da Saúde). Como o estudo utilizou dados secundários, coletados pelos sistemas de vigilância em saúde e compilados nas bases oficiais do Ministério da Saúde, dispensou-se a utilização de Termo de Consentimento Livre Esclarecido (TCLE). A pesquisa foi aprovada pelo Comitê de Ética em Pesquisa (CEP) segundo parecer número 1.635.885 (Anexo II). 


\section{RESULTADOS}

\subsection{Artigo}

Este artigo analisou a distribuição da carga de doença por tuberculose pulmonar nos cenários de desigualdades sociais utilizando indicadores socioeconômicos, epidemiológicos e operacionais no Brasil, no ano de 2014 e será submetido à revista Epidemiology \& Infection. 


\section{Carga de doença por tuberculose pulmonar para cenários de desigualdades sociais no Brasil, no ano de 2014}

M.M. BASTOS ${ }^{1}$, W.M. RAMALHO², W.N. ARAÚJO²

1. Programa de Pós Graduação em Medicina Tropical, Núcleo de Medicina Tropical, Faculdade de Medicina, Universidade de Brasília (UnB), Brasilia/DF;

2. Professor adjunto, Faculdade UnB Ceilândia e Núcleo de Medicina Tropical, Faculdade de Medicina, UnB, Brasília/DF.

\section{RESUMO}

O objetivo do estudo foi analisar a carga de doença por tuberculose pulmonar nos cenários de desigualdades sociais segundo indicadores socioeconômicos, epidemiológicos e operacionais no Brasil, no ano de 2014. Foi conduzido um estudo ecológico transversal nos municípios brasileiros onde estimou-se os Anos de Vida Perdidos Ajustados por Incapacidade $(D A L Y)$ e identificaram-se os indicadores socioeconômicos, epidemiológicos

e operacionais associados à taxa de DALY padronizada (DALY $x \mathrm{xp})$. Os municípios foram agregados quanto às suas similaridades e classificados 
em cenários de desigualdades sociais utilizando o método não hierárquico de K-means. O DALY se distribuiu de forma heterogênea nos municípios brasileiros. A única variável que permaneceu associada à taxa de $D A L Y$ no modelo final foi a taxa de desocupação. Utilizando essa variável, foram identificados três cenários socioeconômicos e subcenários para a tuberculose pulmonar no Brasil. A carga da tuberculose pulmonar se distribui de forma heterogênea na população brasileira e as ações no âmbito da vigilância e na oferta de serviços precisam considerar as particularidades de cada localidade, atuando sobre os determinantes sociais da saúde e fazendo o uso de novas metodologias e tecnologias.

Palavras-chaves: tuberculose pulmonar, carga de doença, desigualdades sociais

\section{INTRODUÇÃO}

A tuberculose (TB) se constitui de uma doença infecciosa de grande magnitude, sendo a forma pulmonar a mais frequente e de extrema relevância para a saúde pública. Apesar dos avanços conquistados nas duas últimas décadas, com uma redução significativa dos óbitos em $22 \%$, a doença está entre as dez que mais matam no mundo [1]. Estima-se que em 2015 ocorreram 10,4 milhões de casos de TB e 1,4 milhão de óbitos mundialmente [1]. O Brasil alcançou as metas propostas pelos Objetivos de Desenvolvimento do Milênio (ODMs) de parar e reverter a incidência da TB, e as metas propostas pela estratégia Stop TB Partnership, de reduzir pela 
metade a prevalência e mortalidade da doença. Ainda assim, o Brasil está entre os 30 países com maior carga da doença e deteve 67.790 casos novos de TB em 2015 e 4.374 óbitos em 2014 [2,3].

Com o início de uma era pós-2015, a Organização Mundial de Saúde (OMS) propôs a estratégia End TB, pelo fim da Tuberculose, em consonância com os Objetivos de Desenvolvimento Sustentável (ODSs), propostos pela Organização das Nações Unidas. Essas estratégias estabelecem metas ousadas e desafiadoras para a eliminação da TB com uma epidemia global até o ano de 2035, que se pautam pela redução do coeficiente de incidência para menos de 10 casos por 100 mil habitantes e dos óbitos por TB em 95\% [1,4].

Considerando que a doença está ligada às condições de vida e de trabalho dos indivíduos e ao contexto em que os mesmos estão inseridos, conjectura-se que a carga da tuberculose pulmonar não se distribui de forma homogênea na população. Isso reflete as desigualdades socioeconômicas, geográficas e de acesso aos serviços de saúde no Brasil, e talvez, em outros países no mundo.

As metas propostas pela OMS ressaltam a importância de considerar os determinantes sociais em saúde para 0 enfrentamento das vulnerabilidades socioeconômicas e das iniquidades em saúde [1,4]. As propostas, contudo, giram em torno da redução dos indicadores tradicionais de carga de doença, como a morbidade e a mortalidade. A incapacidade gerada pela doença talvez seja desconsiderada, assim como sua possível 
distribuição heterogênea na população, de forma que o impacto social da TB também possa incidir em uma população economicamente mais frágil.

O Disability Adjusted Life Years (DALY), Anos de Vida Perdidos Ajustados por Incapacidade, é um indicador composto, proposto por Murray e Lopez [5,6] que combina a morte prematura e o tempo vivido com incapacidade em uma única medida. A mortalidade prematura é mensurada através do Years of Life Lost (YLL), Anos de Vida Perdidos, enquanto que a incapacidade é mensurada através do Years Lived with Disability (YLD), Anos Vividos com Incapacidade. O DALY mensura uma discrepância entre dois estados de saúde, o atual e um estado ideal e pode ser utilizado para elencar prioridades de alocação de recursos para minimizar iniquidades em saúde.

Nessa perspectiva, faz-se necessário o desenvolvimento de estudos que busquem observar como a carga da TB se distribui no país. Desta forma, esse estudo teve por objetivo analisar a distribuição da carga de doença por tuberculose pulmonar nos cenários de desigualdades sociais utilizando indicadores socioeconômicos, epidemiológicos e operacionais no Brasil, no ano de 2014.

\section{MÉTODOS}

\section{Tipo, população e período de estudo}

Foi conduzido um estudo ecológico transversal de base populacional. A população de estudo foi constituída de casos confirmados de tuberculose pulmonar (Classificação Internacional de Doenças - CID 10 - A150 a A153 
e A160 a A162) registrados no Sistema de Informação de Agravos de Notificação - Tuberculose (SINAN-TB), diagnosticados no ano de 2014 nos municípios brasileiros. Também fizeram parte da população de estudo os óbitos que tiveram como causa básica tuberculose pulmonar e TB pulmonar como causa associada à "Doença pelo vírus da imunodeficiência humana" (CID 10 - B20 a B24), registrados no Sistema de Informação sobre Mortalidade (SIM), no ano de 2014 ou 2015.

\section{Seleção dos óbitos}

Com o intuito de melhorar a qualidade e consistência dos registros nas bases de dados nacionais, foi realizada a técnica de relacionamento probabilístico de bases de dados entre o SINAN-TB e o SIM com o auxílio do software Reclink III [7]. Dessa maneira, foi possível obter os registros de óbitos presentes em ambas as bases de dados. Foram selecionados os casos de TB diagnosticados em 2014 e que evoluíram para óbito em 2014 ou 2015. A técnica de relacionamento probabilístico faz parte da rotina do Programa Nacional de Controle da Tuberculose (PNCT).

\section{Denominadores Populacionais e Padronização}

Os denominadores populacionais por sexo e faixa etária para os municípios brasileiros no ano de 2014 estavam indisponíveis. Dessa maneira, a população municipal para os estratos de sexo e faixa etária foi obtida através da multiplicação do tamanho da população residente nos municípios em 2014, pela proporção de indivíduos em cada sexo e faixa 
etária, calculada com base na população advinda do Censo Demográfico realizado no ano de 2010. Para fins de comparação entre municípios, realizou-se uma padronização das taxas de DALY utilizadas por meio da padronização direta. Utilizou-se a população brasileira do ano de 2010, por sexo e faixa etária, como população padrão.

\section{Carga de doença}

A carga de doença foi estimada através dos Disability Adjusted Life Years [5,6]. O indicador é obtido pela soma dos Years of Life Lost e dos Years Lived with Disability. Para o cálculo do DALY esse estudo seguiu a metodologia mais atualizada do Estudo de Carga Global de Doenças, GBD $2015[8]$.

Para estimar o YLL, multiplicou-se o número de óbitos estimados por TB pulmonar como causa básica ou como causa associada à doença pelo vírus do HIV, pela expectativa de vida na idade do óbito da tábua de vida de referência desenvolvida pelo Global Burden of Disease Study 2015 (GBD).

Obteve-se o YDL através da multiplicação dos casos incidentes de tuberculose pulmonar, pelo peso da incapacidade gerada e pela duração média da doença. Adotou-se o peso de 0,333 para tuberculose sem HIV e o peso de 0,408 para TB com HIV (GBD). O tempo de tratamento da tuberculose foi utilizado como uma aproximação da duração média da doença. Definiu-se a duração de 0,5 ano (seis meses) para a maioria dos casos de TB, incluindo HIV. Para os casos de tuberculose droga-resistente (TB-DR) foi adotado a duração de 1,5 ano (18 meses), assumindo o tempo 
médio sob tratamento para os pacientes com tuberculose com e sem multirresistência. A definição do tempo de tratamento da doença foi baseada na literatura e na consulta aos especialistas do Programa Nacional de Controle da Tuberculose (PNCT) do Ministério da Saúde $[9,10]$. Os procedimentos para a obtenção do DALY podem ser observados na figura 1.

\section{Indicadores socioeconômicos, epidemiológicos e operacionais}

Os indicadores socioeconômicos, epidemiológicos e operacionais da tuberculose utilizados nesse estudo foram selecionados através dos critérios de disponibilidade, relevância e plausibilidade com a doença e com o modelo de análise utilizado. Os indicadores socioeconômicos incluem: índice de desenvolvimento humano municipal (IDHM), índice de desenvolvimento humano municipal - dimensão Educação (IDHM-E), taxa de analfabetismo, produto interno bruto (PIB) per capita, renda média domiciliar per capita (RPDC), proporção de extremamente pobres (PIND), proporção de vulneráveis à pobreza $(\mathrm{PPOB})$, percentual de vulneráveis à pobreza que gastam mais de uma hora até o trabalho, índice de GINI, mortalidade infantil, taxa de desemprego, taxa de desocupação - 18 anos ou mais e percentual da população que vive em domicílios com densidade superior a duas pessoas por dormitório.

Os indicadores epidemiológicos, operacionais e de vulnerabilidade incluídos foram: a proporção de casos novos: na população privada de liberdade (PPL), entre profissionais de saúde, na população em situação de rua (PSR), com pelo menos uma dessas vulnerabilidades, com confirmação 
laboratorial, com encerramento ignorado ou transferência e testados para HIV. Ainda foi incluída a taxa de deteç̧ão de casos de Aids e a proporção: de contatos examinados, de cura e de abandono de tratamento entre os casos novos, de coinfecção TB-HIV, de casos de retratamento e de exames de cultura realizados em casos de retratamento.

\section{Critério de inclusão dos municípios brasileiros}

Com o intuito de utilizar no modelo apenas municípios com consistência na notificação de casos e suavizar a variabilidade dos valores em municípios com pequena população, utilizou-se os seguintes procedimentos: 1) calculou-se a média móvel trienal dos coeficientes de incidência dos anos de 2001 a 2015; 2) calculou-se a variação anual da média móvel utilizando dois anos consecutivos e; 3) obteve-se a média da variação de todos os anos. Foram incluídos apenas os municípios que obtiveram uma variação entre -8 e $8 \%$, escolhida de forma arbitrária, considerando a quantidade de municípios inclusos nessa faixa de variação. Os coeficientes de incidência foram utilizados em detrimento das taxas de DALY em razão da indisponibilidade dos relacionamentos probabilísticos das bases do Sinan e SIM para a série histórica utilizada, impossibilitando o cálculo do YLL de maneira precisa.

\section{Análise de dados}

Foi utilizada como variável dependente a taxa de DALY padronizada e como variáveis independentes foram utilizados os indicadores 
socioeconômicos, epidemiológicos e operacionais da TB. A associação entre variável dependente e independentes foram obtidas utilizando uma regressão binomial negativa.

As variáveis independentes foram avaliadas em grupos distintos, a partir da construção de dois modelos de análise, o primeiro utilizando as variáveis socioeconômicas (modelo A) e o segundo compreendendo as variáveis epidemiológicas e operacionais da TB (modelo B). Ambos os modelos foram examinados em uma análise bivariada. As variáveis que se apresentaram associadas ao desfecho com $\mathrm{p}$ valor $<0,20$ foram testadas em uma matriz de correlação para avaliar colinearidade. Foram incluídas na análise multivariada aquelas variáveis que apresentaram correlação $<0,80$ e entre aquelas colineares, foram incorporadas as que possuíam maior associação com a variável dependente.

\section{Agrupamento dos municípios segundo similaridades e classificação em cenários de desigualdade}

Em um segundo momento, para o agrupamento dos municípios segundo suas similaridades, foi utilizado o método não-hierárquico de $\mathrm{K}$ means em que foi possível identificar clusters de municípios a partir de suas semelhanças [11, 12]. Essa metodologia utiliza a medida da distância euclidiana entre os indicadores associados à taxa de DALY padronizada que foram identificados nos modelos $\mathrm{A}$ e $\mathrm{B}$. O número de clusters foi definido a partir do método de Elbow. Os municípios foram agrupados segundo os cenários socioeconômicos a partir do modelo A. Em seguida, uma vez 
definidos os cenários socioeconômicos, as variáveis do modelo B foram inseridas nesses cenários e a partir disso foram construídos os subcenários epidemiológicos e operacionais para a TB [13].

\section{Fonte de dados}

Foram utilizados os dados advindos do Sistema de Informação de Agravos de Notificação - Tuberculose (SINAN-TB) e do Sistema de Informação sobre Mortalidade (SIM), sob responsabilidade da Secretaria de Vigilância em Saúde do Ministério da Saúde. Os dados populacionais e indicadores socioeconômicos foram obtidos a partir do Instituto Brasileiro de Geografia e Estatística (IBGE) através do Departamento de Informática do SUS (DATASUS) e através do Atlas de Desenvolvimento Humano no Brasil, respectivamente.

\section{Aspectos Éticos da Pesquisa}

Os aspectos éticos e legais da pesquisa obedeceram a Resolução $n^{\circ}$ 466 de dezembro de 2012 da Comissão Nacional de Ética em Pesquisas (CONEP). Como o estudo utilizou dados secundários, coletados pelos sistemas de vigilância em saúde e compilados nas bases oficiais do Ministério da Saúde, dispensou-se a utilização de Termo de Consentimento Livre Esclarecido (TCLE). A pesquisa foi aprovada pelo Comitê de Ética em Pesquisa (CEP) da Faculdade de Medicina da Universidade de Brasília, segundo parecer número 1.635.885. 


\section{RESULTADOS}

Foram identificados 74.034 casos de tuberculose pulmonar no Brasil em 2014. Ocorreram 59.811 novos casos da doença no mesmo ano, constituindo um coeficiente de incidência de 29,500 casos para cada 100.000 habitantes. Em relação à mortalidade, foram registrados no SIM 7.268 óbitos por TB como causa básica e/ou associada. Desses, 3.421 $(47,06 \%)$ se referiam à TB pulmonar como causa básica, perfazendo um coeficiente de mortalidade de 1,68 para cada 100.000 habitantes. No que se refere aos óbitos advindos do relacionamento probabilístico de base de dados, 4.687 pares foram identificados no SINAN e no SIM, representando $64,50 \%$ do total de registros de TB nesse último sistema de informação.

A taxa de DALY padronizada (DALYtxp) se distribuiu de forma heterogênea nos municípios brasileiros no ano de 2014. Ocorreu uma intensa variação dos coeficientes, incorrendo de 0 a 3046,19 DALYs para cada 100.000 habitantes. Conforme ilustrado no mapa da Fig. 2, os municípios do estado do Amazonas apresentaram os coeficientes mais elevados enquanto os municípios do estado do Tocantins apresentaram os menores DALYs por 100.000 habitantes. Outros estados da região Norte do Brasil apresentam altas DALY txp como é o caso do Pará e de Rondônia. Na região Centro-Oeste, o estado de Mato Grosso do Sul e o Distrito Federal se destacam assim como os municípios dos estados do Maranhão e do Sul da Bahia, na região Nordeste do país. Nos municípios das regiões Sudeste e 


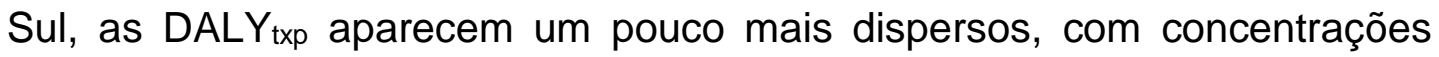
elevadas pontuais.

Ao observar a DALY $\mathrm{txp}$ de acordo com o porte municipal (Fig. 3, identifica-se uma assimetria nos valores dos municípios médios, que possuem população entre 20.000 e 100.000 habitantes. Esses municípios apresentam maior amplitude e uma maior variabilidade nas taxas em relação aos outros grupos. Os municípios pequenos, com população menor do que 20.000 habitantes representam mais de $70 \%$ do total dos municípios brasileiros. Estes possuem uma distribuição de DALY entanto, com muitos valores discrepantes para além do limite superior. Os municípios grandes (com mais de 100.000 habitantes) representam a menor proporção em relação ao total de municípios. Os mesmos apresentam menor amplitude e variabilidade nas $\mathrm{DALY} \mathrm{Y}_{\mathrm{txp}}$ do que os municípios de médio porte. Além disso, esses municípios possuem alguns valores discrepantes para além do limite inferior.

A partir do cálculo da variação anual dos coeficientes de incidência, 3.178 municípios foram utilizados para a identificação dos indicadores socioeconômicos associados com a DALYtxp. $\mathrm{Na}$ análise bivariada do modelo $A$, em que foram incluídas variáveis com $p<0,20$ que não apresentavam colinearidade entre si $(r<0,80)$, os indicadores que entraram para a análise multivariada foram: taxa de analfabetismo, percentual de vulneráveis à pobreza que gastam mais de uma hora até o trabalho, taxa de desocupação, percentual da população que vive em domicílios com densidade superior a duas pessoas por dormitório e PIB per capita. No 
modelo final, apenas a taxa de desocupação se manteve associada com $\mathrm{p}<0,05$ (tabela 1).

Utilizando a variável taxa de desocupação para a definição de cenários socioeconômicos e utilizando o método de Elbow para a definição do número de clusters, foram identificados três cenários socioeconômicos para TB no Brasil, com 2.436, 661 e 2.468 municípios, respectivamente. No cenário 2 se encontram as maiores medianas em indicadores como taxa de mortalidade infantil, taxa de analfabetismo, proporção de vulneráveis à pobreza e densidade intradomiciliar e menores medianas no que se refere aos indicadores de renda, como RPDC e PIB. O cenário 3 apresenta uma mediana mais baixa da taxa de desemprego com intervalo interquartílico curto, maior mediana de IDHM e menor mediana de PIND (tabela 2). Em um segundo momento, após definição dos cenários, foram incluídas as variáveis do modelo B dentro dos cenários socioeconômicos encontrados. No cenário 1 permaneceram no modelo final negativamente associadas à DALYtxp, a proporção de cura entre os casos novos e a proporção de casos novos com encerramento ignorado ou transferência. Já a variável proporção de casos novos testados para HIV permaneceu positivamente associada nesse cenário assim como a proporção de casos novos com pelo menos uma vulnerabilidade e proporção de coinfecção TBHIV (tabela 3).

Já no cenário dois a maioria das variáveis que permaneceu no modelo final se apresentou inversamente associada à DALYtxp, são elas: a proporção de casos examinados entre os casos novos, o percentual de cura 
entre os casos novos, proporção de abandono de tratamento entre os casos novos, percentual de casos novos com encerramento ignorado ou transferência, além do percentual de casos novos entre indígenas e taxa detecção de casos de Aids. Apenas o percentual de casos novos com pelo menos uma vulnerabilidade e proporção de coinfecção TB-HIV foram positivamente associadas (tabela 3).

Observa-se no último cenário, ao contrário dos cenários anteriores, que a proporção de contatos examinados entre os casos novos foi positivamente associada com a DALY $\mathrm{txp}$ no modelo final. Nesse cenário identificou-se também uma associação positiva com a proporção de casos novos entre profissionais de saúde, percentual de casos de retratamento, de exames de cultura realizados em casos de retratamento e de coinfecção TBHIV. Assim como nos cenários anteriores a proporção de cura entre os casos novos e a proporção de casos novos com encerramento ignorado ou transferência permaneceram inversamente associados à DALYtxp. Nesse cenário, a variável proporção de abandono de tratamento também permaneceu negativamente associada no modelo final (tabela 3).

A partir dos três cenários socioeconômicos, foram definidos subcenários epidemiológicos e operacionais para a tuberculose. 0 cenário 1 deu origem a quatro subcenários e um quinto em que não há casos de tuberculose. Esse subcenário é constituído por 551 municípios e apresenta uma mediana da DALY $\mathrm{txp}$ de 750,7/100.000 hab., correspondendo a municípios que apesar de não terem casos registrados no SINAN, provavelmente apresentaram registros de óbitos por TB no SIM em 2014. O 
subcenário 1 é formado por 152 municípios e apresenta uma mediana da DALY $\mathrm{txp}$ de 6,198/100.000 hab. Já o subcenário 2 apresenta o maior número de municípios do cenário 1 (990) com mediana da DALYtxp de 4,433/100.000 hab. O subcenário 3 abrange 434 municípios enquanto o subcenário 4 compreende 309, as medianas de suas taxas de DALY são 3,794 e 2,891/100.000 hab, respectivamente. Os subcenários 1 e 2 aparentam melhores condições em relação aos indicadores operacionais do que os subcenários 3 e 4 . Os primeiros dois possuem maiores medianas da proporção de casos novos com confirmação laboratorial e testagem para HIV. O subcenário 4 apresenta a maior mediana no que se refere ao percentual de casos novos com encerramento ignorado ou transferência (tabela 4). A distribuição dos municípios nos subcenários epidemiológicos e operacionais da TB do cenário 1 podem ser observados no mapa da figura 4.

No cenário dois foram identificados 3 subcenários, além de um subcenário sem casos de TB, formado por 128 municípios (tabela 5). O subcenário 1 é formado por 43 municípios e detém uma mediana da DALYtxp de 5,356/100.000 hab. Esse apresenta as menores medianas de indicadores operacionais como percentual de casos novos com confirmação laboratorial, contatos examinados e cura entre casos novos. O subcenário 2 compreende 262 municípios e possui mediana da DALY $\mathrm{txp}$ de 4,333. Ao contrário do subcenário anterior, esse possui as maiores medianas de confirmação laboratorial, contatos examinados, cura entre casos novos e testagem para HIV. No terceiro subcenário foram identificados 228 municípios e mediana 
da DALY txp de 9,752/100.000 hab. Os municípios que formam esses quatro subcenários estão mais concentrados nas regiões Norte e Nordeste do Brasil (fig. 4).

No cenário três foram identificados 4 subcenários e mais um subcenário sem casos que abrange 1023 municípios (tabela 6). A mediana da DALY txp encontrado foi de 216,8/100.000. O subcenário 1 compreende 135 municípios com mediana da DALY txp de 2,834. Os subcenários 2 e 3 possuem 337 e 169 municípios, respectivamente. As medianas da DALYtxp encontrados foram de 3,715 para o segundo subcenário e 7,834 para o terceiro. O subcenário 4 detém o maior número de municípios (804) e uma mediana da DALY txp de 2,914. As maiores medianas em relação aos indicadores operacionais e epidemiológicos como cura, contatos examinados e confirmação laboratorial foram encontradas nos dois últimos subcenários ( 3 e 4$)$ e as menores nos subcenários 1 e 2 . A mais alta mediana encontrada da proporção dos casos ignorados ou transferência é identificada no subcenário 1 . Os municípios que formam esses cinco subcenários se apresentam de forma mais evidente no centro sul do país (figura 5).

\section{DISCUSSÃO}

A taxa de DALY padronizada (DALYtxp) por tuberculose pulmonar apresentou distribuição heterogênea no território brasileiro no ano de 2014, com grande variação das taxas. De todos os indicadores socioeconômicos testados no modelo A, composto por variáveis epidemiológicas e 
operacionais, apenas a taxa de desocupação mostrou-se associada à

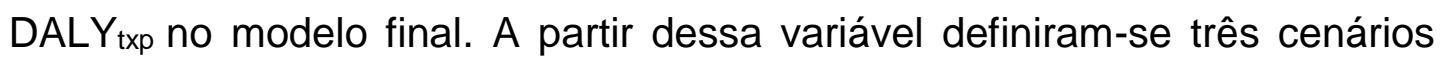
socioeconômicos para a tuberculose pulmonar. Com a inclusão de indicadores epidemiológicas e operacionais, provenientes do modelo B, foram definidos subcenários epidemiológicos e operacionais para a TB pulmonar a partir das variáveis: proporção de cura entre casos novos (cenários um, dois e três), proporção de casos com encerramento ignorado ou transferência (cenários um, dois e três), proporção de testagem para HIV (cenário um), percentual de casos com pelo menos uma vulnerabilidade (cenários um e dois), proporção de coinfecção (cenários um, dois e três), proporção de contatos examinados (cenários dois e três), percentual de abandono de tratamento entre casos novos (cenários dois e três), proporção de casos novos entre indígenas (cenário dois), percentual de casos novos entre profissionais de saúde, percentual de casos de retratamento e proporção de cura entre os casos de retratamento (cenário três).

Dentro dos cenários um e três, quatro subcenários foram identificados e um quinto sem casos da doença no SINAN. No cenário dois, obteve-se três subcenários e um quarto em que não houve registros de casos no sistema de informação. A intensa variação das DALYtxp encontrada nos municípios brasileiros é observada principalmente naqueles municípios de pequeno porte cuja população está abaixo dos 20.000 habitantes [14]. É evidente que devido ao reduzido tamanho populacional os casos e óbitos que ocorram nesses municípios geram um impacto significativo na DALY txp. $_{\text {. }}$ 
A taxa de desocupação, dentre o rol de indicadores socioeconômicos testados, foi o único que se mostrou positivamente associado à $D A L Y_{\text {txp }}$. Essa variável se configura como um marcador socioeconômico importante, traduzindo as fragilidades socioeconômicas de determinada localidade, as vulnerabilidades sociais e as necessidades de determinada população por uma inserção ocupacional adequada que supra suas carências imediatas [15]. Uma variação positiva desse indicador reflete não só no aumento da incidência da tuberculose pulmonar, mas também na incapacidade gerada pela doença e na mortalidade. Isso pode gerar um impacto econômico negativo na sociedade e reforçar o ciclo da pobreza, exclusão social e das precárias condições de vida que contribuem para a constelação causal do adoecimento. Estudos evidenciam que programas condicionados de transferência de renda podem atuar nos determinantes sociais em saúde e, quando combinados com ações intersetoriais no âmbito da atenção básica, podem contribuir para a redução da mortalidade na infância, mortalidade por causas relacionadas à pobreza e melhorar a taxa de cura por TB no Brasil $[16,17]$.

Os cenários socioeconômicos identificados apresentam características distintas entre si. Enquanto o cenário três sugere as melhores condições em relação aos outros cenários, o cenário dois chama a atenção por aparentar condições socioeconômicas mais desfavoráveis. A mortalidade infantil que se trata de um indicador que reflete as condições sociais, econômicas e as condições de vida de determinada localidade [18], por exemplo, possui nesse cenário a maior mediana do coeficiente de 
mortalidade infantil do que os outros. Esse contexto social vulnerabilizado também é reforçado quando se avalia as medianas da proporção de extremamente pobres e de vulneráveis a pobreza (16,39\% e 64,66\%), sendo essa última mais que o dobro do cenário três.

Os municípios que compõe o cenário dois estão distribuídos de forma mais acentuada no Norte e no Nordeste do país. Essas regiões historicamente estão associadas a um contexto socioeconômico frágil, com os menores Índices de Desenvolvimento Humano, maior exposição ao risco de óbito infantil, maiores concentrações de inseguridade alimentar e maiores coeficientes de doenças infecciosas negligenciadas como a tuberculose [19, 20, 21].

Os óbitos por TB pulmonar apontados nas DALYtxp, dos subcenários que não notificaram no SINAN os casos de TB, podem refletir a ineficiência do serviço de saúde a partir do momento em que houve falha na detecção dos casos pelo sistema de vigilância. Ainda, de maneira geral, esses óbitos podem refletir a incapacidade do sistema de saúde municipal de tratar os casos na Atenção Básica de modo que esse nível de complexidade seja resolutivo. Bartholomay et al. (2016) [22] identificaram em seu estudo que a descentralização dos serviços de saúde é um processo que está em andamento no Brasil e que a atenção primária à saúde atende mais da metade dos pacientes recém diagnosticados com TB. Esses achados reforçam a necessidade do fortalecimento da atenção básica como porta de entrada do sistema de saúde, de modo que as ações que concernem a 
vigilância e o tratamento da tuberculose sejam desempenhadas adequadamente.

A identificação dos padrões municipais no que diz respeito à relação da tuberculose com indicadores operacionais e socioeconômicos pode contribuir para levantar questões que permeiam a organização dos sistemas de vigilância do município [23]. Dentro dos três cenários identificados, os indicadores que mostraram associação plausível com a DALYtxp foram em sua maioria indicadores operacionais em detrimento dos epidemiológicos. Contudo, o indicador epidemiológico proporção de coinfecção pelo HIV se mostrou associada à DALY txp nos três cenários. A diminuição na proporção de cura entre casos novos, de contatos examinados entre casos novos e na taxa de detecção de casos de Aids estão associadas a um aumento na DALYtxp. Essas associações podem refletir a qualidade dos sistemas de vigilância dos municípios e a estruturação dos serviços de saúde nessas localidades. De maneira similar, Yamamura et al. (2014) [23] ao analisarem os padrões municipais do estado de São Paulo quanto à relação dos indicadores de oferta e serviços de saúde com a tuberculose, identificaram iniquidades nos grupos estabelecidos quanto ao acesso à tecnologias como o Tratamento Diretamente Observado e a testagem para HIV.

Segundo Castro (2007) [24], os dados da vigilância são de fundamental importância para mensurar a carga das doenças e orientar a tomada de decisão e o planejamento de ações em saúde. Dessa forma, um sistema de vigilância ideal é sensível, preciso e oportuno. A estruturação de um sistema de vigilância no nível municipal, contudo, depende da 
organização dos serviços de saúde em cada localidade. Apesar de contarem com suporte dos estados, a construção de um sistema de vigilância que seja sensível, representativo, flexível e oportuno consiste em uma atividade complexa a depender das condições socioeconômicas e estruturais dos municípios.

Além disso, um modelo de vigilância para a tuberculose que seja uniforme para todo o território nacional parece contribuir para que as ações de vigilância e controle da doença sejam ineficazes em algumas localidades, ainda que muitas vezes sejam dispendidos consideráveis esforços em prol da contenção da TB. A justificativa da não implantação de um modelo único de vigilância se pauta pela heterogeneidade entre os municípios brasileiros e pelas desigualdades que são inerentes a um país de tamanha extensão territorial $[25,26]$.

A organização e a estrutura da oferta de serviços nos municípios brasileiros também parecem refletir as variações dos indicadores operacionais na DALYtxp. Muitas vezes os municípios não estão preparados para atender as demandas referentes à tuberculose e não possuem recursos mínimos necessários que permitam o acompanhamento dos casos para avaliar a evolução do tratamento, evitar o abandono e examinar contatos dos casos. A barreira geográfica também se constitui de uma preocupação para a oferta dos serviços de saúde [25]. Municípios localizados em regiões de difícil acesso, como é a situação de alguns municípios na região Norte do país, podem apresentar dificuldades na 
organização dos serviços de saúde de modo que atenda as demandas em sua totalidade [27].

Os municípios brasileiros diante de um cenário constitucional que prevê autonomia para o desenvolvimento de ações no âmbito da saúde, organizam seus serviços de saúde de acordo com seu contexto epidemiológico, político e social. Dessa maneira, a organização das estratégias de controle para a TB pode variar entre os municípios [23]. As barreiras organizacionais que dificultam a implantação adequada das ações no tratamento de TB de forma sustentável envolve uma série de atores, como profissionais de saúde e gestores, e precisam ser investigadas [28].

A regionalização, como diretriz do SUS e eixo estruturante do Pacto pela Gestão, é colocada como instrumento importante na qualificação e fortalecimento da descentralização do sistema de saúde. Ações pactuadas nas três esferas de governo se concretizam a partir da construção de regiões de saúde em que há o compartilhamento de responsabilidades, a interação entre serviços de saúde e a cooperação para o desenvolvimento de ações conjuntas que supram as necessidades e peculiaridades de saúde de determinado território. A gestão descentralizada, contudo, precisa lidar com a intensa fragmentação municipal, marcada pelas desigualdades sociais e iniquidades em saúde que se traduzem na oferta e qualidade dos serviços de saúde [29].

Lima et. al (2012) [27] identificou em seu estudo que a operacionalização da regionalização está associada principalmente com as dinâmicas territoriais dos estados brasileiros, as políticas de saúde 
estabelecidas no passado e as características do desenvolvimento econômico nessas localidades. Nessa perspectiva e diante dos desafios para alcançar a regionalização, esse trabalho pode contribuir como um instrumento para fortalecer as discussões acerca das políticas de saúde, da estruturação do sistema de vigilância e de um modelo de atenção à tuberculose, que trabalhe na perspectiva do enfrentamento das vulnerabilidades, considerando a incapacidade gerada pela doença e as peculiaridades apresentadas em cada cenário.

Diante de um contexto em que a pobreza e a vulnerabilidade social podem ser produtos da dinâmica das desigualdades na perspectiva econômica e social, as doenças infecciosas continuam a gerar um impacto na carga de doença no Brasil [30]. Um estudo realizado no Peru [31] mostrou que os custos catastróficos entre familiares de indivíduos afetados pela tuberculose são elevados e que intervenções socioeconômicas específicas no âmbito da TB reduziram esses custos e se mostraram acessíveis para pessoas mais pobres.

A utilização do DALY como um indicador composto para mensurar essa carga ao invés da utilização de indicadores tradicionais como morbidade e mortalidade permite compreender a diferença entre dois estados de saúde, utilizando a morte prematura e a incapacidade da doença. Essa ferramenta pode ser utilizada como uma medida de desigualdade. Isso foi demonstrado por Marlow et al. (2015) [32] que utilizaram o "DALY-gap", uma métrica de diferença, com o intuito de mensurar as disparidades na carga de doença em diferentes estratos sociais 
(favela e não favela), que indicadores tradicionais não conseguiram captar.

Em estudo de carga de doenças infecciosas conduzido em Santa Catarina, estado do sul do Brasil, se identificou que $90 \%$ da carga de doenças infecciosas se deve à mortalidade precoce. Foi demonstrada também uma elevada carga de doenças infecciosas em regiões com grandes desigualdades sociais e pobreza [33]. A informação acerca da carga das doenças e a comparação dessa carga entre as doenças podem ser relevantes para orientar a tomada de decisão e priorizar intervenções [34, 35]. Um estudo conduzido por Hacking e Cleary (2016) [36] mostrou a construção de um modelo quantitativo utilizando a Tuberculose na África do Sul como exemplo. A ferramenta metodológica incorpora o DALY na perspectiva da doença que se divide em inevitável com a existência de intervenções, evitável com eficiência melhorada e evitável com a existência de intervenções não custo efetivas.

Apesar do incentivo da OMS para utilização desse indicador e da produção de estudos de carga de doença em consonância com os ODSs, mais estudos incorporando o DALY precisam ser incluídos nas agendas internacionais e nacionais. Dessa forma, o desenvolvimento de ações passa a ser pautado pela priorização de ações em saúde e alocação de recursos de forma equânime, não só no que se refere à tuberculose, mas também a outras doenças negligenciadas [11, 37, 38].

Este estudo apresenta algumas limitações que devem ser consideradas. Primeiro, os dados de mortalidade utilizados para o cálculo do DALY não foram corrigidos por sub registro. Embora o SIM seja considerado 
um sistema padrão outro para mortalidade no Brasil e possua elevada cobertura, ainda pode haver subnotificação de casos, principalmente em municípios e regiões em que o sistema de vigilância não funciona de maneira adequada [39]. Outra limitação consiste na utilização de dados secundários que escondem fragilidades como a baixa padronização, variação na validade dos registros e a subnotificação de casos. Contudo, procedimentos metodológicos foram realizados com o intuito de minimizar essas fragilidades, como, por exemplo, o relacionamento probabilístico de bases de dados. Considerando a taxa de DALY, esse estudo optou pela não exclusão dos valores discrepantes referentes aos municípios de pequeno porte, uma vez que se buscou descrever as taxas em todo o contexto nacional. Embora a não exclusão desses valores possa exercer alguma influência análise descritiva, a avaliação dos indicadores socioeconômicos associados à DALY $\mathrm{txp}$ no modelo $\mathrm{A}$ foi realizada em municípios com constante notificação de casos. Por fim, esse estudo avaliou as variáveis socioeconômicas e as epidemiológicas e operacionais separadamente e não em um modelo misto em que se consideraria a influência das variáveis em diferentes níveis de proximidade e plausibilidade com a variável dependente.

Este trabalho está alinhado com os pilares e componentes da estratégia End TB que adereçam a importância de considerar os determinantes de saúde para a elaboração de políticas de saúde, o enfrentamento da pobreza e de outras condições que geram iniquidades em saúde $[1,40]$. O terceiro pilar pauta-se pelo desenvolvimento de pesquisas e inovações. Essa pesquisa se constitui de uma tecnologia importante à luz 
das metas propostas pelo End TB [1, 40]. Com a definição de cenários socioeconômicos e operacionais para a TB pulmonar, a partir da carga da doença, é possível traçar estratégias e ações específicas, considerando as particularidades de cada território. Sugere-se que essa metodologia de identificação de cenários socioeconômicos e operacionais, construídos a partir de indicadores associados com a carga de doença, possam ser utilizados em outros países com alta carga de TB pulmonar e dentro do território brasileiro para outras doenças marcadas por vulnerabilidades, ou mesmo para estudar o impacto de outras doenças relacionadas à pobreza [41]. 


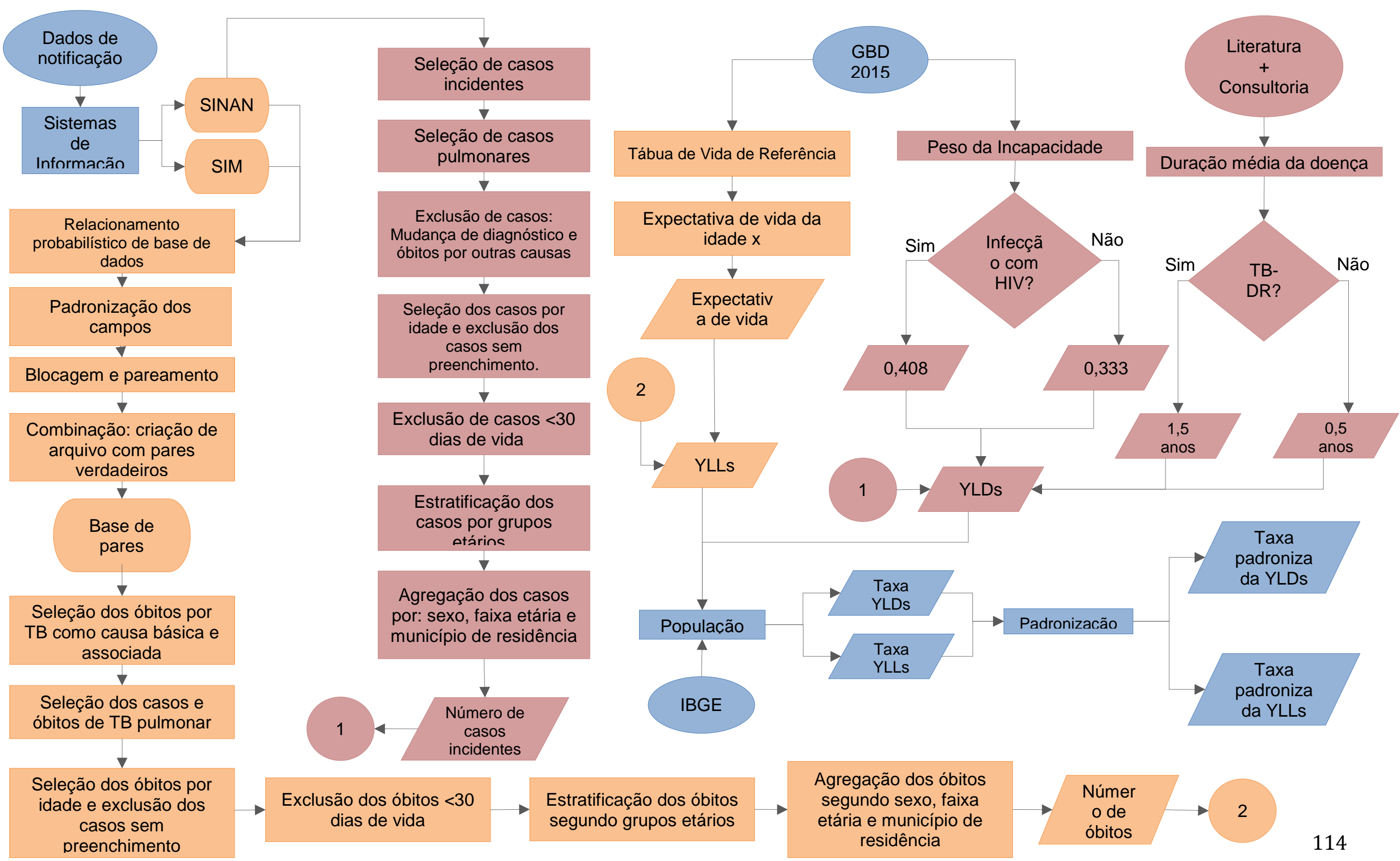

Fig. 1. Fluxograma dos procedimentos para estimativa da carga da doença 

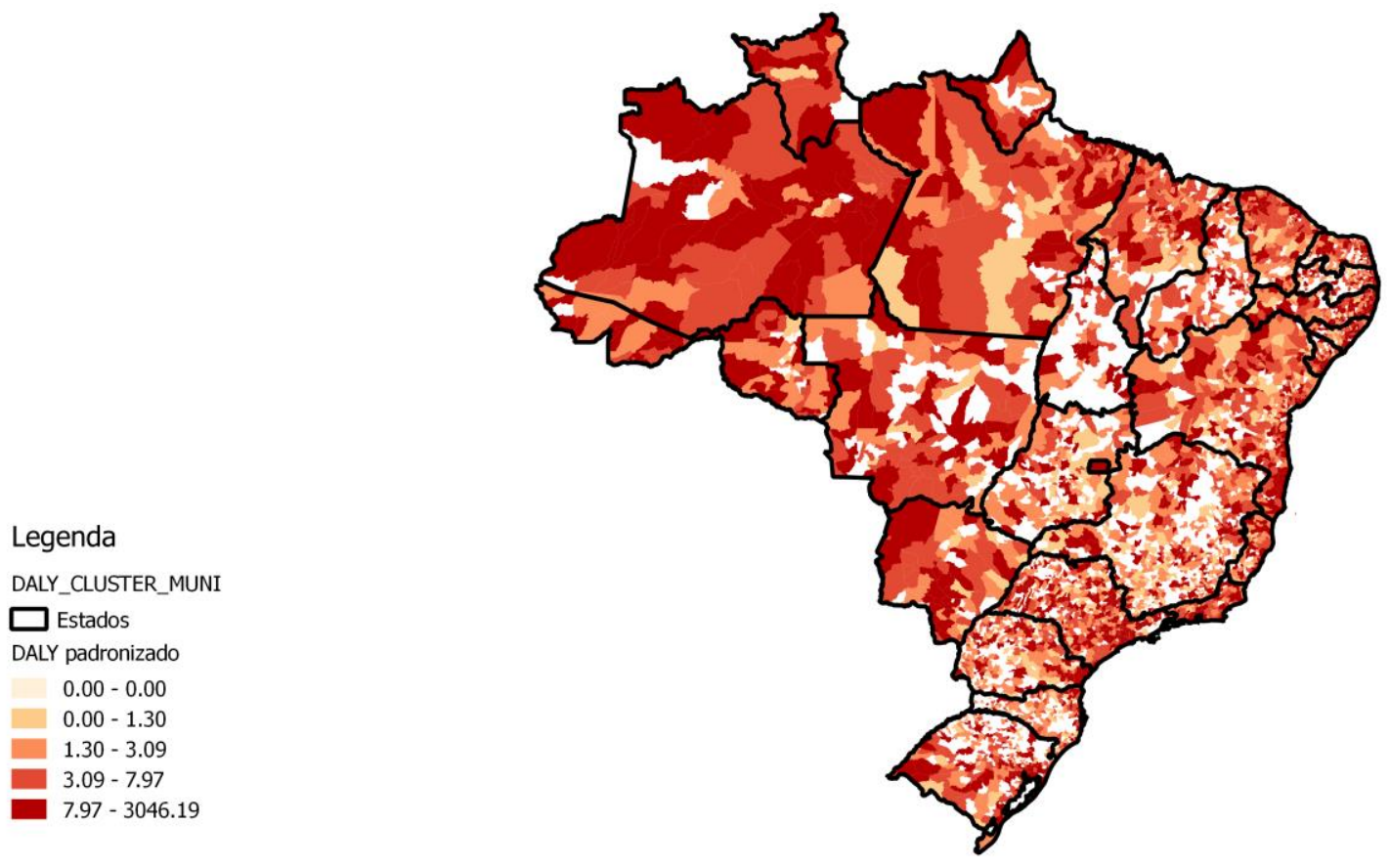

Fig. 1. Distribuição da taxa de DALY padronizada no Brasil, 2014. 


\section{DALY Padronizado}

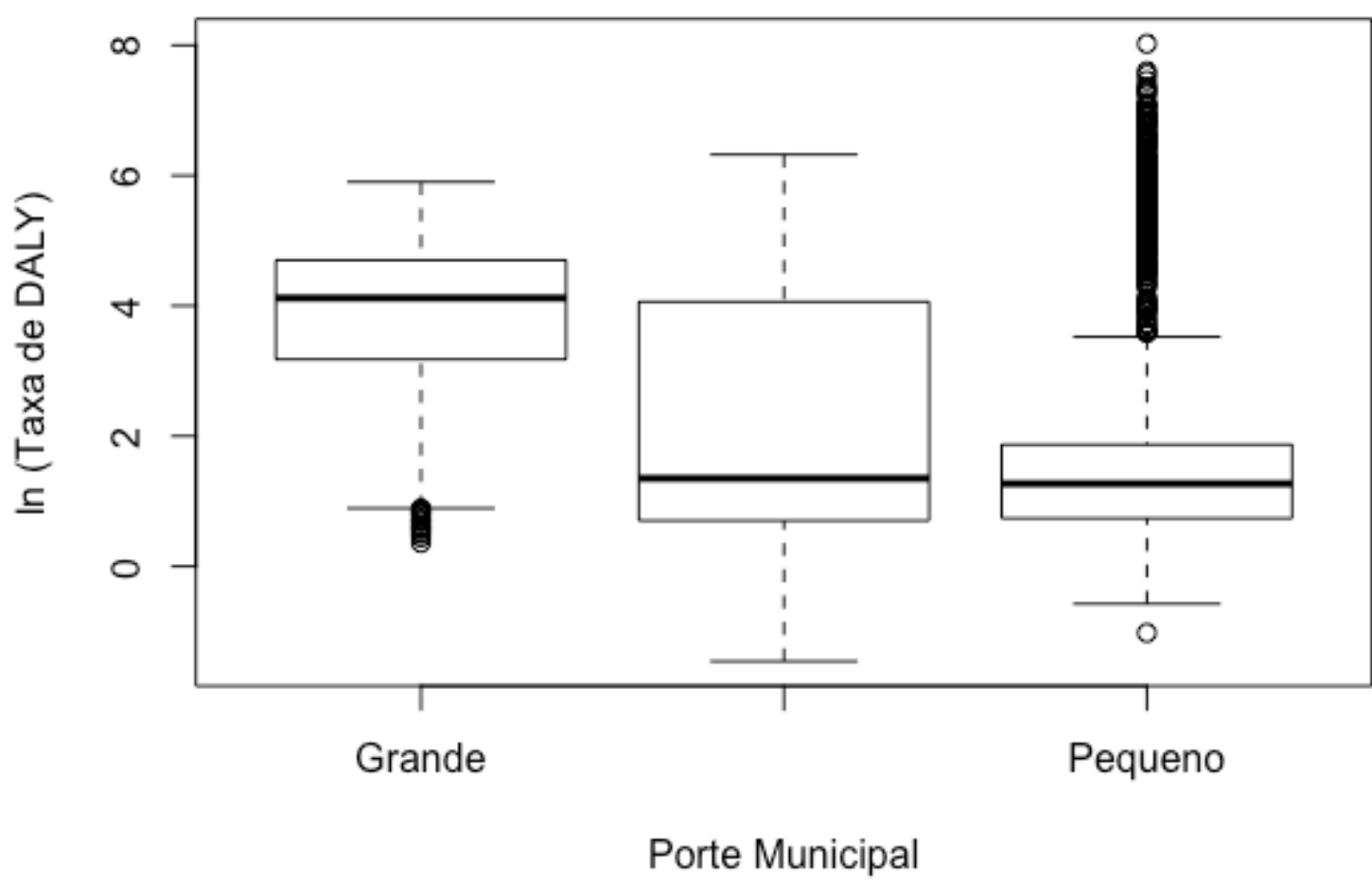

Fig. 2. Taxa de DALY padronizada por tuberculose segundo porte municipal. 
Tabela 1. Análise descritiva e indicadores socioeconômicos associados com a taxa de DALY padronizada por tuberculose $(n=3178$ ).

\begin{tabular}{|c|c|c|c|c|c|}
\hline \multirow[b]{2}{*}{ Variáveis } & \multicolumn{4}{|c|}{ Modelo bivariado } & \multirow{2}{*}{$\begin{array}{l}\text { Modelo multivariado } \\
\text { Exponencial beta ajustado } \\
\text { (IC95\%) }\end{array}$} \\
\hline & Mediana (Q1 - Q3) & Beta & $\mathrm{p}$ valor & Exponencial beta (IC95\%) & \\
\hline Mortalidade infantil & $17.6(14.1-24.7)$ & -0.003 & 0.527 & $0.997(0.987-1.007)$ & \\
\hline Taxa de analfabetismo & $14.12(8.315-25.33)$ & 0.008 & 0.046 & $1.008(1-1.015)$ & \\
\hline Proporção de extremamente pobres & $7.84(1.84-20.98)$ & 0.002 & 0.611 & $1.002(0.996-1.007)$ & \\
\hline $\begin{array}{l}\text { Proporção de vulneráveis à pobreza } \\
\text { (PPOB) }\end{array}$ & $45.75(25.24-66.88)$ & 0.002 & 0.284 & $1.002(0.999-1.005)$ & \\
\hline Índice de GINI & $0.5(0.45-0.54)$ & 0.072 & 0.900 & $1.075(0.355-3.269)$ & \\
\hline $\begin{array}{l}\text { Índice de Desenvolvimento Humano } \\
\text { Municipal }\end{array}$ & $0.656(0.594-0.715)$ & -0.715 & 0.172 & $0.489(0.182-1.306)$ & \\
\hline $\begin{array}{l}\text { Índice de Desenvolvimento Humano } \\
\text { Municipal - Educação }\end{array}$ & $0.553(0.484-0.628)$ & -0.734 & 0.069 & $0.48(0.224-1.023)$ & \\
\hline $\begin{array}{l}\text { Índice de Desenvolvimento Humano } \\
\text { Municipal - Renda }\end{array}$ & $0.645(0.565-0.702)$ & -0.481 & 0.304 & $0.618(0.25-1.529)$ & \\
\hline Renda média domiciliar per capita & $442(268.8-630.5)$ & 0.000 & 0.453 & $1(1-1)$ & \\
\hline $\begin{array}{l}\text { Percentual de vulneráveis à pobreza } \\
\text { que gastam mais de uma hora até o } \\
\text { trabalho }\end{array}$ & $0.98(0.36-2.06)$ & 0.029 & 0.176 & $1.03(0.988-1.075)$ & \\
\hline $\begin{array}{l}\text { Percentual da população que vive } \\
\text { em domicílios com densidade } \\
\text { superior a duas pessoas por } \\
\text { dormitório }\end{array}$ & $24.42(16.18-34.01)$ & 0.004 & 0.127 & $1.004(0.999-1.01)$ & \\
\hline Taxa de desocupação - 18 ou mais & $5.89(3.883-8.198)$ & 0.028 & 0.007 & $1.028(1.009-1.048)$ & $1.028(1.009-1.048)$ \\
\hline Taxa de desemprego & $6.07(4.052-8.318)$ & 0.024 & 0.018 & $1.025(1.006-1.044)$ & \\
\hline Produto Interno Bruto per capita & $8884(4868-14980)$ & 0.000 & 0.088 & $1(1-1)$ & \\
\hline
\end{tabular}


Tabela 2 Análise descritiva segundo cenários socioeconômicos $(n=5565)$.

\begin{tabular}{|c|c|c|c|}
\hline & Cenário 1 & Cenário 2 & Cenário 3 \\
\hline \multirow{2}{*}{ Variáveis } & $n=2436$ & $\mathrm{n}=661$ & $n=2468$ \\
\hline & Mediana (Q1 - Q3) & Mediana (Q1 - Q3) & Mediana (Q1 - Q3) \\
\hline Mortalidade infantil & $18,7(14,9-24,9)$ & $23,2(18,7-28,1)$ & $14,8(12,6-18,2)$ \\
\hline Taxa de analfabetismo & $16,48(9,165-26,08)$ & $22,82(15,23-27,9)$ & $10,22(6,85-15,36)$ \\
\hline $\begin{array}{l}\% \text { de extremamente pobres } \\
\text { (PIND) }\end{array}$ & $9,965(2,38-21,82)$ & $16,39(9,6-24,12)$ & $2,7(0,96-9,575)$ \\
\hline $\begin{array}{l}\% \text { de vulneráveis à pobreza } \\
\text { (PPOB) }\end{array}$ & $52,62(28,92-67,41)$ & $64,66(54,66-71,01)$ & $29,16(17,87-48,68)$ \\
\hline Índice de GINI & $0,51(0,47-0,55)$ & $0,52(0,48-0,55)$ & $0,47(0,43-0,51)$ \\
\hline $\begin{array}{l}\text { Índice de Desenvolvimento } \\
\text { Humano Municipal }\end{array}$ & $0,646(0,592-0,711)$ & $0,606(0,575-0,651)$ & $0,694(0,638-0,729)$ \\
\hline $\begin{array}{l}\text { Índice de Desenvolvimento } \\
\text { Humano Municipal - Educação }\end{array}$ & $0,549(0,481-0,628)$ & $0,509(0,463-0,56)$ & $0,585(0,517-0,639)$ \\
\hline $\begin{array}{l}\text { Índice de Desenvolvimento } \\
\text { Humano Municipal - Renda }\end{array}$ & $0,623(0,563-0,693)$ & $0,578(0,548-0,625)$ & $0,688(0,632-0,725)$ \\
\hline $\begin{array}{l}\text { Renda média domiciliar per } \\
\text { capita (RPDC) }\end{array}$ & $386,4(266,6-598,7)$ & $291,8(242-390,1)$ & $577,9(407,8-729,7)$ \\
\hline $\begin{array}{l}\text { \% de vulneráveis à pobreza que } \\
\text { gastam mais de uma hora até o } \\
\text { trabalho }\end{array}$ & $1,14(0,57-2,142)$ & $2,01(1,14-3,25)$ & $0,455(0,15-1,1)$ \\
\hline $\begin{array}{l}\text { \% da população que vive em } \\
\text { domicílios com densidade } \\
\text { superior a } 2 \text { pessoas por } \\
\text { dormitório }\end{array}$ & $26,78(19,81-35,11)$ & $32,77(27,12-39,14)$ & $16,25(11,26-24,4)$ \\
\hline $\begin{array}{l}\text { Taxa de desocupação - } 18 \text { ou } \\
\text { mais }\end{array}$ & $7,06(6,12-8,26)$ & $12,41(11,11-14,55)$ & $3,4(2,2-4,39)$ \\
\hline Taxa de desemprego & $7,21(6,28-8,4)$ & $12,54(11,27-14,73)$ & $3,56(2,32-4,532)$ \\
\hline Produto Interno Bruto per capita & $7579(4720-13630)$ & $6075(4521-9546)$ & $11570(7334-16980)$ \\
\hline
\end{tabular}


Tabela 3. Indicadores epidemiológicos e operacionais associados com a taxa de DALY padronizada por tuberculose segundo cenários socioeconômicos.

\begin{tabular}{|c|c|c|c|c|c|c|c|c|c|c|c|c|}
\hline \multirow[b]{4}{*}{ Variáveis } & \multicolumn{4}{|c|}{ Cenário 1} & \multicolumn{4}{|c|}{ Cenário 2} & \multicolumn{4}{|c|}{ Cenário 3} \\
\hline & \multicolumn{3}{|c|}{ Modelo bivariado } & \multirow[t]{2}{*}{ Multivariado } & \multicolumn{3}{|c|}{ Modelo bivariado } & \multirow[t]{2}{*}{ Multivariado } & \multicolumn{3}{|c|}{ Modelo bivariado } & \multirow[t]{2}{*}{ Multivariado } \\
\hline & $\mathrm{n}=243$ & & & & $\mathrm{n}=661$ & & & & $\mathrm{n}=246$ & & & \\
\hline & Beta & $\begin{array}{l}\mathrm{p} \\
\text { valor }\end{array}$ & $\begin{array}{l}\text { Exponencial } \\
\text { beta } \\
\text { (IC95\%) }\end{array}$ & $\begin{array}{l}\text { Exponencial } \\
\text { beta } \\
\text { ajustado } \\
\text { (IC95\%) }\end{array}$ & Beta & $\begin{array}{l}\mathrm{p} \\
\text { valor }\end{array}$ & $\begin{array}{l}\text { Exponencial } \\
\text { beta } \\
\text { (IC95\%) }\end{array}$ & $\begin{array}{l}\text { Exponencial } \\
\text { beta } \\
\text { ajustado } \\
\text { (IC95\%) }\end{array}$ & Beta & $\begin{array}{l}\mathrm{p} \\
\text { valor }\end{array}$ & $\begin{array}{l}\text { Exponencial } \\
\text { beta } \\
\text { (IC95\%) }\end{array}$ & $\begin{array}{l}\text { Exponencial beta } \\
\text { ajustado (IC95\%) }\end{array}$ \\
\hline $\begin{array}{l}\% \text { de contatos examinados } \\
\text { entre os casos novos }\end{array}$ & $-0,010$ & 0,000 & $\begin{array}{l}0,99(0,987- \\
0,992)\end{array}$ & & $-0,011$ & 0,000 & $\begin{array}{l}0,989(0,984 \\
-0,994)\end{array}$ & $\begin{array}{l}0,99(0,986- \\
0,994)\end{array}$ & $-0,007$ & 0,000 & $\begin{array}{l}0,993(0,99 \\
-0,996)\end{array}$ & $1,003(1-1,005)$ \\
\hline $\begin{array}{l}\text { \% de casos novos com } \\
\text { confirmação laboratorial }\end{array}$ & $-0,003$ & 0,034 & $\begin{array}{l}0,997(0,995 \\
-1)\end{array}$ & & $-0,005$ & 0,049 & $\begin{array}{l}0,995(0,99 \\
-1)\end{array}$ & & 0,001 & 0,381 & $\begin{array}{l}1,001 \\
(0,998- \\
1,004)\end{array}$ & \\
\hline $\begin{array}{l}\% \text { de cura entre os casos } \\
\text { novos }\end{array}$ & $-0,017$ & 0,000 & $\begin{array}{l}0,983(0,98- \\
0,986)\end{array}$ & $\begin{array}{l}0,974(0,97- \\
0,978)\end{array}$ & $-0,022$ & 0,000 & $\begin{array}{l}0,979(0,973 \\
-0,984)\end{array}$ & $\begin{array}{l}0,961(0,951- \\
0,97)\end{array}$ & $-0,021$ & 0,000 & $\begin{array}{l}0,979 \\
(0,976- \\
0,983)\end{array}$ & $\begin{array}{l}0,958(0,952- \\
0,963)\end{array}$ \\
\hline $\begin{array}{l}\% \text { de abandono de } \\
\text { tratamento entre os casos } \\
\text { novos }\end{array}$ & 0,000 & 0,855 & $\begin{array}{l}1,000(0,994 \\
-1,007)\end{array}$ & & $-0,020$ & 0,000 & $\begin{array}{l}0,98(0,97- \\
0,994)\end{array}$ & $\begin{array}{l}0,946(0,933- \\
0,96)\end{array}$ & $-0,011$ & 0,001 & $\begin{array}{l}0,989(0,98 \\
-0,998)\end{array}$ & $\begin{array}{l}0,951(0,942- \\
0,96)\end{array}$ \\
\hline $\begin{array}{l}\text { \% de casos novos com } \\
\text { encerramento ignorado ou } \\
\text { transferência }\end{array}$ & $-0,004$ & 0,017 & $\begin{array}{l}0,996(0,993 \\
-1)\end{array}$ & $\begin{array}{l}0,978(0,973 \\
-0,982)\end{array}$ & 0,008 & 0,009 & $\begin{array}{l}1,008(1,001 \\
-1,015)\end{array}$ & $\begin{array}{l}0,97(0,959- \\
0,981)\end{array}$ & $-0,007$ & 0,000 & $\begin{array}{l}0,993 \\
(0,989- \\
0,997)\end{array}$ & $\begin{array}{l}0,961(0,955- \\
0,967)\end{array}$ \\
\hline $\begin{array}{l}\text { \% de casos novos testados } \\
\text { para HIV }\end{array}$ & 0,007 & 0,000 & $\begin{array}{l}1,007(1,005 \\
-1,01)\end{array}$ & $\begin{array}{l}1,003(1,001 \\
-1,006)\end{array}$ & $-0,006$ & 0,002 & $\begin{array}{l}0,994(0,989 \\
-0,998)\end{array}$ & & 0,000 & 0,773 & $\begin{array}{l}1,000 \\
(0,998- \\
1,003)\end{array}$ & \\
\hline $\begin{array}{l}\text { \% de casos novos privados } \\
\text { de liberdade }\end{array}$ & 0,006 & 0,056 & $\begin{array}{l}1,006(1- \\
1,013)\end{array}$ & & 0,016 & 0,064 & $\begin{array}{l}1,016(0,996 \\
-1,043)\end{array}$ & & 0,000 & 0,983 & $\begin{array}{l}1,000 \\
(0,992- \\
1,009)\end{array}$ & \\
\hline $\begin{array}{l}\text { \% de casos novos entre } \\
\text { profissionais de saúde }\end{array}$ & $-0,017$ & 0,095 & $\begin{array}{l}0,983(0,962 \\
-1,016)\end{array}$ & & 0,003 & 0,929 & $\begin{array}{l}1,003(0,954 \\
-1,1)\end{array}$ & & 0,016 & 0,181 & $\begin{array}{l}1,017(0,98 \\
-1,067)\end{array}$ & $\begin{array}{l}1,044(1,008- \\
1,091)\end{array}$ \\
\hline $\begin{array}{l}\text { \% de casos novos na } \\
\text { população em situação de } \\
\text { rua }\end{array}$ & 0,000 & 0,994 & $\begin{array}{l}1,000(0,973 \\
-1,035)\end{array}$ & & 0,013 & 0,570 & $\begin{array}{l}1,014(0,967 \\
-1,087)\end{array}$ & & 0,016 & 0,102 & $\begin{array}{l}1,016 \\
(0,996- \\
1,043)\end{array}$ & 119 \\
\hline
\end{tabular}


Tabela 3. Indicadores epidemiológicos e operacionais associados com a taxa de DALY padronizada por tuberculose segundo cenários socioeconômicos (continuação).

\begin{tabular}{|c|c|c|c|c|c|c|c|c|c|c|c|c|}
\hline \multirow[b]{4}{*}{ Variáveis } & \multicolumn{4}{|c|}{ Cenário 1} & \multicolumn{4}{|c|}{ Cenário 2} & \multicolumn{4}{|c|}{ Cenário 3} \\
\hline & \multicolumn{3}{|c|}{ Modelo bivariado } & \multirow[t]{2}{*}{ Multivariado } & \multicolumn{3}{|c|}{ Modelo bivariado } & \multirow[t]{2}{*}{ Multivariado } & \multicolumn{3}{|c|}{ Modelo bivariado } & \multirow[t]{2}{*}{ Multivariado } \\
\hline & $n=243$ & & & & $\mathrm{n}=661$ & & & & $\mathrm{n}=24$ & & & \\
\hline & Beta & $\begin{array}{l}\mathrm{p} \\
\text { valor }\end{array}$ & $\begin{array}{l}\text { Exponencial } \\
\text { beta } \\
(\mathrm{IC} 95 \%)\end{array}$ & $\begin{array}{l}\text { Exponencial } \\
\text { beta } \\
\text { ajustado } \\
\text { (IC95\%) }\end{array}$ & Beta & $\begin{array}{l}\mathrm{p} \\
\text { valor }\end{array}$ & $\begin{array}{l}\text { Exponencial } \\
\text { beta } \\
(\mathrm{IC} 95 \%)\end{array}$ & $\begin{array}{l}\text { Exponencial } \\
\text { beta } \\
\text { ajustado } \\
\text { (IC95\%) }\end{array}$ & Beta & $\begin{array}{l}\mathrm{p} \\
\text { valor }\end{array}$ & $\begin{array}{l}\text { Exponencial } \\
\text { beta } \\
(\mathrm{IC} 95 \%)\end{array}$ & $\begin{array}{l}\text { Exponencial } \\
\text { beta } \\
\text { ajustado } \\
\text { (IC95\%) }\end{array}$ \\
\hline $\begin{array}{l}\% \text { de casos novos entre } \\
\text { HIV positivos }\end{array}$ & 0,028 & 0,000 & $\begin{array}{l}1,028(1,023 \\
-1,034)\end{array}$ & & 0,032 & 0,000 & $\begin{array}{l}1,033 \\
(1,016- \\
1,052)\end{array}$ & & 0,028 & 0,000 & $\begin{array}{l}1,028 \\
(1,021 \\
1,036)\end{array}$ & \\
\hline $\begin{array}{l}\% \text { de casos novos entre } \\
\text { indígenas }\end{array}$ & 0,004 & 0,257 & $\begin{array}{l}1,004(0,997 \\
-1,013)\end{array}$ & & $-0,014$ & 0,040 & $\begin{array}{l}0,986 \\
(0,975- \\
1,001)\end{array}$ & $\begin{array}{l}0,973(0,954- \\
0,992)\end{array}$ & 0,000 & 0,999 & $\begin{array}{l}1(0,993- \\
1,008)\end{array}$ & \\
\hline $\begin{array}{l}\text { \% de casos novos com } \\
\text { pelo menos uma } \\
\text { vulnerabilidade }\end{array}$ & 0,021 & 0,000 & $\begin{array}{l}1,021(1,017 \\
-1,025)\end{array}$ & $\begin{array}{l}1,01(1,006 \\
-1,014)\end{array}$ & 0,015 & 0,001 & $\begin{array}{l}1,015 \\
(1,004- \\
1,027)\end{array}$ & $\begin{array}{l}1,02(1,005- \\
1,038)\end{array}$ & 0,017 & 0,000 & $\begin{array}{l}1,017 \\
(1,013- \\
1,022)\end{array}$ & \\
\hline $\begin{array}{l}\% \text { de casos de } \\
\text { retratamento }\end{array}$ & 0,007 & 0,024 & $\begin{array}{l}1,007(1- \\
1,013)\end{array}$ & & 0,007 & 0,185 & $\begin{array}{l}1,007 \\
(0,995- \\
1,021)\end{array}$ & & 0,009 & 0,008 & $\begin{array}{l}1,009 \\
(1,002- \\
1,017)\end{array}$ & $\begin{array}{l}1,01(1,002 \\
-1,018)\end{array}$ \\
\hline $\begin{array}{l}\% \text { de exames de cultura } \\
\text { realizados em casos de } \\
\text { retratamento }\end{array}$ & $-0,001$ & 0,431 & $\begin{array}{l}0,999(0,996 \\
-1,002)\end{array}$ & & $-0,003$ & 0,241 & $\begin{array}{l}0,997 \\
(0,991 \\
1,003)\end{array}$ & & 0,003 & 0,152 & $\begin{array}{l}1,003 \\
(0,999- \\
1,007)\end{array}$ & $\begin{array}{l}1,005 \\
(1,001- \\
1,009)\end{array}$ \\
\hline \% de coinfecção TB-HIV & 0,033 & 0,000 & $\begin{array}{l}1,034(1,028 \\
-1,04)\end{array}$ & $\begin{array}{l}1,012(1,004 \\
-1,019)\end{array}$ & 0,039 & 0,000 & $\begin{array}{l}1,04(1,021 \\
-1,061)\end{array}$ & $\begin{array}{l}1,05(1,012- \\
1,085)\end{array}$ & 0,029 & 0,000 & $\begin{array}{l}1,029 \\
(1,023- \\
1,037)\end{array}$ & $\begin{array}{l}1,017(1,01 \\
-1,024)\end{array}$ \\
\hline $\begin{array}{l}\text { Taxa de detecção de casos } \\
\text { de AIDS }\end{array}$ & 0,034 & 0,000 & $\begin{array}{l}1,034(1,028 \\
-1,041)\end{array}$ & & 0,033 & 0,000 & $\begin{array}{l}1,033 \\
(1,014- \\
1,055)\end{array}$ & $\begin{array}{l}0,974(0,949- \\
1,007)\end{array}$ & 0,029 & 0,000 & $\begin{array}{l}1,029 \\
(1,022- \\
1,037)\end{array}$ & \\
\hline
\end{tabular}


Tabela 4. Análise descritiva dos indicadores socioeconômicos, epidemiológicos e operacionais segundo subcenários (cenário 1) de tuberculose, Brasil 2010 e 2014.

\begin{tabular}{|c|c|c|c|c|c|}
\hline \multirow[b]{4}{*}{ Variáveis } & \multicolumn{5}{|l|}{ Cenário 1} \\
\hline & Sem casos de TB & Subcenário 1 & Subcenário 2 & Subcenário 3 & Subcenário 4 \\
\hline & $n=551$ & $n=152$ & $\mathrm{n}=990$ & $n=434$ & $n=309$ \\
\hline & Mediana (Q1 - Q3) & Mediana (Q1 - Q3) & Mediana (Q1 - Q3) & Mediana (Q1 - Q3) & Mediana (Q1 - Q3) \\
\hline Mortalidade infantil & $18,8(15,5-24,75)$ & $17(14,5-21,95)$ & $16,6(13,6-23,28)$ & $21,6(16,72-26,6)$ & $23,1(17,3-27,2)$ \\
\hline Taxa de analfabetismo & $17,83(12,48-26,76)$ & $11,19(8,235-22,88)$ & $11,58(6,652-22,59)$ & $21,32(12,33-28,71)$ & $23,74(12,68-30,09)$ \\
\hline$\%$ de extremamente pobres (PIND) & $12,24(3,38-21,94)$ & $3,815(1,61-19,8)$ & $4,84(1,54-17,53)$ & $16,18(4,765-26,14)$ & $17,67(5,27-27,08)$ \\
\hline \% de vulneráveis à pobreza (PPOB) & $55,37(34,78-66,63)$ & $33,78(23,72-65,24)$ & $38,64(22,37-62,64)$ & $62,66(39,7-71,39)$ & $64,41(41,44-71,41)$ \\
\hline Índice de GINI & $0,49(0,45-0,53)$ & $0,49(0,45-0,54)$ & $0,51(0,47-0,55)$ & $0,52(0,48-0,56)$ & $0,52(0,48-0,55)$ \\
\hline $\begin{array}{l}\text { Índice de Desenvolvimento Humano } \\
\text { Municipal }\end{array}$ & $0,633(0,591-0,686)$ & $0,683(0,603-0,719)$ & $0,686(0,615-0,738)$ & $0,615(0,579-0,676)$ & $0,605(0,573-0,666)$ \\
\hline $\begin{array}{l}\text { Índice de Desenvolvimento Humano } \\
\text { Municipal - Educação }\end{array}$ & $0,533(0,479-0,592)$ & $0,589(0,494-0,646)$ & $0,592(0,515-0,666)$ & $0,517(0,461-0,577)$ & $0,507(0,456-0,571)$ \\
\hline $\begin{array}{l}\text { Índice de Desenvolvimento Humano } \\
\text { Municipal - Renda }\end{array}$ & $0,604(0,563-0,667)$ & $0,662(0,577-0,702)$ & $0,671(0,587-0,721)$ & $0,59(0,547-0,665)$ & $0,579(0,543-0,653)$ \\
\hline $\begin{array}{l}\text { Renda média domiciliar per capita } \\
\text { (RPDC) }\end{array}$ & $343,7(266-508,2)$ & $490,2(288,7-632,6)$ & $519,9(307,9-709,1)$ & $314,8(241,2-502,6)$ & $293(234,4-466,7)$ \\
\hline $\begin{array}{l}\text { \% de vulneráveis à pobreza que } \\
\text { gastam mais de uma hora até o } \\
\text { trabalho }\end{array}$ & $1,12(0,52-2,06)$ & $1,06(0,51-2,047)$ & $0,945(0,44-1,73)$ & $1,585(0,84-2,72)$ & $1,6(0,84-2,54)$ \\
\hline $\begin{array}{l}\text { \% da população que vive em } \\
\text { domicílios com densidade superior } \\
\text { a } 2 \text { pessoas por dormitório }\end{array}$ & $23,63(17,29-31)$ & $25,42(18,82-35,23)$ & $26,26(19,95-34,32)$ & $30,77(22,22-39,38)$ & $29,56(22,77-35,73)$ \\
\hline Taxa de desocupação - 18 ou mais & $6,85(5,945-7,92)$ & $6,535(5,948-7,755)$ & $7,145(6,16-8,32)$ & $7,075(6,18-8,34)$ & $7,43(6,34-8,54)$ \\
\hline Taxa de desemprego & $7(6,11-8,13)$ & $6,88(6,088-8,172)$ & $7,315(6,35-8,47)$ & $7,17(6,32-8,4)$ & $7,5(6,28-8,83)$ \\
\hline
\end{tabular}


Tabela 4. Análise descritiva dos indicadores socioeconômicos, epidemiológicos e operacionais segundo subcenários (cenário 1) de tuberculose, Brasil 2010 e 2014 (Continuação).

\begin{tabular}{|c|c|c|c|c|c|}
\hline \multirow[b]{4}{*}{ Variáveis } & \multicolumn{5}{|l|}{ Cenário 1} \\
\hline & Sem casos de TB & Subcenário 1 & Subcenário 2 & Subcenário 3 & Subcenário 4 \\
\hline & $\mathrm{n}=551$ & $n=152$ & $n=990$ & $n=434$ & $n=309$ \\
\hline & Mediana (Q1 - Q3) & Mediana (Q1 - Q3) & Mediana (Q1 - Q3) & Mediana (Q1 - Q3) & Mediana (Q1 - Q3) \\
\hline Produto Interno Bruto per capita & $6801(4650-10870)$ & $9785(5451-13900)$ & $10110(5641-17300)$ & $5497(4134-10090)$ & $5254(4138-10190)$ \\
\hline $\begin{array}{l}\% \text { de contatos examinados entre os } \\
\text { casos novos }\end{array}$ & $0(0-0)$ & $50(0-83,65)$ & $73,33(50-100)$ & $66,67(33,33-100)$ & $33,33(0-60)$ \\
\hline $\begin{array}{l}\% \text { de casos novos com confirmação } \\
\text { laboratorial }\end{array}$ & $0(0-0)$ & $75(42,14-100)$ & $65,59(50-83,33)$ & $60,99(42,6-91,48)$ & $50(16,67-100)$ \\
\hline$\%$ de cura entre os casos novos & $0(0-0)$ & $77,78(38,93-100)$ & $85,2(71,43-100)$ & $83,33(66,67-100)$ & $0(0-33,33)$ \\
\hline $\begin{array}{l}\% \text { de abandono de tratamento entre } \\
\text { os casos novos }\end{array}$ & $0(0-0)$ & $0(0-2,587)$ & $0(0-8,333)$ & $0(0-5,449)$ & $0(0-0)$ \\
\hline Taxa de detecção de casos de AIDS & $0(0-0)$ & $27,21(0-50)$ & $0(0-9,091)$ & $0(0-0)$ & $0(0-0)$ \\
\hline $\begin{array}{l}\% \text { de casos novos privados de } \\
\text { liberdade }\end{array}$ & $0(0-0)$ & $0(0-20)$ & $0(0-0)$ & $0(0-0)$ & $0(0-0)$ \\
\hline $\begin{array}{l}\% \text { de casos novos com pelo menos } \\
\text { uma vulnerabilidade }\end{array}$ & $0(0-0)$ & $79,13(50-100)$ & $0(0-14,29)$ & $0(0-0)$ & $0(0-0)$ \\
\hline$\%$ de casos de retratamento & $0(0-0)$ & $0(0-20)$ & $6,191(0-16,67)$ & $0(0-12,96)$ & $0(0-10)$ \\
\hline \% de casos novos testados para HIV & $0(0-0)$ & $100(78,75-100)$ & $98,66(80-100)$ & $33,33(0-50)$ & $50(0-80)$ \\
\hline $\begin{array}{l}\text { \% de casos novos com } \\
\text { encerramento ignorado ou } \\
\text { transferência }\end{array}$ & $0(0-0)$ & $0(0-10,13)$ & $0(0-6,667)$ & $0(0-9,919)$ & $50(33,33-100)$ \\
\hline \% de coinfecção TB-HIV & $0(0-0)$ & $33,33(3,503-50)$ & $0(0-10)$ & $0(0-0)$ & $0(0-0)$ \\
\hline Taxa de DALY observada & $728,4(491,3-826,5)$ & $5,64(2,49-66,86)$ & $4,4(2,329-45,67)$ & $3,422(2,04-7,312)$ & $2,834(1,738-5,621)$ \\
\hline Taxa de DALY padronizada & $750,7(473,3-928)$ & $6,198(2,765-52,86)$ & $4,433(2,359-46,7)$ & $3,794(2,118-8,099)$ & $2,891(1,786-5,849)$ \\
\hline
\end{tabular}




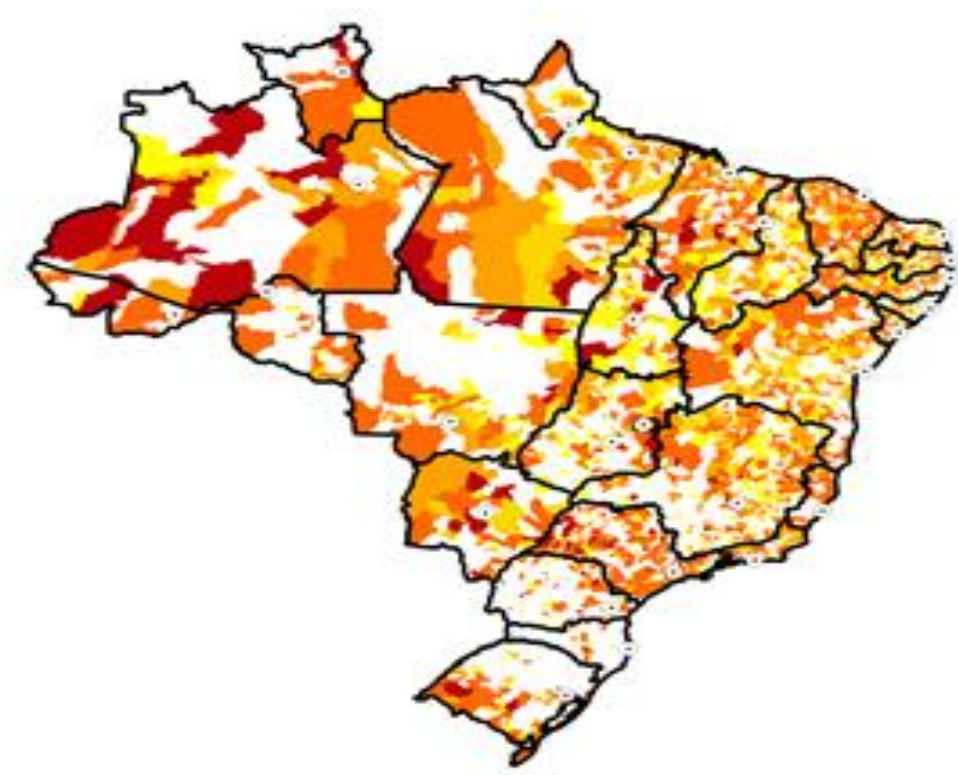

(a)

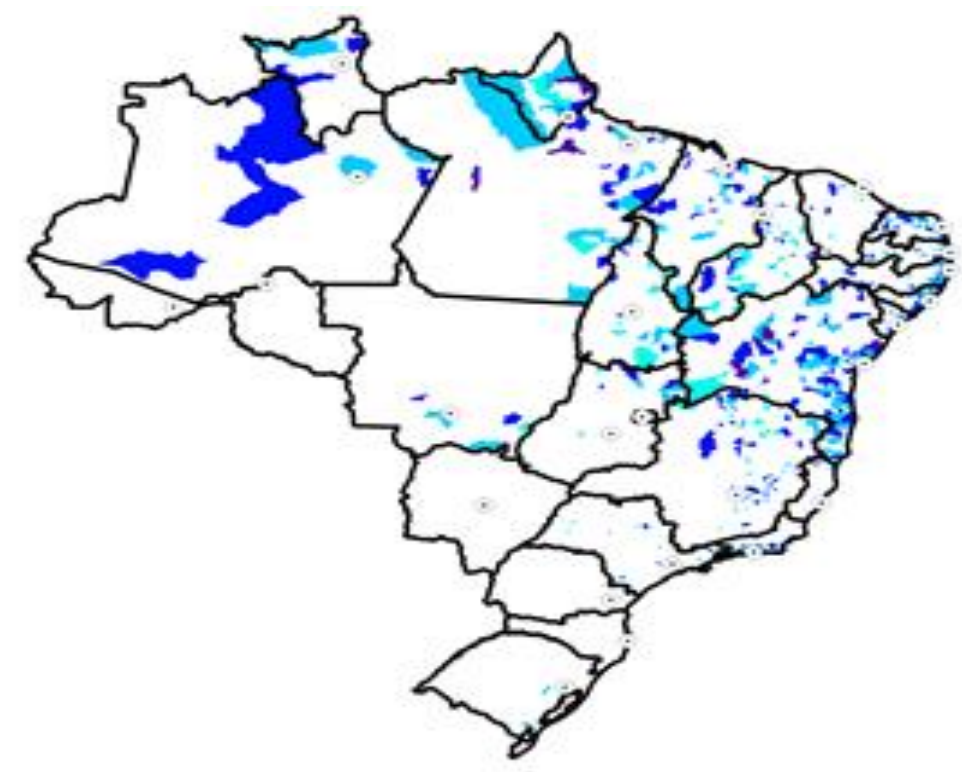

(b)
Legenda

DALY CLUSTER MUNI

\section{- Capitais}

\section{$\square$ Estados}

\section{Cluster}

Cluster socio 1 , cluster tb 1

Cluster socio 1 , cluster tb 2

Cluster socio 1, duster tb 3

Cluster socio 1 , cluster tb 4

Cluster socio 1, sem casos

Cluster socio 2 , cluster tb 1

Cluster socio 2, cluster th 2

Cluster socio 2, duster tb 3

Cluster socio 2, sem casos

Cluster socio 3, cluster tb 1

Cluster socio 3 , duster th 2

Cluster socio 3, cluster tb 3

Cluster socio 3 , duster th 4

Cluster socio 3, sem casos

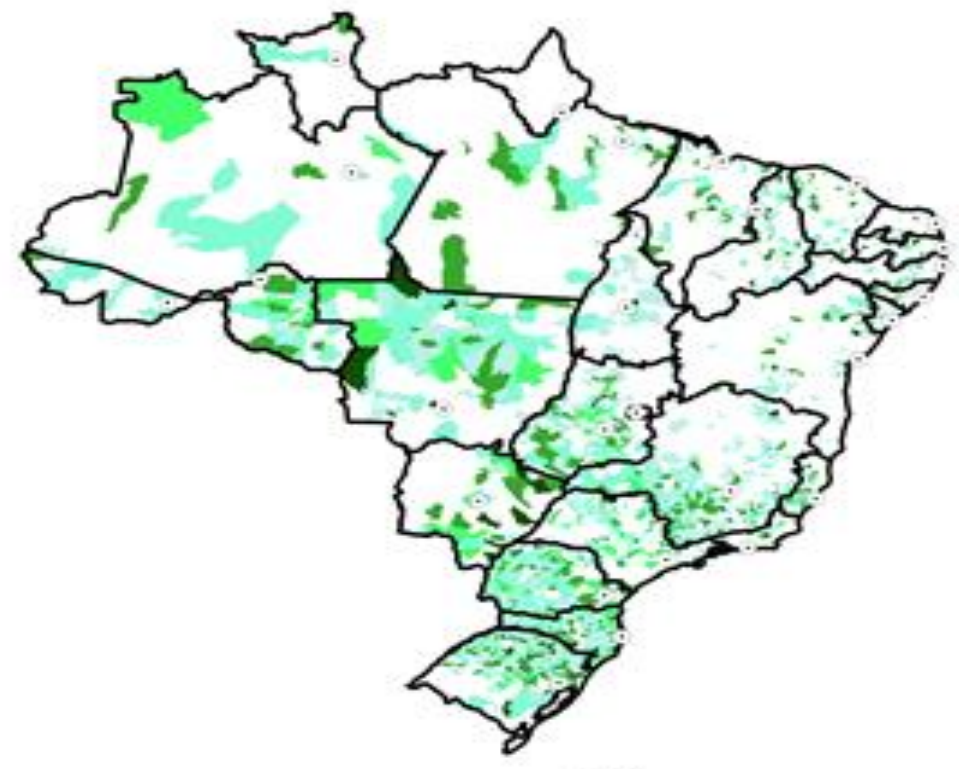

(c)

Fig. 3. Municípios de acordo com os subcenários dos cenários 1(a), 2(b) e 3(c), Brasil, 2014. 
Tabela 5. Análise descritiva dos indicadores socioeconômicos, epidemiológicos e operacionais segundo subcenários (cenário 2 ) de tuberculose, Brasil 2010 e 2014.

\begin{tabular}{|c|c|c|c|c|}
\hline \multirow[b]{4}{*}{ Variáveis } & \multicolumn{4}{|l|}{ Cenário 2} \\
\hline & Sem casos de TB & Subcenário 1 & Subcenário 2 & Subcenário 3 \\
\hline & $n=128$ & $\mathrm{n}=43$ & $n=262$ & $n=228$ \\
\hline & Mediana (Q1 - Q3) & Mediana (Q1 - Q3) & Mediana (Q1 - Q3) & Mediana (Q1 - Q3) \\
\hline Mortalidade infantil & $24,7(20,05-28,83)$ & $23,7(19,9-29,2)$ & $23,25(18,95-27,98)$ & $22,55(17,85-27,02)$ \\
\hline Taxa de analfabetismo & $25,66(20-29,48)$ & $24,77(19,88-29,66)$ & $22,8(15,88-27,99)$ & $21,15(11,53-26,54)$ \\
\hline \% de extremamente pobres (PIND) & $19,68(14,09-29,74)$ & $20,03(12,13-27,63)$ & $16,26(9,515-24,32)$ & $13,72(8,657-20,55)$ \\
\hline \% de vulneráveis à pobreza (PPOB) & $67,82(60,28-71,81)$ & $67,85(60-73,33)$ & $65,19(54,59-71,32)$ & $62,16(49,26-68,25)$ \\
\hline Índice de GINI & $0,51(0,48-0,55)$ & $0,52(0,49-0,55)$ & $0,52(0,48-0,55)$ & $0,52(0,48-0,55)$ \\
\hline $\begin{array}{l}\text { Índice de Desenvolvimento Humano } \\
\text { Municipal }\end{array}$ & $0,596(0,57-0,616)$ & $0,595(0,57-0,636)$ & $0,606(0,572-0,645)$ & $0,619(0,589-0,665)$ \\
\hline $\begin{array}{l}\text { Índice de Desenvolvimento Humano } \\
\text { Municipal - Educação }\end{array}$ & $0,496(0,455-0,532)$ & $0,492(0,452-0,538)$ & $0,506(0,459-0,553)$ & $0,524(0,477-0,581)$ \\
\hline $\begin{array}{l}\text { Índice de Desenvolvimento Humano } \\
\text { Municipal - Renda }\end{array}$ & $0,562(0,537-0,585)$ & $0,569(0,539-0,611)$ & $0,577(0,546-0,626)$ & $0,592(0,563-0,641)$ \\
\hline Renda média domiciliar per capita (RPDC) & $263,7(225,3-304,9)$ & $276,1(228,4-358,5)$ & $289,6(238,6-393,1)$ & $318,9(265,7-433)$ \\
\hline $\begin{array}{l}\text { \% de vulneráveis à pobreza que gastam } \\
\text { mais de uma hora até o trabalho }\end{array}$ & $1,725(0,93-3,242)$ & $1,78(0,975-2,755)$ & $1,88(1,07-2,998)$ & $2,4(1,388-3,668)$ \\
\hline $\begin{array}{l}\text { \% da população que vive em domicílios } \\
\text { com densidade superior a } 2 \text { pessoas por } \\
\text { dormitório }\end{array}$ & $30,55(24,45-37,33)$ & $30,71(24,76-37,84)$ & $32,25(27,29-38,9)$ & $34,01(28,32-40,34)$ \\
\hline Taxa de desocupação - 18 ou mais & $12,44(11,3-14,33)$ & $12,86(11,44-14,5)$ & $12,17(11,06-14,38)$ & $12,58(11,06-14,71)$ \\
\hline Taxa de desemprego & $12,82(11,36-14,82)$ & $12,51(11,44-14,52)$ & $12,25(11,19-14,33)$ & $12,83(11,26-14,97)$ \\
\hline Produto Interno Bruto per capita & $5013(4066-6706)$ & $5640(4336-10030)$ & $6049(4433-10030)$ & $7160(4913-11300)$ \\
\hline
\end{tabular}


Tabela 5. Análise descritiva dos indicadores socioeconômicos, epidemiológicos e operacionais segundo subcenários (cenário 2 ) de tuberculose, Brasil 2010 e 2014 (Continuação).

\begin{tabular}{|c|c|c|c|c|}
\hline \multirow[b]{4}{*}{ Variáveis } & \multicolumn{4}{|l|}{ Cenário 2} \\
\hline & Sem casos de TB & Subcenário 1 & Subcenário 2 & Subcenário 3 \\
\hline & $n=128$ & $n=43$ & $n=262$ & $n=228$ \\
\hline & Mediana (Q1 - Q3) & Mediana (Q1 - Q3) & Mediana (Q1 - Q3) & Mediana (Q1 - Q3) \\
\hline $\begin{array}{l}\% \text { de contatos examinados entre os } \\
\text { casos novos }\end{array}$ & $0(0-0)$ & $12,5(0-50)$ & $74,46(33,33-100)$ & $50(32,59-71,43)$ \\
\hline $\begin{array}{l}\text { \% de casos novos com confirmação } \\
\text { laboratorial }\end{array}$ & $0(0-0)$ & $50(12,5-75)$ & $66,48(40-100)$ & $54,55(42,86-72,8)$ \\
\hline$\%$ de cura entre os casos novos & $0(0-0)$ & $0(0-16,25)$ & $100(80-100)$ & $60(50-66,67)$ \\
\hline $\begin{array}{l}\% \text { de abandono de tratamento entre os } \\
\text { casos novos }\end{array}$ & $0(0-0)$ & $0(0-0)$ & $0(0-0)$ & $6,236(0-14,91)$ \\
\hline Taxa de detecção de casos de AIDS & $0(0-0)$ & $0(0-0)$ & $0(0-2,604)$ & $6,95(0-13,99)$ \\
\hline$\%$ de casos novos privados de liberdade & $0(0-0)$ & $0(0-0)$ & $0(0-0)$ & $0(0-0)$ \\
\hline $\begin{array}{l}\% \text { de casos novos com pelo menos uma } \\
\text { vulnerabilidade }\end{array}$ & $0(0-0)$ & $0(0-0)$ & $0(0-7,555)$ & $10(0-18,18)$ \\
\hline$\%$ de casos de retratamento & $0(0-0)$ & $0(0-14,75)$ & $0(0-14,29)$ & $10(0-18,18)$ \\
\hline \% de casos novos testados para HIV & $0(0-0)$ & $40(0-77,5)$ & $74,34(33,33-100)$ & $66,54(44,05-85,71)$ \\
\hline $\begin{array}{l}\% \text { de casos novos com encerramento } \\
\text { ignorado ou transferência }\end{array}$ & $0(0-0)$ & $100(66,67-100)$ & $0(0-4,97)$ & $14,31(0-25,42)$ \\
\hline \% de coinfecção TB-HIV & $0(0-0)$ & $0(0-0)$ & $0(0-4,496)$ & $8,333(0-15,13)$ \\
\hline Taxa de DALY observada & $807,7(738-1152)$ & $4,439(2,049-7,088)$ & $4,023(2,505-10,24)$ & $9,712(3,876-144,9)$ \\
\hline Taxa de DALY padronizada & $1006(862,8-1219)$ & $5,356(2,193-6,762)$ & $4,333(2,673-10,97)$ & $9,752(4,194-155,3)$ \\
\hline
\end{tabular}


Tabela 6. Análise descritiva dos indicadores socioeconômicos, epidemiológicos e operacionais segundo subcenários (cenário 3) de tuberculose, Brasil 2010 e 2014.

\begin{tabular}{|c|c|c|c|c|c|}
\hline \multirow[b]{4}{*}{ Variáveis } & \multicolumn{5}{|l|}{ Cenário 3} \\
\hline & Sem casos de TB & Subcenário 1 & Subcenário 2 & Subcenário 3 & Subcenário 4 \\
\hline & $n=1023$ & $n=135$ & $n=337$ & $\mathrm{n}=169$ & $\mathrm{n}=804$ \\
\hline & Mediana (Q1 - Q3) & Mediana (Q1 - Q3) & Mediana (Q1 - Q3) & Mediana (Q1 - Q3) & Mediana (Q1 - Q3) \\
\hline Mortalidade infantil & $14,5(12,7-17,65)$ & $16,3(13,1-26,15)$ & $15,1(12,8-20,2)$ & $13,1(11,6-15,1)$ & $15,1(12,9-18,72)$ \\
\hline Taxa de analfabetismo & $10,39(7,165-14,6)$ & $12,72(8,215-27,94)$ & $10,07(6,63-16,95)$ & $6,38(4,16-9,44)$ & $10,58(7,26-17,51)$ \\
\hline \% de extremamente pobres (PIND) & $2,99(1,055-8,215)$ & $5,41(1,965-20,69)$ & $2,5(1,07-13,02)$ & $0,96(0,55-2,89)$ & $2,71(0,97-10,91)$ \\
\hline \% de vulneráveis à pobreza (PPOB) & $30,06(18,51-45,34)$ & $37,36(23,44-64,86)$ & $30,43(18,68-55,8)$ & $17,2(12,19-26,58)$ & $29,34(18,25-53,02)$ \\
\hline Índice de GINI & $0,46(0,42-0,5)$ & $0,48(0,43-0,53)$ & $0,48(0,44-0,52)$ & $0,48(0,44-0,52)$ & $0,47(0,43-0,52)$ \\
\hline $\begin{array}{l}\text { Índice de Desenvolvimento Humano } \\
\text { Municipal }\end{array}$ & $0,694(0,65-0,725)$ & $0,665(0,597-0,705)$ & $0,691(0,617-0,727)$ & $0,733(0,7-0,768)$ & $0,69(0,629-0,728)$ \\
\hline $\begin{array}{l}\text { Índice de Desenvolvimento Humano } \\
\text { Municipal - Educação }\end{array}$ & $0,585(0,524-0,636)$ & $0,551(0,472-0,598)$ & $0,579(0,495-0,632)$ & $0,643(0,593-0,697)$ & $0,582(0,505-0,638)$ \\
\hline $\begin{array}{l}\text { Índice de Desenvolvimento Humano } \\
\text { Municipal - Renda }\end{array}$ & $0,684(0,639-0,72)$ & $0,657(0,564-0,709)$ & $0,686(0,604-0,728)$ & $0,732(0,699-0,766)$ & $0,686(0,621-0,723)$ \\
\hline $\begin{array}{l}\text { Renda média domiciliar per capita } \\
\text { (RPDC) }\end{array}$ & $563,9(425,6-706,8)$ & $476,2(267,2-661,2)$ & $571,6(343,7-741,5)$ & $760,6(618,8-937,3)$ & $572,3(382,2-717,7)$ \\
\hline $\begin{array}{l}\text { \% de vulneráveis à pobreza que } \\
\text { gastam mais de uma hora até o } \\
\text { trabalho }\end{array}$ & $0,43(0,12-1,04)$ & $0,78(0,235-1,725)$ & $0,49(0,2-1,22)$ & $0,29(0,11-0,59)$ & $0,495(0,17-1,142)$ \\
\hline $\begin{array}{l}\text { \% da população que vive em } \\
\text { domicílios com densidade superior a } \\
2 \text { pessoas por dormitório }\end{array}$ & $14,29(9,53-20,54)$ & $17,75(11,8-32,16)$ & $18,03(12,49-28,04)$ & $17,92(13,9-24,74)$ & $17,96(12,71-25,6)$ \\
\hline Taxa de desocupação - 18 ou mais & $2,88(1,605-4,075)$ & $3,36(1,8-4,36)$ & $3,74(2,74-4,52)$ & $4,26(3,41-4,84)$ & $3,66(2,588-4,53)$ \\
\hline Taxa de desemprego & $3,04(1,68-4,18)$ & $3,55(1,765-4,515)$ & $3,895(2,838-4,722)$ & $4,5(3,64-5,05)$ & $3,77(2,72-4,682)$ \\
\hline Produto Interno Bruto per capita & $11650(7589-16370)$ & $10400(5047-15560)$ & $10580(6094-16060)$ & $16210(11860-23960)$ & $11180(6842-16880)$ \\
\hline
\end{tabular}


Tabela 6. Análise descritiva dos indicadores socioeconômicos, epidemiológicos e operacionais segundo subcenários (cenário 3 ) de tuberculose, Brasil 2010 e 2014 (Continuação).

\begin{tabular}{|c|c|c|c|c|c|}
\hline \multirow[b]{4}{*}{ Variáveis } & \multicolumn{5}{|l|}{ Cenário 3} \\
\hline & Sem casos de TB & Subcenário 1 & Subcenário 2 & Subcenário 3 & Subcenário 4 \\
\hline & $\mathrm{n}=1023$ & $\mathrm{n}=135$ & $\mathrm{n}=337$ & $\mathrm{n}=169$ & $\mathrm{n}=804$ \\
\hline & Mediana (Q1 - Q3) & Mediana (Q1 - Q3) & Mediana (Q1 - Q3) & Mediana (Q1 - Q3) & Mediana (Q1 - Q3) \\
\hline $\begin{array}{l}\text { \% de contatos examinados entre } \\
\text { os casos novos }\end{array}$ & $0(0-0)$ & $0(0-50)$ & $50(14,29-83,33)$ & $69,33(50-85,71)$ & $100(50-100)$ \\
\hline $\begin{array}{l}\text { \% de casos novos com } \\
\text { confirmação laboratorial }\end{array}$ & $0(0-0)$ & $40(0-100)$ & $50(22,22-77,78)$ & $61,11(50-80)$ & $57,14(0-100)$ \\
\hline$\%$ de cura entre os casos novos & $0(0-0)$ & $0(0-0)$ & $50(16,67-50)$ & $76,6(66,67-93,75)$ & $100(100-100)$ \\
\hline $\begin{array}{l}\% \text { de abandono de tratamento } \\
\text { entre os casos novos }\end{array}$ & $0(0-0)$ & $0(0-0)$ & $0(0-25)$ & $2,778(0-12,23)$ & $0(0-0)$ \\
\hline $\begin{array}{l}\text { Taxa de detecção de casos de } \\
\text { AIDS }\end{array}$ & $0(0-0)$ & $0(0-0)$ & $0(0-10)$ & $7,407(0-16,67)$ & $0(0-0)$ \\
\hline $\begin{array}{l}\% \text { de casos novos privados de } \\
\text { liberdade }\end{array}$ & $0(0-0)$ & $0(0-0)$ & $0(0-0)$ & $0(0-4)$ & $0(0-0)$ \\
\hline $\begin{array}{l}\% \text { de casos novos com pelo } \\
\text { menos uma vulnerabilidade }\end{array}$ & $0(0-0)$ & $0(0-0)$ & $0(0-20)$ & $12,73(0-26,95)$ & $0(0-0)$ \\
\hline$\%$ de casos de retratamento & $0(0-0)$ & $0(0-0)$ & $0(0-5,556)$ & $18,97(11,9-26,67)$ & $0(0-0)$ \\
\hline $\begin{array}{l}\% \text { de casos novos testados para } \\
\text { HIV }\end{array}$ & $0(0-0)$ & $57,14(0-100)$ & $75(50-100)$ & $93,75(77,27-100)$ & $100(50-100)$ \\
\hline $\begin{array}{l}\text { \% de casos novos com } \\
\text { encerramento ignorado ou } \\
\text { transferência }\end{array}$ & $0(0-0)$ & $100(100-100)$ & $0(0-33,33)$ & $0(0-8,333)$ & $0(0-0)$ \\
\hline \% de coinfecção TB-HIV & $0(0-0)$ & $0(0-0)$ & $0(0-10)$ & $9,524(0-17,39)$ & $0(0-0)$ \\
\hline Taxa de DALY observada & $248,8(208,2-502,3)$ & $3,167(1,637-4,761)$ & $3,902(2,182-16,53)$ & $8,234(2,751-81,82)$ & $3,039(1,805-5,546)$ \\
\hline Taxa de DALY padronizada & $216,8(111,2-469)$ & $2,834(1,66-4,406)$ & $3,715(2,081-14,46)$ & $7,834(2,677-81,68)$ & $2,914(1,705-5,341)$ \\
\hline
\end{tabular}




\section{REFERÊNCIAS BIBLIOGRÁFICAS}

1. World Health Organization (WHO). Global Tuberculosis Report 2015. Geneva: World Health Organization, 2015.

2. Brasil. Ministério da Saúde. Secretaria de Vigilância em Saúde. Boletim epidemiológico: perspectivas brasileiras para o fim da tuberculose como problema de saúde pública. Brasília: Ministério da Saúde, 2016.

3. Brasil. Ministério da Saúde. Secretaria de Vigilância em Saúde. Panorama da Tuberculose no Brasil: A mortalidade em números. Brasília: Ministério da Saúde, 2016.

4. United Nations. Transforming our world: the 2030 agenda for sustainable development. New York: United Nations, 2015.

5. Murray CJL. Quantifying the burden of disease: the technical basis for disability-adjusted life years. Bulletin of the World Health Organization 1994; 72: 429.

6. Murray CJL, et al. The global burden of disease in 1990: summary results, sensitivity analysis and future directions. Bulletin of the World Health Organization 1994; 72: 495-509.

7. Camargo Junior KR, Coeli CM. Reclink: aplicativo para o relacionamento de bases de dados, implementando o método probabilistic record linkage. Cad de Saúde Pública 2000; 16: 439-447.

8. Global Burden of Disease Study 2015 (GBD 2015) Data Resources (http://ghdx.healthdata.org/gbd-2015). Accessed December 2016.

9. Gledovic Z, et al. Burden of tuberculosis in Serbia. American journal of infection control 2006; 34: 676-679.

10. Pasipanodya JG, et al. Pulmonary impairment after tuberculosis and its contribution to TB burden. BMC Public Health 2010; 10: 259.

11. Chen A, et al. The evolution of the disability-adjusted life year (DALY). Socio-Economic Planning Sciences 2015; 49: 10-15.

12. Coates A, Ng AY. Learning feature representations with K-means. Lect Notes Comput Sci (including Subser Lect Notes Artif Intell Lect Notes Bioinformatics) 2012; 561-580. 
13. Lobo AP, et al. Trend and prospect of tuberculosis mortality rate in Brazil: contributions for the National Plan to End Tuberculosis. The International Journal of Tuberculosis and Lung Disease - abstract book 2016; 10: S238.

14. Stamm C. A população urbana e a difusão das cidades de porte médio no Brasil. Interações (Campo Grande), 2012; 14: 251-65.

15. Ribeiro R. Juventude(s): desocupação, pobreza e escolaridade. Nova Econ. 2009; 19: 475-506.

16. Rasella $\mathbf{D}$, et al. Effect of a conditional cash transfer programme on childhood mortality: a nationwide analysis of Brazilian municipalities. The Lancet; 382: 57-64.

17. Torrens AW, et al. Effectiveness of a conditional cash transfer programme on TB cure rate: a retrospective cohort study in Brazil. Trans $R$ Soc Trop Med Hyg 2016; 110: 199-206.

18. Reidpath DD. Infant mortality rate as an indicator of population health. $J$ Epidemiol Community Heal 2003; 57: 344-346.

19. Lindoso JAL, Lindoso AABP. Neglected tropical diseases in Brazil. Rev Inst Med Trop Sao Paulo 2009; 51: 247-253.

20. Gubert MB, et al. Estimates of severe food insecurity in Brazilian municipalities. Cad saude publica / Minist da Saude, Fund Oswaldo Cruz, Esc Nac Saude Publica 2010; 26: 1595-1605.

21. Bühler HF, et al. Análise espacial de indicadores integrados de saúde e ambiente para morbimortalidade por diarreia infantil no Brasil, 2010. Cad Saúde Pública 2014; 30: 1921-1934.

22. Bartholomay $\mathbf{P}$, et al. Quality of tuberculosis care at different levels of health care in Brazil in 2013. Pan Am J Public Heal 2016; 39 :3-11.

23. Yamamura $\mathbf{M}$, et al. Tuberculose e iniquidade social em saúde: uma análise ecológica utilizando técnicas estatísticas multivariadas. Rev Panam Salud Publica 2014; 35: 270-277.

24. Castro KG. Tuberculosis surveillance: Data for decision-making. Clin Infect Dis. 2007; 44: 1268-1270. 
25. Marcolino ABL, et al. Avaliação do acesso as ações de controle da tuberculose no contexto das equipes de saúde da família de Bayeux PB. Rev Bras Epidemiol. 2009; 12: 144-1457.

26. Paim J, et al. The Brazilian health system: history, advances, and challenges. The Lancet 2011; 377:1778-1797.

27. Lima LD De, et al. Regionalização e acesso à saúde nos estados brasileiros: condicionantes históricos e político-institucionais. Cien Saude Colet. 2012; 17: 2881-2892.

28. Figueiredo TMRM de, et al. Desempenho da atenção básica no controle da tuberculose. Rev Saude Publica 2009; 43: 825-831.

29. Brasil. Ministério da Saúde. Secretaria Executiva. Departamento de Apoio à Descentralização Coordenação de Integração Programática / Ministério da Saúde, Secretaria Executiva, Departamento de Apoio à Descentralização. Regionalização Solidária e Cooperativa Série Pactos pela Saúde 2006, v. 3. Brasília: Ministério da Saúde, 2006.

30. Barbosa IR, et al. Análise da distribuição espacial da tuberculose na região Nordeste do Brasil, 2005-2010. Epidemiol e Serviços Saúde 2013; 22: 687-695

31. Wingfield $\mathbf{T}$, et al. The economic effects of supporting tuberculosisaffected households in Peru. Eur Respir J 2016; 48: 1396-1410.

32. Marlow MA, et al. Tuberculosis DALY-Gap: spatial and quantitative comparison of disease burden across urban slum and non-slum census tracts. J Urban Health 2015; 92: 622-634.

33. Traebert $\mathbf{J}$, et al. The burden of infectious diseases in the Brazilian Southern state of Santa Catarina. J Infect Public Health University for Health Sciences 2016; 9: 181-91.

34. Lim D, et al. Disability-adjusted Life Years (DALYs) for Mental and Substance Use Disorders in the Korean Burden of Disease Study 2012. J Korean Med Sci 2016; 31: S191.

35. Lier A Van, et al. Disease Burden of 32 Infectious Diseases in the Netherlands, 2007-2011. PLoS One 2016; 11: 2007-2011. 
36. Hacking D, Cleary S. Setting priorities in health research using the model proposed by the World Health Organization: development of a quantitative methodology using tuberculosis in South Africa as a worked example. Health Research Policy and Systems 2016; 14: 10.

37. Mathers CD, et al. National burden of disease studies: a practical guide. Global Program on Evidence for Health Policy. Geneva: World Health Organization, 2001.

38. Mokdad AH, et al. Global burden of diseases, injuries, and risk factors for young people's health during 1990 - 2013: a systematic analysis for the Global Burden of Disease Study 2013. The Lancet 2016; 387: 23832401.

39. Selig L, et al. Proposta de vigilância de óbitos por tuberculose em sistemas de informação. Rev Saude Publica 2010; 44: 1072-2008.

40. World Health Organization (WHO). Global strategy and targets for tuberculosis prevention, care and control after 2015. Proceedings of The Sixty-seventh World Health Assembly 2014; Geneva: 2014.

41. Stevens P. Diseases of poverty and the 90/10 gap. Int Policy Netw. 2004; 16. 


\section{CONSIDERAÇÕES FINAIS}

A tuberculose pulmonar (TB) é uma doença infecciosa extremamente antiga que ainda se pauta como um importante problema de saúde pública de grande magnitude no Brasil e no mundo. Com as estratégias Stop TB Partnership, os Objetivos de Desenvolvimento do Milênio e esforços de diferentes organismos internacionais em prol do controle da doença, muitos avanços ocorreram nas duas últimas décadas no nível global e nacional. $O$ Brasil atingiu todas as metas propostas de redução do coeficiente de incidência e diminuição na proporção dos óbitos.

Com as metas desafiadoras propostas pela Organização Mundial da Saúde, com a estratégia End TB e sob a influência dos Objetivos de Desenvolvimento Sustentáveis (ODSs), muitos desafios precisam ser superados. Esses desafios se constituem no desenvolvimento de novas tecnologias e ferramentas e no enfrentamento da pobreza e das vulnerabilidades.

O risco de adoecer e a carga da doença pela TB pulmonar não se distribui igualmente na população brasileira considerando que a doença está ligada às condições de vida e trabalho precárias e a um contexto socioeconômico vulnerável.

Nessas perspectivas, esse trabalho analisou a carga de doença por tuberculose pulmonar nos cenários brasileiros de desigualdades sociais. A partir da análise de indicadores associados à taxa de DALY padronizada e do agrupamento das variáveis segundo similaridades, identificou-se três cenários socioeconômicos. Esses cenários apresentaram diferenças quanto às condições de renda, trabalho e vulnerabilidade. Ao incluir as variáveis epidemiológicas e operacionais nos cenários, observou-se de maneira geral que as operacionais mostraram associação mais plausível com a taxa de DALY padronizada em detrimento das variáveis epidemiológicas. Com a 
inclusão dos indicadores epidemiológicos e operacionais foram identificados dentro do cenário um e três mais cinco subcenários, e no cenário dois, foram obtidos quatro subcenários para a TB. Nesses subcenários, a taxa de DALY padronizada se distribui de forma heterogênea entre os subcenários e naqueles em que há ausência de casos, a taxa chama a atenção por se mostrar bastante elevado.

Os resultados aqui encontrados sugerem que a carga da TB pulmonar se distribui de forma heterogênea nos municípios brasileiros e que as ações de vigilância e controle precisam adereçar as necessidades locais. A extensão territorial do Brasil, a heterogeneidade dos municípios no que diz respeito às condições socioeconômicas, estrutura da oferta de serviços e organização do sistema de vigilância dificulta o processo de regionalização e apontam para a necessidade de um modelo de vigilância à luz da equidade.

A definição de cenários socioeconômicos e operacionais para a TB pulmonar utilizando a estimativa da carga da doença pode fortalecer 0 processo de regionalização e a estruturação da atenção básica para atender as demandas da tuberculose. O DALY como medida de impacto e desigualdade pode ser fundamental para elencar ações e intervenções prioritárias em contextos socioeconômicos fragilizados que sofrem influência dos determinantes sociais.

Recomenda-se que estratégias semelhantes, como essa apresentada para definição de cenários no âmbito das doenças negligenciadas, sejam desenvolvidas nas três esferas de governo. A utilização do DALY para mensurar a carga de doença e as discrepâncias nos estados de saúde é crucial para compreender a realidade e os determinantes sociais em saúde. Dessa maneira, permite-se planejar ações específicas que considerem as particularidades de cada localidade e que de fato sejam efetivas para 0 enfrentamento dos problemas de saúde. 


\section{REFERÊNCIAS BIBLIOGRÁFICAS}

Anand S, Hanson K. Disability-adjusted life years: a critical review. J Health Econ 1997; 16: 685-702.

Brasil. Ministério da Saúde. Secretaria de Vigilância em Saúde. Boletim Epidemiológico: Perspectivas brasileiras para o fim da tuberculose como problema de saúde pública. Brasília: Ministério da Saúde; 2016a.

Brasil. Ministério da Saúde. Secretaria de Vigilância em Saúde. Boletim Epidemiológico: Perspectivas brasileiras para o fim da tuberculose como problema de saúde pública. Brasília: Ministério da Saúde; 2016a.

Brasil. Ministério da Saúde. Secretaria de Vigilância em Saúde. Guia de vigilância em saúde. Guia de vigilância em saúde. Brasília: Ministério da Saúde; 2014.

Brasil. Ministério da Saúde. Secretaria de Vigilância em Saúde. Manual de recomendações para o controle da tuberculose no Brasil; 2011.

Brasil. Ministério da Saúde. Secretaria de Vigilância em Saúde. Panorama da Tuberculose no Brasil: A mortalidade em números. Brasília: Ministério da Saúde; 2016d.

Brasil. Ministério da Saúde. Secretaria de Vigilância em Saúde. Panorama da Tuberculose no Brasil: A mortalidade em números. Brasília: Ministério da Saúde; 2016d.

Brasil. Ministério da Saúde. Secretaria de Vigilância em Saúde. Série histórica do número de casos novos de tuberculose. Brasil, Regiões e Unidades Federadas de residência por ano diagnóstico (1990 a 2015). Brasília: Ministério da Saúde; 2016b. Available from: http://portalsaude.saude.gov.br/images/pdf/2016/junho/27/Casos-novostuberculose-1990-2015-base-MAIO-2016.pdf.

Brasil. Ministério da Saúde. Secretaria de Vigilância em Saúde. Série histórica da Taxa de Incidência de Tuberculose. Brasil, Regiões e Unidades Federadas de residência por ano de diagnóstico (1990 a 2015). Brasília: Ministério da Saúde; 2016c. Available from: http://portalsaude.saude.gov.br/images/pdf/2017/janeiro/03/taxa-incidenciatuberculose-1990-2015-OUTUBRO-2016.pdf.

Brasil. Ministério da Saúde. Secretaria de Vigilância em Saúde. Série Histórica da Taxa de Mortalidade de Tuberculose. Brasil, Regiões e Unidades Federadas de residência por ano de diagnóstico (1990 a 2015). Brasília: Ministério da Saúde; 2016e. Available from: http://portalsaude.saude.gov.br/images/pdf/2017/janeiro/03/taxa-mortalidadetuberculose-1999-2015-OUT-2016.pdf. 
Brasil. Ministério da Saúde. Secretaria de Vigilância em Saúde. Série histórica do número de casos novos de tuberculose. Brasil, Regiões e Unidades Federadas de residência por ano diagnóstico (1990 a 2015). Brasília: Ministério da Saúde; 2016b. Available from: http://portalsaude.saude.gov.br/images/pdf/2016/junho/27/Casos-novostuberculose-1990-2015-base-MAIO-2016.pdf.

Brasil. Ministério da Saúde. Secretaria de Vigilância em Saúde. Série histórica da Taxa de Incidência de Tuberculose. Brasil, Regiões e Unidades Federadas de residência por ano de diagnóstico (1990 a 2015). Brasília: Ministério da Saúde; 2016c. Available from: http://portalsaude.saude.gov.br/images/pdf/2017/janeiro/03/taxa-incidenciatuberculose-1990-2015-OUTUBRO-2016.pdf.

Brasil. Ministério da Saúde. Secretaria de Vigilância em Saúde. Série Histórica da Taxa de Mortalidade de Tuberculose. Brasil, Regiões e Unidades Federadas de residência por ano de diagnóstico (1990 a 2015). Brasília: Ministério da Saúde; 2016e. Available from: http://portalsaude.saude.gov.br/images/pdf/2017/janeiro/03/taxa-mortalidadetuberculose-1999-2015-OUT-2016.pdf.

Brólio R, Lima Filho MT. Tuberculose pulmonar. In: Veronesi R, editor. Doenças infecciosas e parasitárias. 6a ed. Rio de Janeiro, Guanabara Koogan, 1976. p. 317-338.

Camargo Junior KR, Coeli CM. Reclink: aplicativo para o relacionamento de bases de dados, implementando o método probabilistic record linkage. Cad de Saúde Pública 2000; 16: 439-447.

Chen A, Jacobsen $\mathrm{KH}$, Deshmukh AA, Cantor SB. The evolution of the disability-adjusted life year (DALY). Socio-Economic Planning Sciences 2015; 49: 10-15.

Commission on Social Determinants of Health (CSDH). Achieving Health Equity: from root causes to fair outcomes. Geneva: World Health Organization; 2007.

Costa AJL, Kale PL, Vermelho LL. Indicadores de Saude. In: Roberto Medronho, editor. Epidemiologia. São Paulo: Atheneu; 2009.

Dahlgren G, Whitehead M. European strategies for tackling social inequities in health: Levelling up part 2. Copenhagen: World Health Organization; 2006.

Dean HD, Fenton KA. Addressing. Social Determinants of Health in the Prevention and Control of HIV/AIDS, Viral Hepatitis, Sexually Transmitted Infections, and Tuberculosis. Public Health Rep. 2010; 4:1-5.

Dempsey M. Decline in tuberculosis. The death rate fails to tell the entire story. American review of tuberculosis 1947; 56: 157-164.

Devleesschauwer B, Havelaar AH, De Noordhout CM, Haagsma JA, Praet N, Dorny P, Duchateau L, Torgerson PR, Van Oyen H, Speybroeck N. 
Calculating disability-adjusted life years to quantify burden of disease. International journal of public health 2014; 59:565.

Duarte EC, Schneider MC, Paes-Sousa R, Ramalho WM, Sardinha LMV, Silva JB, Castillo-Salgado JC. Epidemiologia das desigualdades em saúde no Brasil: um estudo exploratório. Brasília: Organização Pan-Americana da Saúde, Organização Mundial da Saúde, Fundação Nacional de Saúde; 2002.

Farga V, Caminero JA. Tuberculosis. 3a ed. Villasante MPM, editor. Santiago de Chile: Mediterráneo; 2011.

Frazier MS, Drzymkowski JW. Diseases and Conditions of the Respiratory System. In: Essentials of Human Diseases and Conditions. 5a ed. Missouri: Elsevier; 2013.

GBD 2015 Mortality and Causes of Death Collaborators. Global, regional, and national life expectancy, all-cause mortality, and cause- specific mortality for 249 causes of death, 1980-2015: a systematic analysis for the Global Burden of Disease Study 2015. The Lancet 2016b; 388: 459-544.

Gledovic Z, Vlajinac H, Pekmezovic T, Grujicic-Sipetic S, Grgurevic A, Pesut D. Burden of tuberculosis in Serbia. American journal of infection control 2006; 34: 676-679.

Global Burden of Disease 2013 (GBD 2013), HALE Collaborators. Global, regional, and national disability-adjusted life years (DALYs) for 306 diseases and injuries and healthy life expectancy (HALE) for 188 countries, 19902013: quantifying the epidemiological transition. The Lancet 2015; 386: $2145-$ 2191.

Global Burden of Disease Study 2015. Global Burden of Disease Study 2015 (GBD 2015) Reference Life Table. Seattle: Institute for Health Metrics and Evaluation (IHME); 2016a.

Global Burden of Disease Study 2015. Global Burden of Disease Study 2015 (GBD 2015) Disability Weights. Seattle: Institute for Health Metrics and Evaluation (IHME); 2016b.

Hijjar MA, Campos HS, Feitosa JV. Tuberculose. In: Coura JR, editor. Dinâmica das doenças infecciosas e parasitárias. Rio de Janeiro: Guanabara-Koogan; 2005.

Institute for Health Metrics and Evaluation [Internet]. Seattle: University of Washington. Global Burden of Disease Study 2015 (GBD 2015) Data Resources; 2017 [acesso em Dec 2016]. Disponível em: http://ghdx.healthdata.org/gbd-2015.

Kawachi I, Subramanian SV, Almeida-Filho N. A glossary for health inequalities. J Epidemiol Community Health. 2002; 56:647-52.

Lobo AP, Pelissari DM, Quijano FAD, Dantas CO, Andrade KB, Codenotti S, Araújo WN. Trend and prospect of tuberculosis mortality rate in Brazil: 
contributions for the National Plan to End Tuberculosis. The International Journal of Tuberculosis and Lung Disease - abstract book 2016; 10: S238.

Lönnroth K, Jaramillo E, Williams BG, Dye C, Raviglione M. Drivers of tuberculosis epidemics: The role of risk factors and social determinants. Soc Sci Med. 2009; 68: 2240-6.

Lopez AD, Mathers CD, Ezzati M, Jamison DT, Murray CJL. Measuring the Global Burden of Disease and Risk Factors, 1990-2001. In: Lopez AD, Mathers CD, Ezzati M, Jamison DT, Murray CJL, editores. Global Burden of Disease and Risk Factors. Washington: The World Bank, Nova lorque: Oxford University Press; 2006. p. 1-6.

Mathers CD, Vos T, Lopez AD, Salomon J, Ezzati M. National Burden of Disease Studies: A Practical Guide. Global Program on Evidence for Health Policy. Geneva: World Health Organization; 2001.

Melo FAF, Afiune JB, Hijjar AM, Gomes M, Rodrigues DSS, Klautau GB, Kritski AL, Rosemberg J. Tuberculose. In: Foccacia R, editor. VeronesiFocaccia: Tratado de Infectologia. 4a ed. São Paulo: Editora Atheneu; 2009.

Ministério da Saúde, Universidade Federal de Goiás, organizadores. Asis Análise de Situação de Saúde - Volume 1. Brasília: Ministério da Saúde; 2015. p. 122-158.

Murray CJ, Ezzati M, Flaxman AD, Lim S, Lozano R, Michaud C, Naghavi M, Salomon JA, Shibuya K, Vos T, Wikler D. GBD 2010: design, definitions, and metrics. The Lancet 2012; 380: 2063-6.

Murray CJ, Lopez AD. Quantifying disability: data, methods and results. Bulletin of the World Health Organization 1994; 72: 481.

Murray CJL, Acharya AK. Understanding DALYs. Journal of Health Economics 1997; 16: 703-730.

Murray CJL, Lopez AD, Jamison DT. The global burden of disease in 1990: summary results, sensitivity analysis and future directions. Bulletin of the World health Organization 1994; 72: 495-509.

Murray CJL. Quantifying the burden of disease: the technical basis for disability-adjusted life years. Bulletin of the World health Organization 1994; 72: 429.

Organização Pan-americana da Saúde (OPAS). Plano de Ação Para Prevenção e Controle da Tuberculose [Internet]. Washington: Organização Pan-Americana; 2015.2 Avaiable from: http://www.paho.org/hq/index.php?option=com_docman\&task=doc_downloa d\&gid=31243\&ltemid=270\&lang=pt.

Pasipanodya JG, McNabb SJ, Hilsenrath P, Bae S, Lykens K, Vecino E, Munguia G, Garmon R, Bae S, Drewyer G, Weis SE. Pulmonary impairment after tuberculosis and its contribution to TB burden. BMC Public Health 2010; 10: 259. 
Ramalho WM, Duarte EC. Análise das Desigualdades em Saúde. In: Brasil, Raphael D. Social Determinants of Health: an overview of key issues and themes. In: Dennis Raphael, editor. Social Determinants of Health. Toronto: Canadian Scholar's Press Inc.; 2009.

Salomon JA, Vos T, Hogan DR, Gagnon M, Naghavi M, Mokdad A, et al. Common values in assessing health outcomes from disease and injury: disability weights measurement study for the Global Burden of Disease Study 2010." Lancet 2012; 380: 2129-2143.

Santos, ML. Fatores associados à subnotificação de TB e Aids, durante os anos de 2001 a 2010, a partir do Sinan [dissertação]. Centro de Pesquisas Aggeu Magalhães: Fundação Oswaldo Cruz; 2014.

Silva JB, Barros MBA. Epidemiologia e desigualdade: notas sobre a teoria e a história. Rev Panam Salud Pública. 2002; 12: 375-83.

Travassos C, Castro MSM. Determinantes e desigualdades sociais no acesso e utilização de serviços de saúde. In: Giovanella L. Escorel S, Lobato LVC, Norinha JC, Carvalho Al, organizadores. Políticas e Sistema de Saúde no Brasil. Rio de Janeiro: Editora FIOCRUZ; 2008.

United Nations. 55/2. United Nations Millennium Declaration. In: Resolution adopted by the General Assembly; 2000.

United Nations. The Millennium Development Goals Report. United Nations; 2015a.

United Nations. Transforming our world: the 2030 agenda for sustainable development. New York: United Nations; 2015b.

Word Health Organization, The World Bank. Global Plan to Stop TB 20012005. Proceedings of The first Stop TB Partners' Forum; 2001 Oct 22-23; Washington; 2011b.

Word Health Organization, The World Bank. Washington Commitment to Stop TB. Proceedings of The first Stop TB Partners' Forum; 2001 Oct 22-23; Washington; 2001a.

Word Health Organization. Global strategy and targets for tuberculosis prevention, care and control after 2015. Proceedings of The Sixty-seventh World Health Assembly; 2014 May 21; Geneva: 2014.

Word Health Organization. Implementing the end TB strategy: the essentials. Geneva: Word Health Organization; 2015b.

World Health Organization. Global Tuberculosis Report 2015. Geneva: World Health Organization; 2015a.

World Health Organization. Global Tuberculosis Report 2016. Geneva: World Health Organization; 2016.

World Health Organization. Making choices in health: WHO guide to costeffectiveness analysis.Tan-Torres Edejer T, Baltussen R, Adam T, 
Hutubessy R, Acharya A, Evans DB, Murray CJL, editors. Geneva: World Health Organization; 2003.

World Health Organization. Multi-Drug-Resistant Titan Blue (MDR-TB). WHO Biorisk Management Advanced Trainer Programme. World Health Organization; 2012.

World Health Organization. The global plan to stop TB 2006-2015. Geneva: Stop TB Partnership, World Health Organization; 2006.

World Health Organization. The global plan to stop TB 2011-2015: transforming the fight towards elimination of tuberculosis. Stop TB Partnership, World Health Organization; 2010.

World Health Organization. Tuberculosis [Internet]. Geneva: World Health Organization; 2002. [cited 2016 Dec 15]. Available from: http:// www.who.int/mediacentre/factsheets/who104/ en/print.html. 


\section{ANEXOS}

Anexo I - Dicionário de variáveis elaborado para as figuras 9 e 10.

\begin{tabular}{|c|c|c|c|}
\hline Variável & Código & Categoria & Banco de dados \\
\hline causabas & 1 & $\begin{array}{c}A 15.0 \text { a } A 15.3 \text { e } \\
\text { A16.0 a A16.2 }\end{array}$ & $\begin{array}{c}\text { Base de pares (SINAN- } \\
\text { TB + SIM) }\end{array}$ \\
\hline causabas & 1 & B20 a B24 & \\
\hline Idade & 2 & & $\begin{array}{c}\text { Base de pares (SINAN- } \\
\text { TB + SIM) }\end{array}$ \\
\hline sexo & 3 & & $\begin{array}{c}\text { Base de pares (SINAN- } \\
\text { TB }+ \text { SIM) }\end{array}$ \\
\hline ID_MN_RESI & 4 & & $\begin{array}{c}\text { Base de pares (SINAN- } \\
\text { TB + SIM) }\end{array}$ \\
\hline Tipo de Entrada & 5 & $\begin{array}{l}\text { caso novo + não } \\
\text { sabe + pós-óbito }\end{array}$ & SINAN-TB \\
\hline Forma & 6 & $\begin{array}{c}\text { Pulmonar e } \\
\text { Pulmonar }+ \\
\text { Extrapulmonar }\end{array}$ & SINAN-TB \\
\hline SITUA_ENCE & 7 & $\begin{array}{c}\text { Mudança de } \\
\text { diagnóstico e } \\
\text { Óbitos por outras } \\
\text { causas }\end{array}$ & SINAN-TB \\
\hline NU_IDADE & 8 & & SINAN-TB \\
\hline CS_SEXO & 9 & & SINAN-TB \\
\hline ID_MN_RESI & 10 & & ID_MN_RESI \\
\hline
\end{tabular}




\section{FACULDADE DE MEDICINA DA UNIVERSIDADE DE BRASÍLIA - UNB}

\section{PARECER CONSUBSTANCIADO DO CEP}

\section{DADOS DO PROJETO DE PESQUISA}

Título da Pesquisa: DESIGUALDADES SOCIAIS E CARGA DE DOENÇA POR TUBERCULOSE NOS MUNICÍPIOS PRIORITÁRIOS BRASILEIROS, NO ANO DE 2014.

Pesquisador: Wildo Navegantes de Araujo

Área Temática:

Versão: 1

CAAE: 56691016.9 .0000 .5558

Instituição Proponente: Núcleo de Medicina Tropical

Patrocinador Principal: Financiamento Próprio

\section{DADOS DO PARECER}

Número do Parecer: 1.635 .885

\section{Apresentação do Projeto:}

O presente trabalho se propõe a analisar as desigualdades na carga da tuberculose, segundo fatores sociais, econômicos e de qualidade de serviços de saúde, nos municípios prioritários brasileiros. Os pesquisadores pretendem utilizar a base de dados cedida pelo Ministério da Saúde, onde será realizada a técnica de relacionamento probabilístico, por meio do software RecLink, entre o Sistema de Informação de Agravos de Notificação (SINAN) de Tuberculose (TB) e Sistema de Informações sobre Mortalidade (SIM).

Seleção dos indicadores e variáveis:

Se realizará uma análise da qualidade do banco de dados com o intuito de verificar a completude e consistência das informações registradas afim de minimizar erros sistemáticos. As duplicidades do banco serão identificadas no momento da realização da técnica de relacionamento das bases e serão excluídas do banco de dados. Serão incluídas variáveis de sexo, idade, forma clínica da doença e além dessas, serão consideradas variáveis cujos campos tiveram um mínimo de $80 \%$ de preenchimento.

A carga de doença será estimada através do indicador de Anos de Vida Perdidos Ajustados por

Endereço: Universidade de Brasília, Campus Universitário Darcy Ribeiro - Faculdade de Medicina

Bairro: Asa Norte

UF: DF

Município: BRASILIA

CEP: $70.910-900$

Telefone: (61)3107-1918

E-mail: fmd@unb.br 


\section{FACULDADE DE MEDICINA DA UNIVERSIDADE DE BRASÍLIA - Prasioforma}

Continuação do Parecer: 1.635 .885

Incapacidade (DALY). A análise da influência das desigualdades irá se perfazer através do Índice de Desenvolvimento Humano (IDH) e seus componentes - Expectativa de vida ao nascer, Renda Nacional Bruta e Grau de escolaridade - e do Índice de Desempenho do Sistema Único de Saúde, através da síntese dos 24 indicadores que fazem parte desse índice.

\section{Objetivo da Pesquisa:}

Objetivo Geral:

Analisar as desigualdades na carga da tuberculose, segundo fatores sociais, econômicos e de qualidade de serviços de saúde, nos municípios prioritários brasileiros no ano de 2014.

Objetivos Específicos:

1. Descrever o coeficiente de prevalência e de mortalidade por tuberculose;

2. Descrever o Índice de Desenvolvimento Humano Municipal (IDHM) e seus componentes nos municípios prioritários;

3. Descrever o Índice de Desempenho do Sistema Único de Saúde (IDSUS) nos municípios prioritários.

4. Estimar os Anos de Vida Perdidos Ajustados por Incapacidade (DALY) por tuberculose e;

5. Analisar as desigualdades da carga da tuberculose nos municípios prioritários para o controle da tuberculose.

\section{Avaliação dos Riscos e Benefícios:}

Riscos

A execução desse projeto representa risco mínimo aos indivíduos pesquisados, no entanto, os dados de identificação e identificáveis contidos nas bases de dados do Sinan-TB e do SIM serão armazenados em um computador com senha individual, acessível apenas ao pesquisador principal e assistente. Após o relacionamento entre as bases de dados, a ser realizado pelo pesquisador principal e assistente, as informações de identificação e identificáveis serão excluídas das bases de dados para posterior realização das análises estatísticas. Além disso, os resultados serão apresentados de forma agregada, não havendo divulgação de quaisquer identificações.

Benefícios

A compreensão da influência de determinantes sociais em saúde e indicadores que avaliam a qualidade do serviço de saúde na carga de tuberculose em âmbito municipal, é de extrema relevância para nortear as ações e estratégias de controle da tuberculose. Esse estudo pode constituir-se de uma importante ferramenta para orientar a tomada de decisão e a alocação de recursos de forma equânime, considerando além de fatores socioeconômicos e ambientais, a estrutura e organização do serviço de saúde em cada município prioritário brasileiro para o

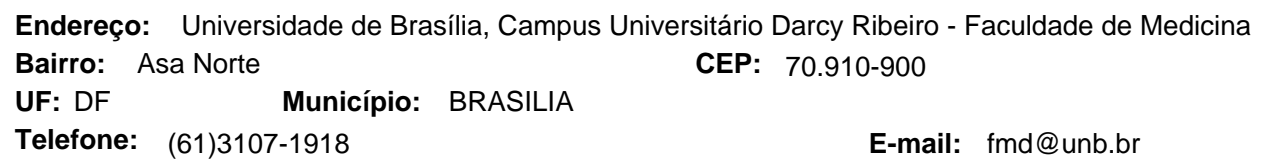




\section{FACULDADE DE MEDICINA DA UNIVERSIDADE DE BRASÍLIA - UNB}

Continuação do Parecer: 1.635 .885

controle da tuberculose.

\section{Comentários e Considerações sobre a Pesquisa:}

A pesquisa em tela demonstra fundamentação teórica, clareza na apresentação do problema e dos objetivos. Ressalta-se que a pesquisa conta com a infraestrutura física e pessoal apropriada, bem como aporte financeiro para o custeio de materiais (escritório, coletas e laboratórios), alimentação, transporte e pagamentos de serviços (pessoa física e jurídica).

\section{Considerações sobre os Termos de apresentação obrigatória:}

Quanto ao termo de consentimento livre e esclarecido, os pesquisadores solicitaram dispensa ao TCLE. Apresentaram como justificativa o fato de o estudo utilizar dados secundários, que serão coletados pelos sistemas de vigilância das doenças, de 181 Municípios Prioritários Brasileiros para o Controle da Tuberculose, e compilados nas bases oficiais do Ministério da Saúde.

\section{Recomendações:}

1. Ajustar as datas no cronograma.

\section{Conclusões ou Pendências e Lista de Inadequações:}

Diante do exposto, recomendo a aprovação da pesquisa.

\section{Considerações Finais a critério do CEP:}

Projeto apreciado na Reunião Extraordinária do CEP-FM-UnB. Após apresentação do parecer do Relator, aberta a discussão para os membros do Colegiado. O projeto foi Aprovado por unanimidade.

Este parecer foi elaborado baseado nos documentos abaixo relacionados:

\begin{tabular}{|c|c|c|c|c|}
\hline Tipo Documento & Arquivo & Postagem & Autor & Situação \\
\hline $\begin{array}{l}\text { Informações Básicas } \\
\text { do Projeto }\end{array}$ & $\begin{array}{l}\text { PB_INFORMAÇÕES_BÁSICAS_DO_P } \\
\text { ROJETO 710354.pdf }\end{array}$ & $\begin{array}{c}17 / 05 / 2016 \\
15: 19: 58 \\
\end{array}$ & & Aceito \\
\hline $\begin{array}{l}\text { Recurso Anexado } \\
\text { pelo Pesquisador }\end{array}$ & Carta_resposta_pendencias.pdf & $\begin{array}{c}17 / 05 / 2016 \\
15: 05: 12 \\
\end{array}$ & $\begin{array}{l}\text { Wildo Navegantes de } \\
\text { Araujo }\end{array}$ & Aceito \\
\hline Folha de Rosto & Folha_de_rosto_2.pdf & $\begin{array}{l}17 / 05 / 2016 \\
15: 03: 07\end{array}$ & $\begin{array}{l}\text { Wildo Navegantes de } \\
\text { Araujo }\end{array}$ & Aceito \\
\hline Outros & Termo_de_responsabilidade.pdf & $\begin{array}{l}09 / 05 / 2016 \\
01: 39: 19\end{array}$ & $\begin{array}{l}\text { Wildo Navegantes de } \\
\text { Araujo }\end{array}$ & Aceito \\
\hline Outros & Lattes_Mabia.pdf & $\begin{array}{c}09 / 05 / 2016 \\
01: 31: 40\end{array}$ & $\begin{array}{l}\text { Wildo Navegantes de } \\
\text { Araujo }\end{array}$ & Aceito \\
\hline Outros & Lattes_Wildo.pdf & $09 / 05 / 2016$ & Wildo Navegantes & Aceito \\
\hline
\end{tabular}

Endereço: Universidade de Brasília, Campus Universitário Darcy Ribeiro - Faculdade de Medicina

Bairro: Asa Norte

UF: DF

Município: BRASILIA

CEP: $70.910-900$

Telefone: (61)3107-1918

E-mail: fmd@unb.br 


\section{FACULDADE DE MEDICINA DA UNIVERSIDADE DE BRASÍLIA - UNB}

Continuação do Parecer: 1.635 .885

\begin{tabular}{|c|c|c|c|c|}
\hline Outros & Lattes_Wildo.pdf & $01: 30: 26$ & de Araujo & Aceito \\
\hline $\begin{array}{l}\text { Declaração de } \\
\text { Instituição e } \\
\text { Infraestrutura } \\
\end{array}$ & Termo_de_concordancia1.pdf & $\begin{array}{c}09 / 05 / 2016 \\
01: 29: 21\end{array}$ & $\begin{array}{l}\text { Wildo Navegantes de } \\
\text { Araujo }\end{array}$ & Aceito \\
\hline $\begin{array}{l}\text { TCLE / Termos de } \\
\text { Assentimento / } \\
\text { Justificativa de } \\
\text { Ausência }\end{array}$ & Dispensa_TCLE.pdf & $\begin{array}{c}09 / 05 / 2016 \\
01: 27: 42\end{array}$ & $\begin{array}{l}\text { Wildo Navegantes de } \\
\text { Araujo }\end{array}$ & Aceito \\
\hline $\begin{array}{l}\text { Projeto Detalhado / } \\
\text { Brochura } \\
\text { Investigador } \\
\end{array}$ & Projeto_detalhado2.pdf & $\begin{array}{c}09 / 05 / 2016 \\
01: 24: 59\end{array}$ & $\begin{array}{l}\text { Wildo Navegantes de } \\
\text { Araujo }\end{array}$ & Aceito \\
\hline Outros & Carta_de_encaminhamento.pdf & $\begin{array}{c}03 / 05 / 2016 \\
22: 46: 04 \\
\end{array}$ & $\begin{array}{l}\text { Wildo Navegantes de } \\
\text { Araujo }\end{array}$ & Aceito \\
\hline
\end{tabular}

Situação do Parecer:

Aprovado

Necessita Apreciação da CONEP:

Não

BRASILIA, 13 de Julho de 2016

Assinado por:

Florêncio Figueiredo Cavalcanti Neto

(Coordenador)

Endereço: Universidade de Brasília, Campus Universitário Darcy Ribeiro - Faculdade de Medicina

Bairro: Asa Norte

CEP: $70.910-900$

UF: DF

Município: BRASILIA

Telefone: (61)3107-1918

E-mail: fmd@unb.br 